\title{
Fatores Relacionados ao Uso de Drogas e Condições de Risco entre Alunos de Graduação da Universidade de São Paulo
}

\section{SUELI DE QUEIROZ}

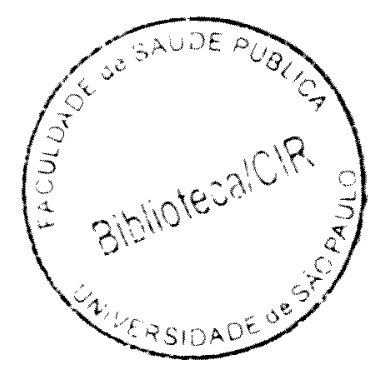

Tese de Doutorado apresentada ao Departamento de Saúde Materno-Infantil da Faculdade de Saúde Pública da Universidade de São Paulo para obtenção do Grau de Doutor em Saúde Pública.

Orientador: Prof. Adj. Cornélio Pedroso Rosenburg

São Paulo 
Autorizo, exclusivamente para fins acadêmicos e cientificos, a reprodução total ou parcial desta tese, por processos fotocopiadores.

Assinatura:

Data:

$40751 / 2001 \quad(d 0 c)$ 
Aos meus pais,

Nícia e Octávio,

com saudade e gratidão 


\section{AGRADECIMENTOS}

Ao Prof. Dr. Cornélio Pedrosa Rosenburg, meu paciente orientador e pessoa maravilhosa, que me deu em muitos momentos o prazer raro da troca de idéias.

Ao Prof. Dr. Arthur Guerra de Andrade, que com sua firmeza, otimismo e espírito agregador, muito me ensinou e impulsionou.

Aos Profs. Drs. Arnaldo Augusto Franco de Siqueira, Wallace Mandell e James Anthony, que me apoiaram e incentivaram, em meus primeiros passos, na carreira universitária.

Aos professores e secretários do Departamento Materno-Infantil, que sempre me acolheram com tanta simpatia.

À Dra. Maria do Rosário Dias de Oliveira Latorre pela generosidade do acompanhamento do trabalho estatístico.

Ao Sr. Fernão Dias de Lima, pelo indispensável auxílio com o tratamento dos dados no programa estatístico.

A todos do GREA, particularmente àqueles que participaram da equipe de prevenção entre 1996 e 1999, pela inestimável ajuda. Um agradecimento muito especial ao Ednei Rufino de Souza, pela paciência e gentileza, no apoio logístico.

À estatística Maria Cecília G. P. Alves pela elaboração do plano de amostragem.

À Prof. Dra. Fumika Peres pela cuidadosa revisão.

Ao Dr. John Manoel de Souza, amigo de tantos anos, pelo empenho e apuro nas críticas e correções.

À amiga Maria da Gracia Cardoso de Mello e à madrinha Ruth Novaes La Scala, dois anjos que me deram muito amor e apoio numa das horas mais dificeis de minha vida.

Ao CNPq e FAPESP pelos auxílios recebidos. 


\section{ÍNDICE}

Lista de tabelas e gráficos

Resumo

Summary

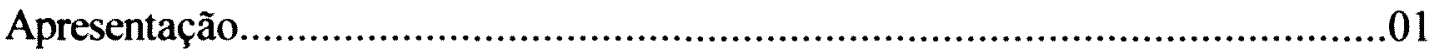

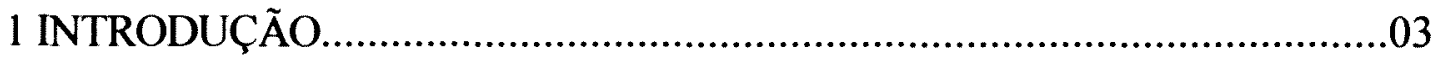

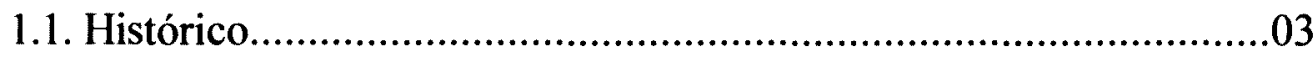

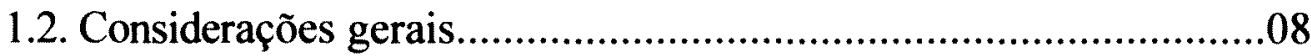

1.3. Fatores de risco e fatores protetores...............................................13

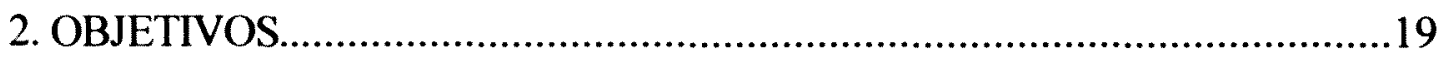

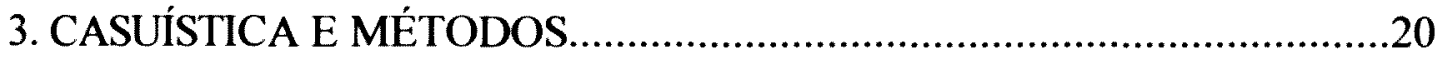

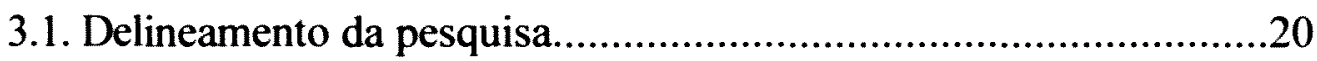

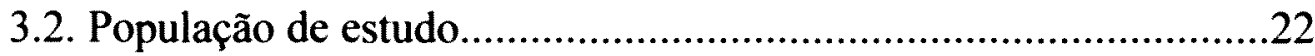

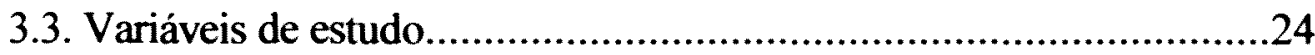

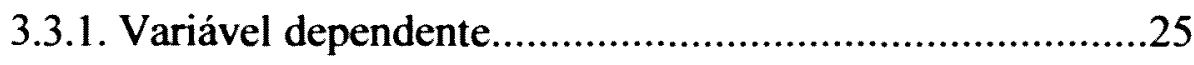

3.3.2. Variáveis independentes.....................................................25

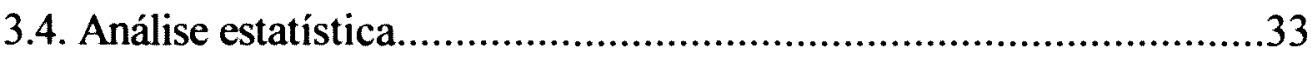

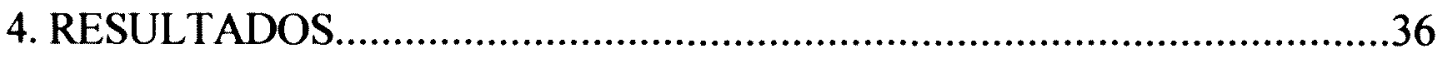

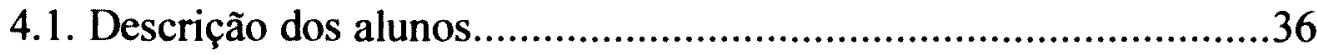

4.2. Comparação entre usuários e não-usuários de droga.......................37

4.2.1. Perfil do aluno....................................................................

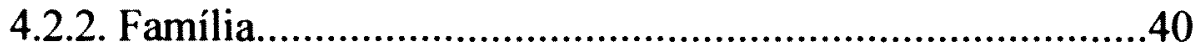

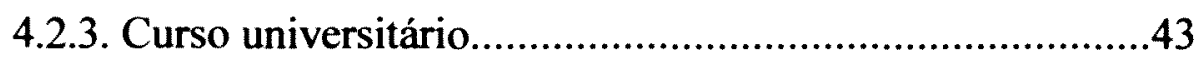

4.2.4. Vida acadêmica.................................................................47

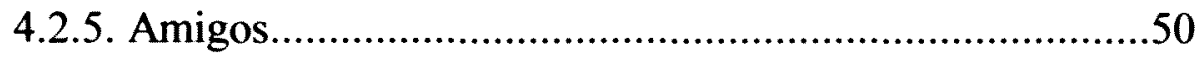

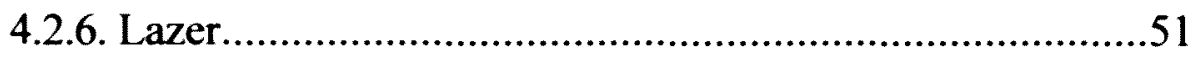

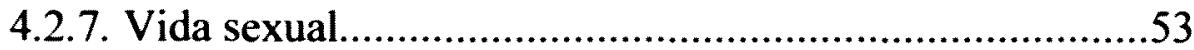




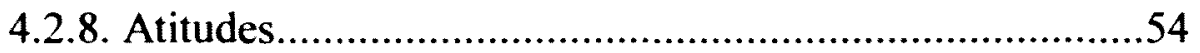

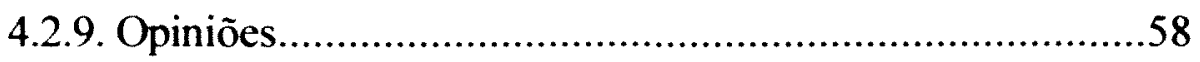

4.2.10. Uso pessoal de drogas.........................................60

4.3. Variáveis de risco associadas ao uso de droga........................61

4.3.1. Características pessoais............................................63

4.3.2. Características do ambiente familiar...........................66

4.3.3. Características da vida acadêmica...............................68

4.3.4. Caracteristicas da vida social...................................72

4.3.5. Características de a atitudes, opiniões e uso pessoal........74

4.3.6. Características gerais.............................................76

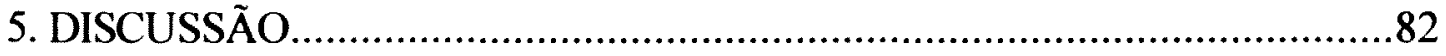

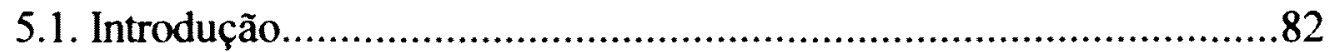

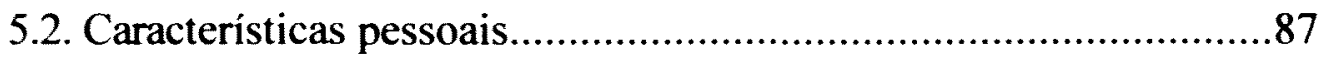

5.3. Características do ambiente familiar.....................................92

5.4. Características do ambiente social.......................................97

5.5. Características da vida acadêmica.......................................100

5.6. Atitudes, opiniões e uso pessoal de drogas.............................105

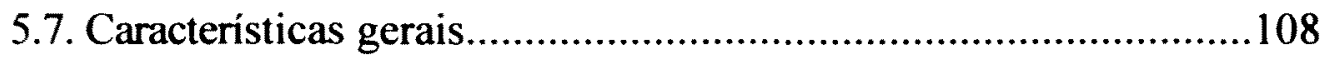

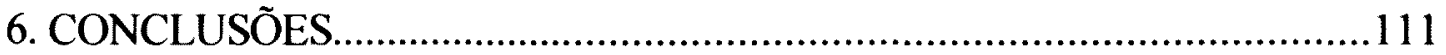

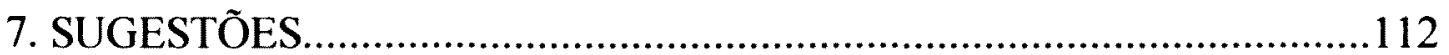

8. REFERÊNCIAS BIBLIOGRÁFICAS.............................................. 113

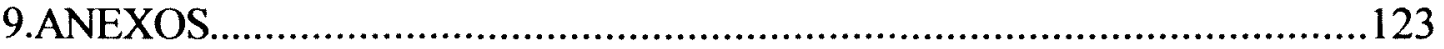

Anexo 1 (Distribuição da amostra)

Anexo 2 (Plano de amostragem)

Anexo 3 (Questionário)

Anexo 4 (Artigo)

Anexo 5 (Resultados da análise univariada)

Anexo 6 (Detalhamento dos modelos multivariados finais) 


\section{LISTA DE TABELAS}

Tabela 1a - Número e porcentagem de estudantes universitários da USP, segundo o uso de droga e características pessoais (1996)..

Tabela 1b - Número e porcentagem de estudantes universitários da USP, segundo o uso de droga e características pessoais (1996).

Tabela 2a - Número e porcentagem de estudantes universitários da USP, segundo $o$ uso de droga e características do ambiente familiar (1996).

Tabela 2b - Número e porcentagem de estudantes universitários da USP, segundo o uso de droga e características do ambiente familiar (1996).

Tabela 3a - Número e porcentagem de estudantes universitários da USP, segundo o uso de droga e caracteristicas do curso universitário (1996).

Tabela 3b - Número e porcentagem de estudantes universitários da USP, segundo o uso de droga e características do curso universitário (1996).

Tabela 4a - Número e porcentagem de estudantes universitários da USP, segundo o uso de droga e características da vida acadêmica (1996).

Tabela 4b - Número e porcentagem de estudantes universitários da USP, segundo o uso de droga e características da vida acadêmica (1996).

Tabela 5 - Número e porcentagem de estudantes universitários da USP, segundo o uso de droga e características do grupo de amigos (1996)..

Tabela 6 - Número e porcentagem de estudantes universitários da USP, segundo o uso de droga e características relacionadas ao lazer (1996)..

Tabela 7 - Número e porcentagem de estudantes universitários da USP, segundo o uso de droga e características da vida sexual (1996).

Tabela 8a - Número e porcentagem de estudantes universitários da USP, segundo o uso de droga e atitudes quanto ao uso experimental de algumas drogas (1996)....56

Tabela 8b - Número e porcentagem de estudantes universitários da USP, segundo o uso de droga e atitudes quanto ao uso regular de algumas drogas (1996). 
Tabela 9 - Número e porcentagem de estudantes universitários da USP, segundo o uso de droga e opiniões relacionadas ao uso de drogas (1996).

Tabela 10 - Número e porcentagem de estudantes universitários da USP, segundo o uso de droga e informações relacionadas ao uso pessoal de droga (1996)............60

Tabela 11a - Relação das variáveis escolhidas para elaboração do modelo multivariado segundo os tópicos: atitudes, opiniões e uso de drogas

Tabela 11b - Relação das variáveis escolhidas para elaboração do modelo multivariado segundo os tópicos: perfil do aluno, familia, curso universitário, vida acadêmica, amigos, lazer, vida sexual.

Tabela 12 - Modelo multivariado final das variáveis associadas ao risco de uso de droga para características pessoais dos alunos da USP

Tabela 13 - Modelo multivariado final das variáveis associadas ao risco de uso de droga para características do ambiente familiar dos alunos da USP.

Tabela 14 - Modelo multivariado final das variáveis associadas ao risco de uso de droga para características da vida acadêmica dos alunos da USP.

Tabela 15 - Modelo multivariado final das variáveis associadas ao risco de uso de droga para características da vida social dos alunos da USP

Tabela 16 - Modelo multivariado final das variáveis associadas ao risco de uso de droga para atitudes, opiniões e uso pessoal dos alunos da USP

Tabela 17a - Modelo multivariado final geral das variáveis associadas ao risco de uso de droga para os alunos de USP.

Tabela 17b - Modelo multivariado final geral das variáveis associadas ao risco de uso de droga para os alunos de USP

\section{LISTA DE GRÁFICOS}

Gráfico 1 - Uso de drogas por alunos da USP 


\section{RESUMO}

Queiroz, S. Fatores relacionados ao uso de drogas e condições de risco entre os alunos de graduação da Universidade de São Paulo. São Paulo, 2000. [ Tese de Doutorado - Faculdade de Saúde Pública da USP].

Objetivo. A prevalência do uso de drogas psicoativas por jovens brasileiros vem aumentando nos últimos anos, mas poucas, ainda, são as pesquisas epidemiológicas brasileiras voltadas para a compreensão do problema. Este estudo buscou identificar fatores de risco de uso de drogas entre alunos de graduação dos 21 cursos da Universidade de São Paulo, na cidade de São Paulo. Métodos. Utilizando-se 69 variáveis obtidas através de um questionário anônimo e de auto-preenchimento, respondido por 2564 alunos sorteados, foram elaborados 5 modelos de regressão logística múltipla. Cada modelo agrupou fatores de risco para uso de droga, segundo as características pessoais, familiares, sociais, da vida acadêmica, e de atitudes, crenças, e uso pessoal de drogas. Para a variável dependente 'uso de droga', foi considerado o uso das seguintes drogas: maconha, alucinógenos, cocaína, crack, anfetaminas, anticolinérgicos, inalantes, tranqüilizantes, opiáceos, sedativos e anabolizantes. Todas as variáveis que compunham os 5 modelos encontrados foram submetidas a uma análise de regressão logística, da qual surgiu um único modelo multivariado final. Resultados. $\mathrm{O}$ aluno usuário (comparado com o não-usuário) de nossa amostra é predominantemente do sexo masculino (29,3\%), tem entre 20 e 24 anos $(29,4 \%)$, é solteiro $(27,3 \%)$, trabalha $(28,7 \%)$, mora com amigos $(36,4 \%)$ ou só $(34,9 \%)$, não tem $(33,4 \%)$ ou não pratica $(29,7 \%)$ uma religião, e não mantém um bom diálogo com seus pais, principalmente com a mãe (17,2\%). Obtivemos 6 modelos multivariados finais, cada um dos quais nos aponta um perfil de risco para uso de droga segundo as características analisadas. Para o modelo final geral encontramos 17 variáveis: pais e amigos que usam drogas, ter usado drogas antes de entrar na universidade, fumar, trabalhar, ser influenciável, baixo rendimento escolar, curso e lugares que freqüenta na universidade, acidente de carro após o uso de droga, satisfação com o tempo de lazer, quem procura para esclarecer dúvidas relacionadas às drogas, $\mathrm{e}$ atitude aprovadora quanto a qualquer pessoa experimentar ou usar regularmente maconha e experimentar inalantes.

Descritores: Uso de drogas. Estudantes universitários. Fatores de risco. 


\section{SUMMARY}

Queiroz, S. Fatores relacionados ao uso de drogas e condições de risco entre os alunos de graduação da Universidade de São Paulo. [Related factors and risk conditions for drug use in undergraduate students of the University of São Paulo] São Paulo (BR); 2000. [ Tese de Doutorado - Faculdade de Saúde Pública da Universidade de São Paulo].

Objective. The prevalence of drug use by young Brasilians has been increasing in recent years, however, there are few epidemiological studies aiming at a better comprehension of the subject. This study investigates risk factors for drug use in undergraduate students from 21 courses at the University of São Paulo (USP), in the city of São Paulo. Methods. Five models of multiple logistic regression were constructed using data from 69 variables, in an anonymous, self-administered questionnaire, which was answered by 2,564 randomly sampled students. Each model grouped risk factors by personal characteristics, familial factors, social environment academic life and attitudes. For the dependent variable 'drug use', the following drugs were considered: marijuana, hallucinogens, cocaine, crack, amphetamines, anticholinergics, inhalants, tranquilizers, anxiolytics, antidystonics, opiates, sedatives, barbiturates, and anabolizers. All the variables examined in the 5 models were analyzed by logistic regression and gave rise to a single multivariate model. Results. In the sample, the user (compared with the nonuser) is male $(29.3 \%), 20-24$ years old $(29.4 \%)$, single $(27.3 \%)$, work $(28.7 \%)$, lives alone $(34.9 \%)$ or with friends $(36.4 \%)$, do not have a religion $(33.4 \%)$, or at least do not practicise it $(29.7 \%)$, have some difficulty communicating with his parents, particularly with his mother (17.2\%). This resulted in 6 models each of which revealed a drug use risk profile according to the characteristics analyzed. In the final general model, 17 factors remained: use of drugs by parents and peers, use of drugs before entering university, use of tobacco, work, be influenced by others, poor performance at school, course of study, places frequented in the campus, envolvement in an automobile accident after any drug use, satisfaction with leisure time, person to consult on drug questions, approval of experimental and regular use of marijuana, approval of experimental use of inhalants.

Descriptors: Drug use. University students. Risk factors. 


\section{APRESENTAÇÃo}

Quando se fala que o uso de drogas, hoje em dia, é um problema de Saúde Pública, é preciso ter em mente que num passado, não muito distante, tal não acontecia. Talvez, até há alguns milhares de anos, as drogas tenham sido favoráveis ao ser humano, facilitando o desenvolvimento da consciência de si mesmo, colaborando com o aprofundamento dos sentimentos religiosos e, acima de tudo, ajudando a suportar as dificuldades da sobrevivência em tempos árduos. As maneiras pelas quais as drogas foram e são usadas e as formas de convivência do indivíduo com elas, têm tido significados diferentes ao longo do processo histórico. É, portanto, necessário que se situe o problema no tempo e no espaço para não se incorrer em grotescas deformações.

Como princípio básico das drogas psicoativas - aquelas substâncias que alteram o estado de consciência e afetam o humor - está o fato de que elas não são, por si mesmas, boas ou ruins. Alguns educadores, políticos e religiosos mais exaltados atribuem à droga poderes mágicos $\mathrm{e}$ 
diabólicos, como se a própria substância química fosse possuída por intenções vis. Quando se culpa a droga, os esforços para correção dos problemas a ela relacionados tendem a focalizar, exclusivamente, a eliminação da substância e a ignorar todos os outros fatores que levam ao uso abusivo. É preciso considerar que, a par das conseqüências negativas do uso de drogas, há também importantes efeitos positivos. Além dos óbvios benefícios dos psico-fármacos - tranqüilizantes, ansiolíticos, sedativos, barbitúricos e outros - deve-se lembrar que a heroína é um ótimo analgésico, tão eficiente quanto a morfina, e é usada medicamente em muitos países. A cocaína é um bom anestésico local e tem sido utilizada, até os dias atuais, para procedimentos médicos. Os efeitos relaxantes do álcool, quando usado em quantidades moderadas, são também considerados benéficos.

Este estudo visa detectar a existência, no meio estudantil universitário, de fatores que se relacionam com o uso de drogas e que, em conjunto, permitam traçar o perfil de risco desses estudantes. Espera-se que o levantamento desses fatores proporcione discussão e propostas de estratégias preventivas para as universidades brasileiras. 


\section{INTRODUÇÃO}

\subsection{Histórico}

O uso de drogas psicoativas não é um fenômeno recente. Seres humanos vêm fazendo uso de álcool e de outras drogas há milhares de anos e, pelo que se sabe, desde que o Homo sapiens surgiu no planeta (RAY e KSIR 1993).

Segundo relato de algumas autoridades, a bebida alcoólica mais antiga, feita de mel, surgiu na Era Paleolítica, cerca de 8000 a.C. A cerveja e o vinho de amora (mulberry) são conhecidos desde 6400 a.C. Relata-se que o vinho de uva teria sido introduzido pelos gregos, no Egito, na $18^{\circ}$ dinastia, cerca de 1300 a 1550 a.C. Os índios brasileiros faziam uma bebida fermentada, o cauim, com raiz de mandioca mastigada. Os licores, que são bebidas doces de enormes variedades de cores e sabores têm, em comum, o alto teor de açúcar e começaram a ser fabricados na Idade Média por alquimistas e médicos. A eles eram atribuídos poderes diversos, como afrodisíacos, medicinais e de filtros amorosos. Através dos séculos foram conhecidos como bálsamos, elixires, óleos, licores ou cordiais (Enciclopédia Barsa 1964). 
No caso da Cannabis sativa - maconha e haxixe - a primeira citação conhecida encontra-se em um livro farmacêutico, escrito em 2737 a.C., de autoria do imperador chinês Shen Nung. Há referências aos efeitos euforizantes da Cannabis - chamada por ele de "libertadora de pecados" e também alguns usos medicinais são recomendados, como nos quadros de fraqueza feminina, gota, reumatismo, malária, beriberi, constipação e ausências. Por volta do ano 1000 a.C. o uso social da planta espalhou-se pelo mundo islâmico e da África do Norte. Nessa época, na região leste do Mediterrâneo, surgiu uma lenda em torno de um culto religioso que praticava assassinatos por motivos religiosos. Esse culto era chamado hashishiyya, de onde se originaria a palavra 'assassino'. Essa história foi contada em 1299 por Marco Polo e sobreviveu através dos anos, pois tinha todos os elementos para isso - intriga, assassinato, sexo, drogas e terras misteriosas. A lenda foi contada de muitas formas diferentes ao longo dos anos, e o Decameron, de Boccaccio, contém uma história baseada nela.

No começo do século XIX, a expedição de Napoleão Bonaparte ao Egito e outros viajantes levam a droga para a Europa, que está pronta para recebê-la. Pintores e escritores - ávidos por experiências capazes de trazer novas formas de criatividade e enfoques ampliados do mundo - aderem rapidamente ao uso da maconha. Entre eles estão Baudelaire, Dumas e Gautier, três que escreveram sobre suas experiências com o haxixe (RAY e KSIR 1993). 
Em 1843 e 1890, respectivamente, dois médicos ingleses fazem referência ao uso medicinal da Cannabis. O'Shaughnessy a recomenda como antiepilético e espasmolítico, e Reynolds sugere a utilidade para epilepsia, neuralgia e enxaqueca (CARLINI 1995).

A importância da maconha, como medicamento, vai diminuindo no final do século passado, e esse declínio é assim explicado por Carlini:

“A principal razão para o desuso na Medicina foi, provavelmente, o não isolamento de seus princípios ativos $e$ as conseqüentes utilizações de preparações brutas (extratos), cuja variabilidade química e deterioração com o tempo e luz faziam com que os efeitos clínicos fossem imprevisíveis. Ao lado desta razão de ordem técnico-farmacêutica, surge uma outra, de ordem legal e policial. Alguns países começam a relacionar o uso não médico ("abuso") da maconha à deterioração psíquica, ao crime e à marginalização do indivíduo."

A composição química da Cannabis é muito complexa, e isolar e extrair o princípio ativo é difícil ainda hoje. Há mais de 400 substâncias diferentes na maconha, mas apenas 61 delas pertencem unicamente às 
plantas Cannabis e são chamadas canabinóides. Um deles é o $\Delta-9$ tetraidrocanabinol ( $\Delta-9-$ THC), que foi isolado e sintetizado em 1964 e é, sem dúvida, o mais importante princípio ativo.

O ópio - extraído da planta Papaver somniferum - tem uma história de uso médico datada de 6000 anos. Até cerca de 150 anos atrás, o ópio era o único agente de que os médicos dispunham para obter resultados seguros de diminuição da dor e do sofrimento. Por proporcionar intenso prazer e alívio da ansiedade, seu uso recreativo espalhou-se pelo mundo ao longo do tempo, e o problema da dependência foi experimentado por muitos de seus usuários.

As folhas de coca mais antigas de que se tem conhecimento foram encontradas na costa norte do Peru, no sítio arqueológico de Huaca Prieta, datado de 2500 a 1800 a.C. Escavações nas proximidades de Lima confirmaram a utilização da folha de coca por índios da América há mais de 4500 anos (DELPIROU e LABROUSSE 1988). Sabe-se que a folha de coca era parte importante da civilização Inca. No início era usada, principalmente, em cerimônias religiosas, mas na época da invasão de Pizarro, no século XVI, já era tratada como dinheiro. Os conquistadores espanhóis adotaram esse costume e davam folhas de coca aos trabalhadores nativos, como pagamento pelos serviços de mineração e transporte de ouro e prata. A coca não interessou aos europeus até a segunda metade do século XIX, quando Angelo Mariani - um químico francês - ficou rico e famoso e ainda foi condecorado pelo papa Leão XIII, graças ao seu vinho Mariani, 
um tônico contendo extrato de folhas de coca. As folhas de coca contêm, além dos óleos que lhes dão sabor, a substância química ativa cocaína. A cocaina foi isolada antes de 1860 mas, ainda hoje, há divergências sobre exatamente por quem e quando. Por volta de 1880 , dois médicos que mais tarde ficariam muito famosos, iniciaram experimentos com a cocaína. Um deles, o americano W.S. Halsted, depois conhecido como 'o pai da cirurgia moderna', observou a habilidade da cocaína em produzir anestesia local e em bloquear sensações em uma área extensa, desde que a droga fosse injetada próxima a um tronco nervoso. O outro, em Viena, era Sigmund Freud, então um simples médico recém-formado. Freud se encantou com os efeitos estimulantes da cocaína, tanto que, em carta à sua noiva, entusiasticamente lhe sugeria o uso, afirmando que ele próprio inalava regularmente pequenas doses da droga, contra depressão e, também, indigestão, com enorme sucesso. Esses dois grandes médicos viriam a ser vítimas da cocaína. Freud, de maneira indireta, por ter recomendado cocaína ao seu amigo Ernest von Fleischl-Marxow para tratar de um problema de dependência de morfina. Em pouco tempo, Fleischl passa a depender da cocaína.

Já Halsted foi, ele próprio, uma vítima de seus experimentos com a cocaína. Enquanto estava vivo, pensou-se que, com muitas dificuldades e algumas internações, ele havia dominado o intenso desejo que desenvolvera pela droga. $\mathrm{O}$ que se descobriu, 47 anos após sua morte, é que o desejo de cocaína só foi subjugado através do uso de morfina, numa luta 
violenta até o final de sua vida, para não ultrapassar a dosagem de $150 \mathrm{mg}$ por dia (GRINSPOON e BAKALAR 1978).

É preciso que se diga que até essa época, final do século XIX, ainda não havia por parte da sociedade, nenhuma restrição moral ou legal ao uso de drogas.

\subsection{Considerações Gerais}

Atualmente, o consumo de substâncias psicoativas tem gerado, em todas as partes do mundo, relevantes problemas sociais e de saúde, especialmente devido à sua crescente prevalência (KESSLER et al. 1994). A amplitude e gravidade desses problemas vêm exigindo dos órgãos governamentais, de todos os países, políticas e estratégias que possam diminuir o uso de drogas na população geral, bem como evitar as conseqüências do abuso dessas substâncias.

A questão das drogas nos dias atuais, encarada como um 'problema social', tem origens e ramificações de natureza política e econômica ( LINS e SILVA 1992). O uso de drogas, no entanto, é aqui tratado, fundamentalmente, como um problema de Saúde Pública. Como tal, é importante a identificação precoce de seu uso e posterior abuso, o encaminhamento adequado dos usuários com quadros de dependência e, 
principalmente, a multiplicação de ações preventivas. Para grande parte da sociedade brasileira, no entanto, encarar o uso de drogas como um problema de Saúde Pública ainda é uma idéia incipiente. $\mathrm{Na}$ época em que este trabalho teve início, a violência urbana já vinha ocupando diariamente um grande espaço na mídia. A gratuidade com que jovens assaltantes matam, culminando com a morte de três estudantes de classe média na cidade de São Paulo, faz com que a população, acuada, se mobilize (LOZANO 1996). Há evidências de que essa violência esteja associada ao uso e tráfico de drogas, principalmente do crack, mas o clamor geral é pelo acirramento da repressão. Pede-se policiamento mais intenso, endurecimento das leis, mais cadeias, e é esquecida a necessidade de políticas públicas, de um posicionamento claro do governo, que certamente englobaria estratégias preventivas e de tratamento.

No mundo todo, a repressão, no que se refere a álcool e drogas, tem apresentado tímidos resultados. Os Estados Unidos, país que investiu alto no combate ao narcotráfico no período de 1987 a 1991, reconheceram a ineficácia do método isolado e, em 1992, o Congresso Americano aprovou uma verba, cuja maior parte era destinada à prevenção e não mais à repressão. A partir daquele ano começou a ficar clara aos norte-americanos a idéia de que, para se diminuir o problema do uso e do abuso de drogas, seria necessário investir prioritariamente na prevenção. Compreenderam, também, a ineficácia de apenas combater os efeitos, através dos tratamentos, porque quando o problema da dependência já está instalado, a solução se 
torna bem mais complicada e onerosa.

A própria história das drogas, pincelada anteriormente, mostra a qualidade prazerosa da droga, que poderia explicar, em grande parte, os primeiros usos. As pesquisas em prevenção passam a se dedicar, então, à busca da compreensão de como superar essa condição prazerosa da droga. Muitas das medidas preventivas tentam evitar que o indivíduo se inicie no uso, dado que, quanto maior o prazer resultante desse uso, maior a chance de o indivíduo continuar a fazê-lo, e maior o risco do desenvolvimento de uma dependência.

Entretanto, apesar de todos os esforços dirigidos à prevenção nos últimos 30 anos, nos EUA, ainda não se tem uma idéia muito clara de como fazê-la. Conhecimentos importantes foram adquiridos, mas prevenção ao uso de drogas permanece um assunto que suscita controvérsias.

LEUKEFELD e BUKOSKI (1991) citam dois autores que ilustram bem a polêmica: "Swisher (1979) identifica os seguintes temas problemáticos: evidências claras de que a prevenção vale a pena; dificuldades de concordância na demonstração da efetividade das estratégias preventivas; confusão quanto às diferenças entre tratamento, intervenção e esforços preventivos; e preocupação com o alvo da prevenção - a população-alvo deve ser a que não usa ou a que faz uso esporádico? Em 1992, Silverman rebate essas posições afirmando que a pesquisa em prevenção está evoluindo e continuará a se desenvolver como conseqüência direta de um pensamento teórico e conceitual mais complexo, medidas mais 
válidas e confiáveis dos problemas relacionados ao uso de drogas, melhor compreensão dos fatores de risco individuais, melhor identificação dos indivíduos e grupos de alto risco, aprimoramento no delineamento de pesquisas e estudos longitudinais, e melhor integração entre os vários segmentos - família, escola, comunidade, religião, e justiça criminal."(p.1).

Dentre os trabalhos de pesquisa na área de álcool e drogas existentes no Brasil, estudos epidemiológicos realizados com estudantes do primeiro e segundo graus, em dez capitais brasileiras e sete cidades do interior do estado de São Paulo, revelaram alta prevalência do uso na vida de substâncias psicoativas, indo de 17,8\% em Belém até 27,3\% em São Paulo. Dessas, as mais usadas foram os solventes $(15,4 \%)$, a maconha (5,5\%) e os ansiolíticos (5,0\%) (GALDURÓZ et al.1994).

Outro levantamento, realizado por MAGALHÃES e colaboradores (1991) constatou uma prevalência maior de uso de drogas entre estudantes universitários da cidade de São Paulo, do que entre estudantes de primeiro e segundo graus. Quanto às drogas mais usadas alguma vez na vida, à exceção de álcool e tabaco, aparecem: os inalantes (28\%), a maconha (26\%), os medicamentos prescritos (17\%) e a cocaína $(10 \%)$.

Ainda tendo os universitários como público-alvo, pesquisa sobre o uso de substâncias psicoativas por estudantes de medicina da Universidade de São Paulo, apresentou prevalências diversas às constatadas pelo estudo de Magalhães e cols., concordando, porém, com a ordem das 
drogas mais usadas na vida: solventes $(23 \%)$, maconha $(19 \%)$, e tranqüilizantes (11\%) (MESQUITA et al. 1995).

Embora seja dificil comparar essas e outras pesquisas na área, em função da adoção de diferentes metodologias, os resultados encontrados em diversos estudos indicam que, para a maioria dos estudantes, o uso de álcool e drogas é esporádico e experimental (ZANINI et al. 1977; MURAD 1979; GORENSTEIN 1983; PLOTNIK 1986; BRENES et al. 1986; CARVALHO 1986; BUCHER e TOTUGUI 1988; MESQUITA et al. 1992; BOSKOWITZ et al. 1995; ANDRADE et al. 1995, 1997a).Este fato reforça a necessidade de se investir em programas de prevenção dirigidos a esses alunos, buscando evitar que o uso esporádico se transforme em abuso e dependência, e, ao mesmo tempo, preparando melhor os futuros profissionais para assumirem seus papéis enquanto agentes formadores de opinião pública.

O uso de drogas é aqui entendido como resultado da interação entre três fatores: droga, ambiente e indivíduo e, para BUCHER (1992), a prevenção é a melhor estratégia para se intervir nesta interação. Dai, a importância do desenvolvimento da pesquisa sobre prevenção no Brasil, pois não se pode simplesmente importar modelos de intervenção com base em resultados obtidos no estrangeiro e tentar aplicá-los aqui. Esses modelos poderão servir apenas como referências e ajudar na caracterização de um determinado ambiente e do indivíduo nele inserido.

De fato, instituições e pesquisadores têm observado que a 
efetividade de programas de prevenção de drogas depende do conhecimento prévio das condições do ambiente (fatores de risco ambientais), e das características sócio-demográficas, atitudes e padrão de uso de drogas da população em foco (fatores de risco do indivíduo), porque são essas as informações que deverão definir o tipo de intervenção a ser realizada (CARLINI 1990, OMS 1992).

Contudo, não basta encontrar os fatores associados ao uso de drogas. A pesquisa preventiva precisa, ainda, saber como utilizar os resultados dessas investigações. E este é um de nossos desafios.

\subsection{Fatores de Risco e Fatores Protetores}

Colocado como um problema universal não equacionado - que pode atingir pessoas, independente de sexo, escolaridade, religião, classe social, ou raça - o uso, abuso e dependência de droga apresentam duas categorias de indicadores: os que se relacionam com o uso de drogas e aqueles que não se relacionam com o uso.

Dentre os que se relacionam com o uso, pesquisas atualmente em curso buscam identificar duas vertentes importantes para a ampliação dos conhecimentos do problema: os fatores de risco e os fatores protetores.

Os primeiros são aqueles diretamente relacionados ao uso 
inicial ou experimental e sua continuação, isto é, fatores que tornam o indivíduo mais vulnerável ao uso de drogas.

Fatores protetores, por sua vez, são aqueles que podem explicar porque certos indivíduos, mesmo fazendo parte dos grupos de risco, não experimentam drogas, ou, se experimentam, não passam de usuários esporádicos, sem chegar a desenvolver complicações como, por exemplo, a dependência.

Do ponto de vista histórico, a pesquisa de fatores de risco associados ao uso de drogas, evoluiu em três etapas distintas. Na primeira, estudos transversais pesquisaram basicamente variáveis demográficas em diferentes grupos de jovens. A etapa seguinte procurou examinar aspectos psico-sociais relacionados ao grupo de amigos, à família e à escola. Mais recentemente voltou-se a atenção para os fatores de risco biológicos (KUMPFER 1992).

Fatores demográficos são úteis na escolha dos grupos-alvos para o trabalho preventivo, mas não fornecem informações sobre porque as pessoas desses grupos estão mais em risco, ou mesmo o que pode ser feito para reduzir o risco. Foram essas questões que levaram pesquisadores a se voltarem mais para a pesquisa experimental e a procurarem fatores psicosociais de risco e de proteção ao uso de drogas.

KUMPFER e DEMARSH (1985) construíram um modelo teórico para abranger e organizar os resultados dessas pesquisas. Nesse modelo, três aspectos são considerados para cada um dos quatro grandes 
domínios: fatores individuais, fatores do ambiente familiar, fatores do ambiente comunitário e fatores do ambiente social e de amigos. Os três aspectos considerados se referem a: 1.Atitudes e valores; 2 . Estressores; 3. Potencialidades e habilidades de cooperação. Os dois primeiros aspectos estão associados ao uso de drogas, enquanto que as potencialidades de cooperação protegem contra o uso. Segundo o modelo, cada um desses conjuntos de fatores (família, comunidade, amigos e indivíduo) influenciam e são influenciados por todos os outros, mas a preponderância da influência dos outros fatores sobre o indivíduo varia ao longo de seu desenvolvimento. A família tem seu predomínio nos primeiros anos de vida e a comunidade (televisão, escola, livros, gibis, instituições religiosas) inicia sua influência ainda na infầncia. Já a ascendência dos amigos vai crescendo até ser muito forte, às vezes quase absoluta, durante a adolescência.

Quanto aos indicadores que se relacionam, ou não, com o uso de drogas, um bom exemplo é encontrado em um levantamento nacional sobre abuso de drogas, realizado em 1991 nos Estados Unidos (NIDA 1992). Nesse levantamento, a idade foi apontada como um importante indicador na caracterização de usuários. Os maiores índices de uso de drogas correspondiam à faixa etária de 18 a 25 anos. Outro indicador que aparece consistentemente é o sexo. Homens, independente da idade, fazem uso maior de álcool e drogas que as mulheres. Talvez, as maiores surpresas sejam para os indicadores que não se correlacionam bem com o uso de drogas. Um desses indicadores é a classe social. Com exceção dos 
indivíduos de família muito pobre, para os quais o índice de uso de drogas é elevado, para todo o resto da sociedade - "classe baixa", "média" e "alta" - não se detectou diferença nos índices de uso de álcool e drogas (OETTING e BEAUVAIS 1988).

Outra surpresa é o resultado sistemático de que aspectos da personalidade não são bons na previsão do uso de drogas. Apesar de muitas teorias atribuírem o uso de drogas à baixa auto-estima, à depressão ou à ansiedade, sucessivos estudos mostram fraca correlação entre essas características e o uso de drogas (OETTING e BEAUVAIS 1988).

Esses estudos, também, mostram consistentemente a relação de alguns indicadores psico-sociais com o uso de drogas. Jovens religiosos, que freqüentam a escola com regularidade e apresentam bom desempenho, têm bom relacionamento com seus pais e não infringem leis, são aqueles que referem menor uso de álcool e drogas. Na outra ponta da escala aparecem os jovens que não se submetem às regras sociais e, nesse caso, o uso de drogas seria apenas uma parte desse quadro. Indivíduo não conformista, em geral, tem uma relação mais próxima com companheiros do que com os pais, e seus companheiros têm características semelhantes a ele ou a ela (RAY e KSIR 1993).

Pensando nesses indicadores, relacionados acima como fatores de risco, pode-se dizer que nenhum deles, isoladamente, é determinante do uso de drogas, mas quanto maior a quantidade desses fatores juntos, maior a chance de o indivíduo usar ou vir a usar drogas. Daí, a importância do 
processo de identificação desses fatores para a constituição de um trabalho de prevenção.

Encontrar características associadas ao uso de drogas não ajuda, de forma definitiva, a entender as relações causais. Continua-se sem saber, por exemplo, se adolescentes se envolvem primeiro com um grupo com atitudes não conformistas e aí começam a usar drogas, ou se eles primeiro usam drogas e daí começam a se aproximar de outros que fazem o mesmo. Neste sentido fica a indagação: seria o uso de drogas que leva jovens a brigas e roubos, ou esses comportamentos precedem e até empurram jovens para o uso de drogas?

Para melhor entender esses problemas faz-se necessário o desenvolvimento de outros estudos longitudinais - pesquisa que tem um elevado nível de dificuldade, além do alto custo financeiro - buscando-se os antecedentes, isto é, fatores que antecedem ao início do uso de drogas.

Enquanto modelos causais procuram uma única variável que determinaria um aspecto particular, vários estudos, em diversos campos, concluíram que é o número, muito mais que a natureza dos fatores de risco, que prediz melhor o resultado (GREENSPAN 1980).

O quadro de fatores de risco descritos na literatura é vasto, principalmente pela multiplicidade e complexidade dos problemas associados ao uso de drogas. Assim como ocorre em relação à vulnerabilidade a uma doença qualquer, fatores de risco em diferentes combinações e em diferentes níveis podem resultar no uso de drogas. 
A busca de características biológicas que atuem como fatores de risco para o uso de drogas está aumentando, embora já estejam bem mais avançadas as pesquisas no campo do alcoolismo, principalmente com filhos de alcoólatras. Em 1987, um modelo de vulnerabilidade bio-psico-social foi proposto por KUMPFER (1992), baseado em evidências crescentes de que filhos de pais que abusam de álcool ou drogas podem apresentar diferenças genéticas, bioquímicas, neuro-físicas e neuro-psicológicas - significativas em relação às outras crianças. Devido a essas diferenças, o modelo supõe que crianças desse grupo sejam mais propensas a desenvolver problemas com o uso de álcool e drogas. Supõe ainda que, quanto maior o número desses fatores de risco, maior a chance das crianças de virem a desenvolver esse tipo de problema.

Pelo exposto anteriormente, tem-se que, para uma análise linear, muitos são os fatores que parecem ter significado dentro de uma dada realidade. Em minha metodologia, porém, busco a interação entre os diversos fatores. $\mathrm{O}$ resultado desta pesquisa, portanto, passa a ser função dessa relação circunstancial, segundo o conceito de circunstância do filósofo espanhol Ortega y Gasset (1883-1955). Para Gasset o homem é sempre ele mesmo e sua circunstância, sendo ambos indissociáveis na consideração da realidade (KUJAWSKI 1994). 


\section{OBJETIVOS}

\subsection{Objetivo Geral}

Identificar fatores relacionados ao uso de drogas entre alunos de graduação da Universidade de São Paulo, da cidade de São Paulo.

\subsection{Objetivo Específico}

Buscar a inter-relação entre os diversos fatores identificados e as condições de risco para o uso de drogas. 


\section{CASUÍSTICA E MÉTODOS}

\subsection{Delineamento da pesquisa}

Este trabalho é um sub-projeto do projeto-mãe "Programa de Prevenção ao Uso de Drogas para a Universidade de São Paulo", no qual participei como coordenadora da pesquisa epidemiológica, realizada em 1996.

No estudo epidemiológico inicial foi realizado um levantamento do padrão de uso de drogas de alunos dos primeiros aos últimos anos, dos diferentes cursos de graduação da USP, matriculados na cidade de São Paulo. Utilizando um questionário anônimo e de autopreenchimento, com 71 questões, e nos moldes propostos pela Organização Mundial da Saúde (SMART et al. 1980), foram levantadas informações sobre o uso na vida, nos últimos doze meses e nos últimos trinta dias das seguintes substâncias psicoativas: álcool, tabaco, maconha, alucinógenos, cocaína, crack, anfetaminas, anticolinérgicos, solventes orgânicos, tranqüilizantes, ansiolíticos e antidistônicos, opiáceos, sedativos e barbitúricos e anabolizantes. 
Os dados obtidos foram analisados para caracterizar alunos de graduação da USP da cidade de São Paulo, e conhecer a prevalência do uso de álcool e drogas na vida, nos últimos doze meses e nos últimos trinta dias nessa população específica, verificando se existiriam diferenças significativas entre as seguintes variáveis: área de estudo, período de freqüência ao curso, ano de ingresso na universidade, forma de moradia e sexo.

O gráfico 1 nos mostra o padrão de uso de drogas por alunos, referente ao uso na vida, no ano ou no mês, e dividido em 3 categorias: uso de álcool, uso de tabaco, e uso de 'drogas', categoria esta que incluiu todas as drogas pesquisadas, à exceção de álcool e tabaco.

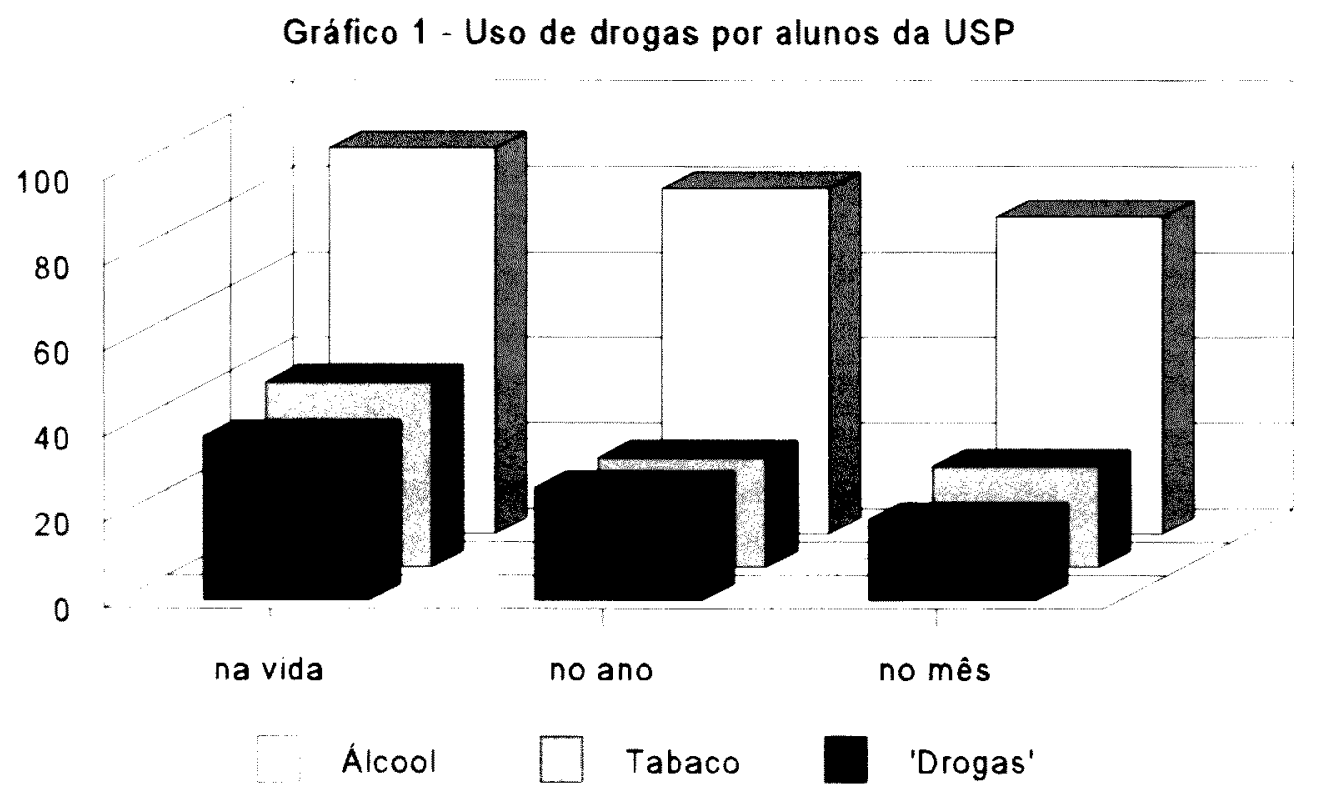


O detalhamento dos resultados obtidos nesse estudo anterior encontram-se no anexo 4, em artigo publicado na revista da Associação Brasileira de Psiquiatria e Associação de Psiquiatria da América Latina (ABP-APAL) "Uso de Álcool e Drogas em Alunos de Graduação da Universidade de São Paulo (1996)" (ANDRADE et al. 1997b).

\subsection{População de estudo}

A população desta pesquisa são estudantes da Universidade de São Paulo. Usou-se como critérios de inclusão:

1. Ser aluno de graduação da USP.

2. Estar matriculado na USP em 1996.

3. Cursar a USP na cidade de São Paulo.

O número total de alunos de graduação da USP na cidade de São Paulo em janeiro de 1996 era de 29675 . Com este total foi realizado um sorteio estratificado por áreas e unidades, chegando-se a 3539 o total de alunos sorteados, distribuídos de acordo com a tabela apresentada no anexo 1. No anexo 2, tem-se o plano de amostragem, fornecendo maiores detalhes dos procedimentos para estimação e sorteio da amostra.

Foi utilizado o mesmo instrumento do estudo epidemiológico inicial (anexo 3). Além das questões sobre o uso das diversas substâncias 
psicoativas descritas anteriormente, esse questionário também contém questões sobre atitudes das pessoas frente ao uso experimental e regular de substâncias psicoativas, qualidade de vida, lazer e dados sócio-demográficos da população pesquisada. Todas as perguntas formuladas o foram no sentido de levantar informações, atitudes e padrão de uso de drogas e não para avaliar o indivíduo quanto à existência, ou não, de um quadro de maior gravidade, como a dependência de drogas.

Considerando que pesquisas dessa natureza devem garantir o anonimato dos participantes para a obtenção de maior fidedignidade nas respostas, todo o processo de coleta de dados foi padronizado e realizado por profissionais treinados para esta tarefa. Levando-se em conta as localizações geográficas das unidades da USP na cidade de São Paulo bastante espalhadas - e o fato de terem características muito diferenciadas, quanto à forma de funcionamento, todo o processo de coleta de dados contou, também, com supervisão de campo. Pesquisa anterior mostrou a importância do treinamento dos pesquisadores de campo nesta área específica, embora se reconheça que o treinamento, sozinho, não é suficiente para garantir a padronização da coleta de dados (ANDRADE et al. 1995).

Em se tratando de um tema delicado, a linguagem utilizada desempenhou papel preponderante para facilitar o acesso à população alvo, proporcionando a sua aproximação e participação na pesquisa, na busca de maior efetividade nos resultados. Procurou-se, assim, evitar títulos e 
palavras que pudessem gerar mal estar nas pessoas, sobretudo naquelas que não acreditam que as drogas possam causar problemas, ou mesmo, nos usuários ocasionais que só conhecem o lado prazeroso que as drogas proporcionam.

Apesar de todos esses cuidados, os alunos sorteados foram convidados a preencher o questionário em cinco momentos diferentes, devido à dificuldade de se conseguir a totalização de $80 \%$ da amostra, percentual considerado necessário às exigências estatísticas de confiabilidade, uma vez que foi calculada, admitindo-se uma perda de até $20 \%$ (ver Plano de amostragem - anexo 2).

\subsection{Variáveis do estudo}

Neste estudo buscou-se identificar os fatores associados ao uso de drogas, fatores esses comuns a 11 das 13 substâncias psicoativas pesquisadas, a saber: maconha, alucinógenos, cocaína, crack, anfetaminas, anticolinérgicos, inalantes, tranqüilizantes, opiáceos, sedativos e anabolizantes. Nesta busca de fatores comuns não foram incluídas apenas duas das drogas pesquisadas, por se tratarem de drogas com um padrão de uso muito diferenciado: o álcool e o tabaco. Estas duas substâncias se incluem na categoria drogas lícitas e têm seu uso social amplamente aceito, pelo menos até o presente momento, em nossa cultura. 
Das 71 questões existentes no instrumento utilizado, 10 foram retiradas $^{1}$ da análise, por não se referirem ao grupo de comparação de não usuários, ou por se tratarem de dados que fugiam ao objetivo deste estudo.

\subsubsection{Variável dependente: uso de droga}

Para o presente estudo, foi definido como droga a reunião das 11 substâncias acima descritas e, como uso, qualquer referência de utilização das mesmas no último ano. Optou-se pela variável uso nos últimos 12 meses e não uso na vida, pelo fato de se trabalhar com uma população de jovens adultos, que poderiam ter experimentado uma substância psicoativa aos 12 ou 13 anos, sem outros usos posteriores, e que, incluídos nas análises, trariam um viés temporal às mesmas.

Ficou definido como usuário de droga qualquer aluno que houvesse relatado ter feito uso de droga nos últimos 12 meses.

\subsubsection{Variáveis independentes}

As variáveis independentes estão aqui apresentadas em 10

\footnotetext{
'As questões retiradas encontram-se marcadas com o símbolo $\propto$ antes do número da questão, no questionário encontrado no anexo 3.
} 
grupos, reunidas por diferentes temas, descritos nos quadros 1 a 10 .

Quadrol. Perfil do aluno

\begin{tabular}{|c|c|}
\hline variável & categoria \\
\hline sexo & $\begin{array}{l}\text { masculino } \\
\text { feminino }\end{array}$ \\
\hline faixa etária & $\begin{array}{l}15 \text { a } 19 \\
20 \text { a } 24 \\
25 \text { a } 29 \\
30 \text { ou }+\end{array}$ \\
\hline estado civil & $\begin{array}{l}\text { solteiro } \\
\text { casado } \\
\text { vive junto }\end{array}$ \\
\hline condições de moradia & $\begin{array}{l}\text { pais } \\
\text { cônjuge } \\
\text { amigos } \\
\text { sozinho } \\
\text { CRUSP² } \\
\text { outros }\end{array}$ \\
\hline ter religião & $\begin{array}{l}\text { sim } \\
\text { não }\end{array}$ \\
\hline praticar religião & $\begin{array}{l}\text { sim } \\
\text { não }\end{array}$ \\
\hline atividade remunerada & $\begin{array}{l}\text { sim } \\
\text { não }\end{array}$ \\
\hline principal confidente & $\begin{array}{l}\text { mãe } \\
\text { pai } \\
\text { irmão } \\
\text { amigos } \\
\text { namorado(a) } \\
\text { terapeuta } \\
\text { ninguém } \\
\text { outros }\end{array}$ \\
\hline
\end{tabular}

${ }^{2}$ CRUSP - Centro Residencial da USP 
Quadro 2. Ambiente familiar

\begin{tabular}{|l|l|}
\hline \multicolumn{1}{|c|}{ variável } & \multicolumn{1}{|c|}{ categoria } \\
\hline escolaridade do pai & nenhuma educação formal \\
& $1^{\circ}$ grau incompleto \\
$1^{\circ}$ grau completo \\
$2^{\circ}$ grau incompleto \\
$2^{\circ}$ grau completo \\
superior incompleto \\
superior completo \\
não sabe
\end{tabular}




\section{Quadro 3. Curso universitário}

\begin{tabular}{|l|l|}
\hline \multicolumn{1}{|c|}{ variável } & \\
\hline ano de ingresso & até 1990 \\
& $1991-1993$ \\
& $1994-1996$ \\
\hline área & humanas \\
& biológicas \\
& exatas \\
\hline unidade & ECA (Escola de Comunicações e Artes) \\
& EE (Escola de Enfermagem) \\
& EEFE (Escola de Educação Física e Esporte) \\
& EP (Escola Politécnica) \\
& FAU (Fac. de Urbanismo e Arquitetura) \\
& FCF (Fac. de Ciências Farmacêuticas) \\
& FD (Faculdade de Direito) \\
& FE (Faculdade de Educação) \\
& FEA (Fac. de Economia e Administração) \\
& FFLCH (Fac. de Fil., Letras e C. Humanas) \\
& FM (Faculdade de Medicina) \\
& FMVZ (Fac. de Med. Veterinária e Zootecnia) \\
& FO (Faculdade de Odontologia) \\
& FSP (Faculdade de Saúde Pública) \\
& IAG (Instituto Agronômico e Geofisico) \\
& IB (Instituto de Biociências) \\
& IF (Instituto de Física) \\
& IG (Instituto de Geociências) \\
& IME (Instituto de Matemática e Estatística) \\
& IP (Instituto de Psicologia) \\
& IQ (Instituto de Química) \\
\hline \multirow{2}{*}{ ano do curso } & $1^{\circ}$ ano \\
& $2^{\circ}$ ano \\
& $3^{\circ}$ ano \\
& $4^{\circ}$ ano \\
& $5^{\circ}$ ano \\
& $6^{\circ}$ ano \\
\hline & diurno \\
& noturno \\
\hline & \\
\hline &
\end{tabular}


Quadro 4. Vida acadêmica

\begin{tabular}{|c|c|}
\hline variável & categoria \\
\hline lugares que freqüenta na universidade & $\begin{array}{l}\text { centro acadêmico } \\
\text { centro esportivo } \\
\text { biblioteca } \\
\text { lanchonete } \\
\text { outros }\end{array}$ \\
\hline satisfação com escolha profissional & $\begin{array}{l}\operatorname{sim} \\
\text { não }\end{array}$ \\
\hline pensou em abandonar o curso & $\begin{array}{l}\operatorname{sim} \\
\text { não } \\
\text { ainda pensa }\end{array}$ \\
\hline ano em que pensou em abandonar o curso & $\begin{array}{l}1^{\circ} \text { ano } \\
2^{\circ} \text { ano } \\
3^{\circ} \text { ano } \\
4^{\circ} \text { ano } \\
5^{\circ} \text { ano } \\
6^{\circ} \text { ano }\end{array}$ \\
\hline deixa de fazer trabalhos acadêmicos & $\begin{array}{l}\operatorname{sim} \\
\text { não }\end{array}$ \\
\hline desempenho escolar & $\begin{array}{l}\text { bom/excelente } \\
\text { fraco/regular } \\
\text { insuficiente }\end{array}$ \\
\hline $\begin{array}{l}\text { perspectivas de trabalho e financeiras após } \\
\text { formatura }\end{array}$ & $\begin{array}{l}\text { realização profissional e financ. } \\
\text { realização profissional e ñ financ. } \\
\text { realização financ. e ñ profissional } \\
\text { sem realização profis.. ou financ. }\end{array}$ \\
\hline aprovação no último semestre & $\begin{array}{l}\text { passou direto } \\
\text { passou com recuperação } \\
\text { passou com dependência } \\
\text { repetiu } \\
\text { outro }\end{array}$ \\
\hline atividade quando falta às aulas & $\begin{array}{l}\text { não falta } \\
\text { cinema/clube } \\
\text { estuda em casa } \\
\text { estuda na faculdade } \\
\text { não faz nada } \\
\text { só falta quando doente } \\
\text { trabalha } \\
\text { dorme/descansa } \\
\text { centro acadêmico/centro esportivo } \\
\text { outros }\end{array}$ \\
\hline
\end{tabular}


Quadro 5. Grupo de amigos

\begin{tabular}{|l|l|}
\hline \multicolumn{1}{|c|}{ variável } & \multicolumn{1}{c|}{ categoria } \\
\hline dificuldades em fazer novos amigos & $\begin{array}{l}\text { sim } \\
\text { não }\end{array}$ \\
\hline sentir-se rejeitado pelos amigos & $\begin{array}{l}\text { sim } \\
\text { não }\end{array}$ \\
\hline julga-se facilmente influenciável pelos amigos & $\begin{array}{l}\text { sim } \\
\text { não }\end{array}$ \\
\hline amigos fazem uso freqüente de álcool & $\begin{array}{l}\text { sim } \\
\text { não }\end{array}$ \\
\hline amigos fazem uso freqüente de drogas & $\begin{array}{l}\text { sim } \\
\text { não }\end{array}$ \\
\hline
\end{tabular}

\section{Quadro 6. Lazer}

\begin{tabular}{|l|l|}
\hline \multicolumn{1}{|c|}{ variável } & \multicolumn{1}{c|}{ categoria } \\
\hline horas livres nos dias úteis & nenhuma \\
& $\begin{array}{l}\text { até } 2 \text { hs. } \\
\text { de } 2 \text { a } 4 \text { hs. } \\
\text { de } 4 \text { a } 6 \text { hs. } \\
\text { mais do que } 6 \text { hs. }\end{array}$ \\
\hline horas livres nos fins de semana & $\begin{array}{l}\text { todo o tempo } \\
\text { algumas horas/dia } \\
\text { menos de } 1 \text { hora/dia } \\
\text { nenhuma hora }\end{array}$ \\
\hline atividades nas horas livres & $\begin{array}{l}\text { igreja } \\
\text { sai/viaja } \\
\text { esportes } \\
\text { TV } \\
\text { atividades culturais } \\
\text { bares/festas } \\
\text { leitura } \\
\text { outros }\end{array}$ \\
\hline dedica às atividades tempo satisfatório & $\begin{array}{l}\text { sim } \\
\text { não }\end{array}$ \\
\hline
\end{tabular}


Quadro 7. Vida sexual

\begin{tabular}{|l|l|}
\hline \multicolumn{1}{|c|}{ variável } & \multicolumn{1}{c|}{ categoria } \\
\hline gostaria de mais informações sobre DST's e AIDS & $\begin{array}{l}\text { sim } \\
\text { não }\end{array}$ \\
\hline acha importante o uso de preservativos & $\begin{array}{l}\text { sim } \\
\text { não }\end{array}$ \\
\hline faz uso de preservativos & $\begin{array}{l}\text { sempre } \\
\text { nunca } \\
\text { às vezes }\end{array}$ \\
\hline motivo para não usar preservativo & $\begin{array}{l}\text { usa sempre } \\
\text { tem parceiro fixo } \\
\text { não faz sexo } \\
\text { outros motivos }\end{array}$ \\
\hline
\end{tabular}

Quadro 8. Uso pessoal de drogas

\begin{tabular}{|l|l|}
\hline \multicolumn{1}{|c|}{ variável } & \multicolumn{1}{|c|}{ categoria } \\
\hline usou álcool nos últimos 12 meses & $\begin{array}{l}\text { sim } \\
\text { não }\end{array}$ \\
\hline usou tabaco nos últimos 12 meses & $\begin{array}{l}\text { sim } \\
\text { não }\end{array}$ \\
\hline experimentou drogas antes de entrar na universidade & $\begin{array}{l}\text { sim } \\
\text { não }\end{array}$ \\
\hline envolveu-se em acidente de carro após uso de drogas & $\begin{array}{l}\text { sim } \\
\text { não }\end{array}$ \\
\hline
\end{tabular}




\section{Quadro 9. Atitudes relacionadas às drogas}

\begin{tabular}{|c|c|}
\hline variável & categoria \\
\hline o que pensa a respeito de uma pessoa experimentar álcool & $\begin{array}{l}\text { aprova } \\
\text { desaprova }\end{array}$ \\
\hline o que pensa a respeito de uma pessoa experimentar maconha & $\begin{array}{l}\text { aprova } \\
\text { desaprova }\end{array}$ \\
\hline o que pensa a respeito de uma pessoa experimentar cocaína & $\begin{array}{l}\text { aprova } \\
\text { desaprova }\end{array}$ \\
\hline o que pensa a respeito de uma pessoa experimentar crack & $\begin{array}{l}\text { aprova } \\
\text { desaprova }\end{array}$ \\
\hline o que pensa a respeito de uma pessoa experimentar tranqüilizantes & $\begin{array}{l}\text { aprova } \\
\text { desaprova }\end{array}$ \\
\hline o que pensa a respeito de uma pessoa experimentar anfetaminas & $\begin{array}{l}\text { aprova } \\
\text { desaprova }\end{array}$ \\
\hline o que pensa a respeito de uma pessoa experimentar inalantes & $\begin{array}{l}\text { aprova } \\
\text { desaprova }\end{array}$ \\
\hline o que pensa a respeito de uma pessoa usar regularmente álcool & $\begin{array}{l}\text { aprova } \\
\text { desaprova }\end{array}$ \\
\hline o que pensa a respeito de uma pessoa usar regularmente maconha & $\begin{array}{l}\text { aprova } \\
\text { desaprova }\end{array}$ \\
\hline o que pensa a respeito de uma pessoa usar regularmente cocaína & $\begin{array}{l}\text { aprova } \\
\text { desaprova }\end{array}$ \\
\hline o que pensa a respeito de uma pessoa usar regularmente crack & $\begin{array}{l}\text { aprova } \\
\text { desaprova }\end{array}$ \\
\hline o que pensa a respeito de uma pessoa usar regularmente tranqüilizantes & $\begin{array}{l}\text { aprova } \\
\text { desaprova }\end{array}$ \\
\hline o que pensa a respeito de uma pessoa usar regularmente anfetaminas & $\begin{array}{l}\text { aprova } \\
\text { desaprova }\end{array}$ \\
\hline o que pensa a respeito de uma pessoa usar regularmente inalantes & $\begin{array}{l}\text { aprova } \\
\text { desaprova }\end{array}$ \\
\hline
\end{tabular}


Quadro 10. Opiniões relacionadas às drogas

\begin{tabular}{|l|l|}
\hline \multicolumn{1}{|c|}{ variável } & \multicolumn{1}{c|}{ categoria } \\
\hline dependência de drogas é um problema de saúde & $\begin{array}{l}\text { sim } \\
\text { não }\end{array}$ \\
\hline opinião sobre a maioria dos alcoolistas & $\begin{array}{l}\text { se curam } \\
\text { melhoram } \\
\text { não melhoram } \\
\text { pioram }\end{array}$ \\
\hline opinião sobre a maioria dos dependentes de drogas & $\begin{array}{l}\text { se curam } \\
\text { melhoram } \\
\text { não melhoram } \\
\text { pioram }\end{array}$ \\
\hline quem procura para esclarecer dúvidas sobre álcool e drogas & $\begin{array}{l}\text { professores } \\
\text { amigos/colegas } \\
\text { pais } \\
\text { profissionais } \\
\text { líder religioso } \\
\text { livros/artigos cient. }\end{array}$ \\
\hline gostaria de ter mais informações e/ou ajudar pessoas & $\begin{array}{l}\text { ter mais informações } \\
\text { ajudar pessoas } \\
\text { as duas coisas } \\
\text { nenhuma delas }\end{array}$ \\
\hline
\end{tabular}

\subsection{Análise Estatística}

As variáveis foram, inicialmente, agrupadas em 10 tópicos:

Perfil do Aluno, Ambiente familiar, Curso Universitário, Vida Acadêmica, Grupo de Amigos, Lazer, Vida Sexual, Atitudes, Opiniões, e Uso pessoal de drogas. Construíram-se, para cada tópico, tabelas contendo as 
freqüências absolutas e relativas dos dois grupos estudados (usuários e nãousuários de droga) e do total da amostra. Para avaliar a associação entre o uso de droga e cada variável independente, foi utilizado o teste de quiquadrado de Pearson.

Para o levantamento dos fatores e/ou situações com maior probabilidade de predispor o aluno ao uso de substâncias psicoativas, foram elaborados modelos de regressão logística múltipla, mediante a execução dos seguintes passos:

Primeiramente foram construídos modelos univariados, com todas as variáveis que mostraram associação $(p<0,05)$ pelo teste de quiquadrado. Obtidos os modelos univariados, apenas aquelas variáveis que mostraram alguma associação $(\mathrm{p}<0,05)$ passaram para a etapa seguinte de regressão logística múltipla, com procedimento de seleção stepwise forward. As variáveis foram submetidas à análise de regressão logística múltipla, reunidas por tópicos, conforme descrição no início deste item. A partir dos 10 tópicos iniciais foram elaborados 5 modelos multivariados finais, selecionando-se, assim, as variáveis de risco para o uso de droga em alunos da USP, segundo características específicas para cada modelo. Foram considerados fatores que predispõem ao risco, as categorias com odds ratio (OR) maiores que 1,0. Foram escolhidas como categorias de referência (baseline), aquelas com o menor índice de uso de droga. Estas são as categorias com OR sempre igual a 1,0, e com as quais se estabelece a comparação das OR das outras categorias. 
Por último, foi elaborado um modelo multivariado final geral, incluindo-se nele, apenas as variáveis que constituíam os 5 modelos anteriores. 


\section{RESULTADOS}

\subsection{Descrição dos Alunos}

A casuística deste estudo compreendeu um total de 2506 alunos.

Para a descrição dos alunos, foram usadas as tabelas citadas levando-se em conta a coluna. Para o sub-item seguinte (4.2.), as análises foram feitas considerando-se a linha e não mais a coluna.

Conforme apresentado nas tabelas la e $1 \mathrm{~b}$, verifica-se que $80,7 \%$ da amostra estudada encontrava-se na faixa etária entre 15 e 24 anos, com maior proporção entre os 20 e 24 anos (60\%). A maioria dos alunos é solteira $(91,4 \%)$ e mora com os pais $(74,1 \%)$.

Quanto ao sexo, tem-se uma distribuição de $57,2 \%$ para o sexo masculino e de $42,8 \%$ para o sexo feminino.

Dos alunos pesquisados, um pouco mais da metade $(57,5 \%)$ relatou ter trabalhado no semestre anterior à coleta de dados.

Conforme apresentado na tabela $2 \mathrm{a}, 60,1 \%$ dos pais e $44,7 \%$ 
das mães desses alunos possuem grau de escolaridade superior, seja completo ou incompleto.

\subsection{Comparação entre usuários e não-usuários de droga}

Foi realizado o cruzamento entre a variável dependente uso de

droga e as demais variáveis independentes, que são aqui apresentadas agrupadas em 10 tópicos. Essa divisão em tópicos teve, como principal razão, o grande número de variáveis com que se trabalhou, aliada ao fato de serem encontrados, na literatura, estudos que também referem essas divisões, o que veio facilitar a comparação de resultados e a conseqüente discussão dos mesmos.

\subsubsection{Perfil do Aluno}

Ao se compararem os grupos dos que usam droga, com os que não usam droga em relação às variáveis sexo $(\mathrm{p}=0,0003)$, faixa etária $(p=0,0003)$, estado civil $(p=0,0074)$, condições de moradia $(p=0,0001)$, ter religião $(p<0,0001)$, praticar religião $(p<0,0001)$, exercer atividade 
remunerada $(p=0,0070)$ e principal confidente $(p<0,0001)$, constatou-se que todas elas apresentaram uma associação estatisticamente significativa. É o que mostram as tabelas $1 \mathrm{a}$ e $1 \mathrm{~b}^{3}$

Tabela 1a - Número e porcentagem de estudantes universitários da USP, segundo o uso de droga e características pessoais (1996)

\begin{tabular}{|c|c|c|c|c|c|c|c|c|}
\hline \multirow[t]{2}{*}{ Variável } & \multirow[t]{2}{*}{ Categoria } & \multicolumn{2}{|c|}{ Usa } & \multicolumn{2}{|c|}{ Não Usa } & \multicolumn{2}{|c|}{ Total } & \multirow[t]{2}{*}{$\mathbf{p}^{\star}$} \\
\hline & & $\mathbf{n}$ & $\%$ & $\mathbf{n}$ & $\%$ & $\mathbf{n}$ & $\%$ & \\
\hline \multirow[t]{2}{*}{ Sexo } & Masculino & 417 & 29,3 & 1006 & 70,7 & 1423 & 57,2 & \\
\hline & Feminino & 244 & 229 & 821 & 77,1 & 1065 & 42,8 & \\
\hline Total & & 661 & 26,6 & 1827 & 73,4 & 2488 & 100,0 & 0,0003 \\
\hline \multirow[t]{4}{*}{ Faixa Etária } & $15-19$ & 123 & 24,0 & 389 & 76,0 & 512 & 20,6 & \\
\hline & $20-24$ & 440 & 29,4 & 1057 & 70,6 & 1497 & 60,1 & \\
\hline & $25-29$ & 73 & 22,5 & 252 & 77,5 & 325 & 13,1 & \\
\hline & $30 \mathrm{ou}+$ & 26 & 16,7 & 130 & 83,3 & 156 & 6,3 & \\
\hline Total & & 662 & 26.6 & 1828 & 73,4 & 2490 & 100,0 & 0,0003 \\
\hline \multirow[t]{3}{*}{ Estado Civil } & Solteiro & 622 & 27,3 & 1655 & 72,7 & 2277 & 91,4 & \\
\hline & Casado/juntado & 33 & 17,2 & 159 & 82,8 & 192 & 7,7 & \\
\hline & Outro & 07 & 33,3 & 14 & 66,7 & 21 & 0,8 & \\
\hline Total & & 662 & 26,6 & 1828 & 73,4 & 2490 & 100,0 & 0,0074 \\
\hline \multirow[t]{6}{*}{ Moradia } & Pais & 473 & 25,7 & 1368 & 74,3 & 1841 & 74,1 & \\
\hline & Cônjuge & 33 & 17,8 & 152 & 82,2 & 185 & 7,4 & \\
\hline & Amigos & 91 & 36,5 & 158 & 63,5 & 249 & 10,0 & \\
\hline & Sozinho & 44 & 34,9 & 82 & 65,1 & 126 & 5,1 & \\
\hline & CRUSP $^{+}$ & 16 & 24,6 & 49 & 75,4 & 65 & 2,6 & \\
\hline & Outros & 04 & 20,0 & 16 & 80,0 & 20 & 0,8 & \\
\hline Total & & 661 & 26,6 & 1825 & 73,4 & 2486 & 100,0 & 0,0001 \\
\hline
\end{tabular}

p*: nível descritivo do teste de associação de Pearson. Na realização do teste foi excluída a categoria 'ignorado'. $+:$ CRUSP $=$ Centro Residencial da USP.

${ }^{3}$ A tabela $1 \mathrm{~b}$ é continuação da tabela la. 
À semelhança de outros estudos sobre o tema, os resultados revelaram que os homens usam mais droga do que as mulheres. $\mathrm{O}$ uso de droga aumenta até a faixa etária de 20 a 24 anos, que é a faixa que apresentou maior uso $(29,4 \%)$ e, em seguida, diminui entre os alunos mais velhos.

Quanto ao estado civil foi encontrada uma proporção menor de uso entre aqueles que são casados ou têm um(a) companheiro(a) (17,2\%), enquanto os solteiros apresentaram uma chance aumentada de uso $(27,3 \%)$. Nesta mesma linha, para a variável 'condições de moradia do aluno', viver com o cônjuge está associado ao mais baixo índice de uso (17,8\%), enquanto os mais altos índices estão entre os que moram com amigos (36,5\%), ou sozinhos $(34,9 \%)$.

Ter religião e, mais ainda, praticá-la, mostrou diminuir a porcentagem de uso de droga. É interessante notar que aqueles que exerciam atividades remuneradas mostraram um uso maior de droga do que os que não haviam trabalhado no semestre anterior à coleta dos dados.

Na variável 'principal confidente', em que a pergunta formulada foi: 'qual a pessoa que procura em primeiro lugar quando tem um problema sério?', constatou-se que a mãe é a menos procurada e o terapeuta, o mais procurado pelos que usam droga, enquanto o inverso ocorre no grupo que não faz uso de drogas. 
Tabela 1b - Número e porcentagem de estudantes universitários da USP, segundo o uso de droga e características pessoais (1996)

\begin{tabular}{|c|c|c|c|c|c|c|c|c|}
\hline \multirow[t]{2}{*}{ Variável } & \multirow[t]{2}{*}{ Categoria } & \multicolumn{2}{|c|}{ Usa } & \multicolumn{2}{|c|}{ Não Usa } & \multicolumn{2}{|c|}{ Total } & \multirow[t]{2}{*}{$\mathbf{p}^{*}$} \\
\hline & & $\mathbf{n}$ & $\%$ & $\mathbf{n}$ & $\%$ & $\mathbf{n}$ & $\%$ & \\
\hline \multirow[t]{2}{*}{ Ter religião } & Sim & 435 & 24,0 & 1379 & 76,0 & 1814 & 73,2 & \\
\hline & Não & 222 & 33.4 & 442 & 66,6 & 664 & 26,8 & \\
\hline Total & & 657 & 26,5 & 1821 & 73,5 & 2478 & 100,0 & $<0,0001$ \\
\hline Praticar & Sim & 158 & 19,3 & 661 & 80,7 & 819 & 34,8 & \\
\hline Religião & Não & 455 & 29,7 & 1079 & 70,3 & 1534 & 65,2 & \\
\hline Total & & 613 & 26,1 & 1740 & 73,9 & 2353 & 100,0 & $<0,0001$ \\
\hline Atividade & Sim & 410 & 28,7 & 1021 & 71,3 & 1431 & 57,5 & \\
\hline Remunerada & Não & 252 & 23,8 & 806 & 76,2 & 1058 & 42,5 & \\
\hline Total & & 662 & 26.6 & 1827 & 73,4 & 2489 & 100,0 & 0,0070 \\
\hline Principal & Mãe & 109 & 17,2 & 525 & 82,8 & 634 & 27,0 & \\
\hline \multirow{7}{*}{ Confidente } & Pai & 38 & 24,1 & 120 & 75,9 & 158 & 6,7 & \\
\hline & Irmão & 48 & 31,2 & 106 & 68,8 & 154 & 6,6 & \\
\hline & Amigos & 201 & 39,7 & 305 & 60,3 & 506 & 21,6 & \\
\hline & Namorado(a) & 122 & 24,2 & 382 & 75,8 & 504 & 21,5 & \\
\hline & Terapeuta & 18 & 42,9 & 24 & 57,1 & 42 & 1,8 & \\
\hline & Ninguém & 81 & 25,2 & 240 & 74,8 & 321 & 13,7 & \\
\hline & Outros & 02 & 8,0 & 23 & 92,0 & 25 & 1,1 & \\
\hline Total & & 619 & 26,4 & 1725 & 73,6 & 2344 & 100,0 & $<0,0001$ \\
\hline
\end{tabular}

p*: nível descritivo do teste de associação de Pearson. Na realização do teste foi excluída a categoria 'ignorado'.

\subsubsection{Família}

De todas as variáveis relacionadas à família do aluno, apenas uma delas - algum membro da família bebeu ao ponto de causar problemas 
em casa, no trabalho ou com amigos $(p=0,4817)$ - não mostrou diferença entre os grupos de usuários e não-usuários. Para as outras variáveis, conforme apresentadas nas tabelas $2 \mathrm{a}$ e $2 \mathrm{~b}^{4}$, foi encontrada uma forte associação com o uso de droga.

Tabela 2a - Número e porcentagem de estudantes universitários da USP, segundo o uso de droga e características do ambiente familiar (1996)

\begin{tabular}{|c|c|c|c|c|c|c|c|c|}
\hline \multirow[t]{2}{*}{ Variável } & \multirow[t]{2}{*}{ Categoria } & \multicolumn{2}{|c|}{ Usa } & \multicolumn{2}{|c|}{ Nảo Usa } & \multicolumn{2}{|c|}{ Total } & \multirow[t]{2}{*}{$\mathbf{p}^{*}$} \\
\hline & & $\mathbf{n}$ & $\%$ & $\mathbf{n}$ & $\%$ & $\mathbf{n}$ & $\%$ & \\
\hline $\begin{array}{l}\text { Escolaridade } \\
\text { do pai }\end{array}$ & $\begin{array}{l}\text { Sem educação formal } \\
1^{\circ} \text { grau incompleto } \\
1^{\circ} \text { grau } \\
2^{\circ} \text { grau incompleto } \\
2^{\circ} \text { grau } \\
\text { Superior incompleto } \\
\text { Superior } \\
\text { Não sabe }\end{array}$ & $\begin{array}{c}02 \\
34 \\
32 \\
22 \\
83 \\
43 \\
435 \\
10\end{array}$ & $\begin{array}{c}7,4 \\
13,1 \\
15,2 \\
18,6 \\
23,5 \\
29,9 \\
32,3 \\
52.6\end{array}$ & $\begin{array}{c}25 \\
226 \\
179 \\
96 \\
270 \\
101 \\
911 \\
09\end{array}$ & $\begin{array}{l}92,6 \\
86,9 \\
84,8 \\
81,4 \\
76,5 \\
70,1 \\
67,7 \\
47,4\end{array}$ & $\begin{array}{c}27 \\
260 \\
211 \\
118 \\
353 \\
144 \\
1346 \\
19\end{array}$ & $\begin{array}{c}1,1 \\
10,5 \\
8,5 \\
4,8 \\
14,2 \\
5,8 \\
54,3 \\
0,8\end{array}$ & \\
\hline Total & & 661 & 26,7 & 1817 & 73,3 & 2478 & 100,0 & $<0.0001$ \\
\hline $\begin{array}{l}\text { Escolaridade } \\
\text { da mãe }\end{array}$ & $\begin{array}{l}\text { Sem educação formal } \\
1^{\circ} \text { grau incompleto } \\
1^{\circ} \text { grau } \\
2^{\circ} \text { grau incompleto } \\
2^{\circ} \text { grau } \\
\text { Superior incompleto } \\
\text { Superior } \\
\text { Não sabe }\end{array}$ & $\begin{array}{c}03 \\
48 \\
54 \\
31 \\
146 \\
57 \\
319 \\
04\end{array}$ & $\begin{array}{l}13.6 \\
15,4 \\
16,9 \\
21,2 \\
26,2 \\
34,8 \\
33,7 \\
26,7\end{array}$ & $\begin{array}{l}19 \\
264 \\
265 \\
115 \\
412 \\
107 \\
628 \\
11\end{array}$ & $\begin{array}{l}86,4 \\
84,6 \\
83,1 \\
78,8 \\
73,8 \\
65,2 \\
66,3 \\
73,3\end{array}$ & $\begin{array}{c}22 \\
312 \\
319 \\
146 \\
558 \\
164 \\
947 \\
15\end{array}$ & $\begin{array}{c}0,9 \\
12,6 \\
12,8 \\
5,9 \\
22,5 \\
6,6 \\
38,1 \\
0,6\end{array}$ & \\
\hline Total & & 662 & 26.7 & 1821 & 73,3 & 2483 & 100,0 & $<0,0001$ \\
\hline $\begin{array}{l}\text { Renda } \\
\text { Familiar }\end{array}$ & $\begin{array}{l}\text { Até } 10 \mathrm{SM}^{*} \\
\text { De } 11 \text { a } 20 \mathrm{SM} \\
\text { De } 21 \text { a } 30 \mathrm{SM} \\
\text { De31 a } 40 \mathrm{SM} \\
+ \text { de } 40 \mathrm{SM}\end{array}$ & $\begin{array}{c}65 \\
125 \\
123 \\
104 \\
212\end{array}$ & $\begin{array}{l}18.6 \\
21.9 \\
26.3 \\
28.1 \\
35.1\end{array}$ & $\begin{array}{l}284 \\
445 \\
344 \\
266 \\
392\end{array}$ & $\begin{array}{l}81,4 \\
78.1 \\
73,7 \\
71,9 \\
64,0\end{array}$ & $\begin{array}{l}349 \\
570 \\
467 \\
370 \\
604\end{array}$ & $\begin{array}{l}14.8 \\
24.2 \\
19.8 \\
15,7 \\
25,6\end{array}$ & \\
\hline Total & & 629 & 26,7 & 1731 & 73,3 & 2360 & 100,0 & $<0.0001$ \\
\hline
\end{tabular}

p*: nivel descritivo do teste de associação de Pearson. Na realização do teste foi excluida a categoria 'ignorado". $+: \mathrm{SM}=$ salário mínimo

${ }^{4} \mathrm{~A}$ tabela $2 \mathrm{~b}$ é continuação da tabela $2 \mathrm{a}$. 
Tabela $2 \mathbf{b}$ - Número e porcentagem de estudantes universitários da USP, segundo o uso de droga e características do ambiente familiar (1996)

\begin{tabular}{|c|c|c|c|c|c|c|c|c|}
\hline \multirow[t]{2}{*}{ Variável } & \multirow[t]{2}{*}{ Categoria } & \multicolumn{2}{|c|}{ Usa } & \multicolumn{2}{|c|}{ Não Usa } & \multicolumn{2}{|c|}{ Total } & \multirow[t]{2}{*}{$\mathbf{p}^{\star}$} \\
\hline & & $\mathbf{n}$ & $\%$ & $\mathbf{n}$ & $\%$ & $\mathbf{n}$ & $\%$ & \\
\hline Pais vivem & $\begin{array}{l}\text { Juntos } \\
\text { Separados } \\
\text { Falecido(s) }\end{array}$ & $\begin{array}{c}503 \\
108 \\
53\end{array}$ & $\begin{array}{l}26,2 \\
35,5 \\
20,5\end{array}$ & $\begin{array}{l}1420 \\
196 \\
205\end{array}$ & $\begin{array}{l}73,8 \\
64,5 \\
79,5\end{array}$ & $\begin{array}{l}1923 \\
304 \\
258\end{array}$ & $\begin{array}{l}77,4 \\
12,2 \\
10,4\end{array}$ & \\
\hline Total & & 664 & 26,7 & 1822 & 73,3 & 2486 & 100,0 & 0,0005 \\
\hline $\begin{array}{l}\text { Familiar causou } \\
\text { prob. pela bebida }\end{array}$ & $\begin{array}{l}\text { Sim } \\
\text { Não }\end{array}$ & $\begin{array}{c}94 \\
547\end{array}$ & $\begin{array}{l}29,3 \\
27,4\end{array}$ & $\begin{array}{l}227 \\
1450\end{array}$ & $\begin{array}{l}70,7 \\
72,6\end{array}$ & $\begin{array}{l}321 \\
1997\end{array}$ & $\begin{array}{l}13,8 \\
86,2\end{array}$ & \\
\hline Total & & 641 & 27,7 & 1677 & 72,3 & 2318 & 100,0 & 0,4817 \\
\hline $\begin{array}{l}\text { Pai/uso freqüente } \\
\text { de álcool }\end{array}$ & $\begin{array}{l}\text { Sim } \\
\text { Não }\end{array}$ & $\begin{array}{l}150 \\
499\end{array}$ & $\begin{array}{l}32,4 \\
26,4\end{array}$ & $\begin{array}{c}313 \\
1388\end{array}$ & $\begin{array}{l}67,6 \\
73,6\end{array}$ & $\begin{array}{l}463 \\
1887\end{array}$ & $\begin{array}{l}19,7 \\
80,3\end{array}$ & \\
\hline Total & & 649 & 27,6 & 1701 & 72,4 & 2350 & 100,0 & 0,0102 \\
\hline $\begin{array}{l}\text { Mãe/uso freqüente } \\
\text { de álcool }\end{array}$ & $\begin{array}{l}\text { Sim } \\
\text { Não }\end{array}$ & $\begin{array}{l}48 \\
601\end{array}$ & $\begin{array}{l}52,7 \\
26,6\end{array}$ & $\begin{array}{c}43 \\
1658\end{array}$ & $\begin{array}{l}47,3 \\
73,4\end{array}$ & $\begin{array}{c}91 \\
2259\end{array}$ & $\begin{array}{c}3,9 \\
96,1\end{array}$ & \\
\hline Total & & 649 & 27,6 & 1701 & 72,4 & 2350 & 100,0 & $<0,0001$ \\
\hline $\begin{array}{l}\text { Irmão/uso } \\
\text { freqüente de álcool }\end{array}$ & $\begin{array}{l}\text { Sim } \\
\text { Não }\end{array}$ & $\begin{array}{l}109 \\
540\end{array}$ & $\begin{array}{l}41,1 \\
25,9\end{array}$ & $\begin{array}{c}156 \\
1545\end{array}$ & $\begin{array}{l}58,9 \\
74,1\end{array}$ & $\begin{array}{c}265 \\
2085\end{array}$ & $\begin{array}{l}11,3 \\
88,7\end{array}$ & \\
\hline Total & & 649 & 27,6 & 1701 & 72,4 & 2350 & 100,0 & $<0,0001$ \\
\hline $\begin{array}{l}\text { Pai/uso freqüente } \\
\text { de drogas }\end{array}$ & $\begin{array}{l}\text { Sim } \\
\text { Não }\end{array}$ & $\begin{array}{l}22 \\
645\end{array}$ & $\begin{array}{l}57,9 \\
26,1\end{array}$ & $\begin{array}{c}16 \\
1823\end{array}$ & $\begin{array}{l}42,1 \\
73,9\end{array}$ & $\begin{array}{c}38 \\
2468\end{array}$ & $\begin{array}{c}1,5 \\
98,5\end{array}$ & \\
\hline Total & & 667 & 26,6 & 1839 & 73,4 & 2506 & 100,0 & $<0,0001$ \\
\hline $\begin{array}{l}\text { Mãe/uso freqüente } \\
\text { de drogas }\end{array}$ & $\begin{array}{l}\text { Sim } \\
\text { Não }\end{array}$ & $\begin{array}{l}43 \\
624\end{array}$ & $\begin{array}{l}47,8 \\
25,8\end{array}$ & $\begin{array}{c}47 \\
1792\end{array}$ & $\begin{array}{l}52,2 \\
74,2\end{array}$ & $\begin{array}{c}90 \\
2416\end{array}$ & $\begin{array}{c}3,6 \\
96,4\end{array}$ & \\
\hline Total & & 667 & 26,6 & 1839 & 73,4 & 2506 & 100,0 & $<0,0001$ \\
\hline $\begin{array}{l}\text { Irmão/uso } \\
\text { freqüente de drogas }\end{array}$ & $\begin{array}{l}\text { Sim } \\
\text { Não }\end{array}$ & $\begin{array}{c}92 \\
575\end{array}$ & $\begin{array}{l}60.9 \\
24,4\end{array}$ & $\begin{array}{c}59 \\
1780\end{array}$ & $\begin{array}{l}39,1 \\
75,6\end{array}$ & $\begin{array}{c}151 \\
2355\end{array}$ & $\begin{array}{c}6,0 \\
94,0\end{array}$ & \\
\hline Total & & 667 & 26,6 & 1839 & 73,4 & 2506 & 100,0 & $<0,0001$ \\
\hline
\end{tabular}


Nas variáveis 'escolaridade do pai' e 'escolaridade da mãe', verifica-se que a proporção de uso de droga cresce com o aumento do grau de escolaridade. $\mathrm{O}$ mesmo se observa em relação à renda familiar: quanto maior a renda, maior a proporção de alunos que fazem uso de drogas.

$\mathrm{O}$ índice de uso é maior entre alunos, cujos pais vivem separados $(35,5 \%)$, do que entre aqueles, cujos pais vivem juntos $(26,2 \%)$ ou já são falecidos $(20,5 \%)$.

Quanto ao uso freqüente de álcool ou de outras drogas pelos familiares, foi encontrada uma diferença significativa, qualquer que fosse a pessoa da família ou a droga utilizada.

\subsubsection{Curso Universitário}

Neste tópico comparam-se, como pode ser visto nas tabelas $3 \mathrm{a}$ e $3 b^{5}$, os usuários e os não-usuários de droga, com relação a algumas variáveis que caracterizam o curso universitário do aluno. Duas dessas variáveis, ano do curso $(\mathrm{p}=0,2727)$ e período $(\mathrm{p}=0,9181)$, não mostraram associação estatisticamente significativa com o uso de droga, enquanto que as variáveis área $(\mathrm{p}<0,0001)$, unidade $(\mathrm{p}<0,0001)$ e ano de ingresso $(p=0,0429)$ revelaram-se positivamente associadas ao uso.

\footnotetext{
${ }^{5} \mathrm{~A}$ tabela $3 \mathrm{~b}$ é continuação da tabela $3 \mathrm{a}$.
} 
Tabela 3a - Número e porcentagem de estudantes universitários da USP, segundo o uso de droga e características do curso universitário (1996)

\begin{tabular}{|c|c|c|c|c|c|c|c|c|}
\hline \multirow{2}{*}{ Variável } & \multirow{2}{*}{ Categoria } & \multicolumn{2}{|c|}{ Usa } & \multicolumn{2}{|c|}{ Não Usa } & \multicolumn{2}{|c|}{ Total } & \multirow[t]{2}{*}{$\mathbf{p}^{*}$} \\
\hline & & $\mathbf{n}$ & $\%$ & $\mathbf{n}$ & $\%$ & $\mathbf{n}$ & $\%$ & \\
\hline \multirow[t]{3}{*}{ Área } & Humanas & 179 & 27,0 & 484 & 73,0 & 663 & 26,5 & \\
\hline & Biológicas & 309 & 30,7 & 697 & 69,3 & 1006 & 40,1 & \\
\hline & Exatas & 179 & 21,4 & 658 & 78,6 & 837 & 33,4 & \\
\hline Total & & 667 & 26,6 & 1839 & 73,4 & 2506 & 100,0 & $<0,0001$ \\
\hline \multirow[t]{21}{*}{ Unidade } & ECA & 19 & 32,8 & 39 & 67,2 & 58 & 2,3 & \\
\hline & $\mathrm{EE}$ & 13 & 17,6 & 61 & 82,4 & 74 & 3,0 & \\
\hline & EEFE & 34 & 41,0 & 49 & 59,0 & 83 & 3,3 & \\
\hline & $\mathrm{EP}$ & 116 & 23,9 & 370 & 76,1 & 486 & 19,4 & \\
\hline & FAU & 25 & 41,7 & 35 & 58,3 & 60 & 2,4 & \\
\hline & FCF & 31 & 24,0 & 98 & 76,0 & 129 & 5,1 & \\
\hline & FD & 34 & 23,4 & 111 & 76,6 & 145 & 5,8 & \\
\hline & $\mathrm{FE}$ & 06 & 28,6 & 15 & 71,4 & 21 & 0,8 & \\
\hline & FEA & 39 & 23,9 & 124 & 76,1 & 163 & 6.5 & \\
\hline & FFLCH & 56 & 25,9 & 160 & 74,1 & 216 & 8,6 & \\
\hline & $\mathrm{FM}$ & 75 & 28,2 & 191 & 71,8 & 266 & 10,6 & \\
\hline & FMVZ & 23 & 30,3 & 53 & 69,7 & 76 & 3,0 & \\
\hline & FO & 45 & 30,4 & 103 & 69,6 & 148 & 5,9 & \\
\hline & FSP & 04 & 15,4 & 22 & 84,6 & 26 & 1,0 & \\
\hline & IAG & 07 & 35,0 & 13 & 65,0 & 20 & 0,8 & \\
\hline & IB & 55 & 42,0 & 76 & 58,0 & 131 & 5,2 & \\
\hline & IF & 26 & 18,6 & 114 & 81,4 & 140 & 5,6 & \\
\hline & IG & 16 & 47,1 & 18 & 52,9 & 34 & 1,4 & \\
\hline & IME & 09 & 7,2 & 116 & 92,8 & 125 & 5,0 & \\
\hline & IP & 29 & 39,7 & 44 & 60,3 & 73 & 2,9 & \\
\hline & IQ & 05 & 15,6 & 27 & 84,4 & 32 & 1,3 & \\
\hline Total & & 667 & 26,6 & 1839 & 73,4 & 2506 & 100,0 & $<0,0001$ \\
\hline
\end{tabular}

p*: nível descritivo do teste de associação de Pearson. Na realização do teste foi excluída a categoria 'ignorado'.

Para a variável área, os resultados revelam que o maior uso está entre estudantes de biológicas e o menor uso, entre alunos de exatas. Este é um resultado que necessita estudos mais aprofundados, que procurem compreender porque alunos da área de biológicas, que supostamente 
recebem maiores explicações e informações sobre as conseqüências negativas do uso das drogas, são justamente aqueles que delas fazem maior uso.

Ao se decomporem os resultados dentro das áreas, por unidades, verifica-se que os maiores índices de uso estão localizados no Instituto de Geociências - IG (47,1\%) que pertence à área de Exatas; no Instituto de Biociências - IB (42,0\%), na Escola de Educação Física e Esporte - EEFE (41,0\%) e no Instituto de Psicologia - IP ( 39,7\%), os três da área de Biológicas; e ainda na Faculdade de Arquitetura e Urbanismo - FAU $(41,7 \%)$ pertencente à área de Humanas. O menor uso foi constatado no Instituto de Matemática e Estatística - IME (7,2\%), no Instituto de Química IQ $(15,6 \%)$ e no Instituto de Física - IF $(18,6 \%)$, todos da área de Exatas. Também entre as unidades de menor uso se destacam a Faculdade de Saúde Pública - FSP (15,4\%) e a Escola de Enfermagem - EE (17,6\%), ambas da área de Biológicas.

Sintetizando, pode-se dizer que , na área de Humanas, nenhuma das sete unidades que a compõem apresentou um uso menor que $20 \%$, por parte de seus alunos. Fica um destaque para a FAU, cujos alunos apresentaram o terceiro maior uso. Já na área de Exatas, composta por seis unidades, a metade delas apresentou um consumo abaixo de $20 \%$, com destaque para os dois extremos: o IG, com o maior uso e o IME, com o menor uso de droga. Das oito unidades da área de Biológicas, apenas duas apresentaram um índice de uso menor que $20 \%$, resultado esse que requer 
uma discussão mais aprofundada, conforme já assinalado anteriormente.

Tabela 3b - Número e porcentagem de estudantes universitários da USP, segundo o uso de droga e características do curso universitário (1996)

\begin{tabular}{|c|c|c|c|c|c|c|c|c|}
\hline \multirow[t]{2}{*}{ Variável } & \multirow[t]{2}{*}{ Categoria } & \multicolumn{2}{|c|}{ Usa } & \multicolumn{2}{|c|}{ Não Usa } & \multicolumn{2}{|c|}{ Total } & \multirow[t]{2}{*}{$\mathbf{p}^{*}$} \\
\hline & & $\mathbf{n}$ & $\%$ & $\mathbf{n}$ & $\%$ & $\mathbf{n}$ & $\%$ & \\
\hline \multirow[t]{3}{*}{ Ano de Ingresso } & Até 1990 & 36 & 22,5 & 124 & 77,5 & 160 & 6.5 & \\
\hline & $1991-93$ & 254 & 28,3 & 644 & 71,7 & 898 & 36,4 & \\
\hline & $1994-96$ & 366 & 25,9 & 1044 & 74,1 & 1410 & 57,1 & \\
\hline Total & & 656 & 26,6 & 1812 & 73,4 & 2468 & 100,0 & 0,0429 \\
\hline \multirow[t]{6}{*}{ Ano do Curso } & $1^{\circ}$ ano & 135 & 25,6 & 392 & 74,4 & 527 & 21,5 & \\
\hline & $2^{\circ}$ ano & 127 & 24,7 & 387 & 75,3 & 514 & 20,9 & \\
\hline & $3^{\circ}$ ano & 136 & 26.7 & 373 & 73,3 & 509 & 20,7 & \\
\hline & $4^{\circ}$ ano & 124 & 26,3 & 348 & 73,7 & 472 & 19,2 & \\
\hline & $5^{\circ}$ ano & 86 & 29,2 & 209 & 70,8 & 295 & 12,0 & \\
\hline & $6^{\circ}$ ano & 47 & 34.3 & 90 & 65,7 & 137 & 5,6 & \\
\hline Total & & 655 & 26,7 & 1799 & 73,3 & 2454 & 100,0 & 0,2727 \\
\hline \multirow[t]{2}{*}{ Período } & Diurno & 498 & 26,5 & 1383 & 73,5 & 1881 & 76,1 & \\
\hline & Noturno & 158 & 26,7 & 434 & 73,3 & 592 & 23,9 & \\
\hline Total & & 656 & 26,5 & 1817 & 73,5 & 2473 & 100,0 & 0,9181 \\
\hline
\end{tabular}

$\mathrm{p}^{*}$ : nivel descritivo do teste de associação de Pearson. Na realização do teste foi excluída a categoria 'ignorado'.

A terceira e última variável desse tópico que mostrou uma associação com o uso de droga foi o ano de ingresso. Resultados revelam que alunos que entraram entre 1991 e 1993 apresentaram o maior índice de uso $(28,3 \%)$, seguidos pelos que ingressaram entre 1994 e $1996(25,9 \%)$, e por aqueles que passaram no vestibular antes de 1991 (22,5\%). 


\subsubsection{Vida Acadêmica}

Nas tabelas $4 \mathrm{a}$ e $4 \mathrm{~b}^{6}$ são apresentadas as variáveis relacionadas à vida acadêmica do aluno. As respostas dos alunos para 'suas perspectivas de trabalho e perspectivas financeiras, após a formatura' $(\mathrm{p}=0,5689)$, não mostraram diferenças entre os dois grupos comparados. $\mathrm{O}$ grupo de usuários de droga referiu pensar em abandonar o curso com maior freqüência do que o grupo de não-usuários, embora sem diferenças quanto ao ano em que o aluno pensou em abandonar o curso $(\mathrm{p}=0,7242)$.

Para a variável sobre o que faz quando falta às aulas, a maior associação encontrada com o uso de droga foi a alternativa "ficar nos centros acadêmicos ou centros esportivos' $(47,7 \%)$, seguido de 'não fazer nada' $(41,0 \%)$ e 'dormir ou descansar' $(34,9 \%)$. A atividade de menor chance apontada por esse mesmo grupo foi 'faltar às aulas para estudar na faculdade' $(12,2 \%)$.

\footnotetext{
${ }^{6}$ A tabela $4 b$ é continuação da tabela $4 a$.
} 
Tabela 4a - Número e porcentagem de estudantes universitários da USP, segundo o uso de droga e características da vida acadêmica (1996)

\begin{tabular}{|c|c|c|c|c|c|c|c|c|}
\hline \multirow[t]{2}{*}{ Variável } & \multirow[t]{2}{*}{ Categoria } & \multicolumn{2}{|c|}{ Usa } & \multicolumn{2}{|c|}{ Não Usa } & \multicolumn{2}{|c|}{ Total } & \multirow[t]{2}{*}{$\mathbf{p}^{*}$} \\
\hline & & $\mathbf{n}$ & $\%$ & $\mathbf{n}$ & $\%$ & $\mathbf{n}$ & $\%$ & \\
\hline \multirow{3}{*}{$\begin{array}{l}\text { Tem deixado } \\
\text { de fazer trab. } \\
\text { acadêmicos } \\
\text { Total }\end{array}$} & $\operatorname{Sim}$ & 165 & 38,0 & 269 & 62,0 & 434 & 17,5 & \\
\hline & Não & 497 & 24,3 & 1545 & 75,7 & 2042 & 82,5 & \\
\hline & & 662 & 26,7 & 1814 & 73,3 & 2476 & 100,0 & $<0,0001$ \\
\hline \multirow{3}{*}{$\begin{array}{l}\text { Desempenho } \\
\text { escolar }\end{array}$} & Bom/excel. & 338 & 23,7 & 1086 & 76,3 & 1424 & 57,3 & \\
\hline & Fraco/reg. & 287 & 30,3 & 661 & 69,7 & 948 & 38,2 & \\
\hline & Insuficiente & 37 & 33,3 & 74 & 66.7 & 111 & 4,5 & \\
\hline Total & & 662 & 26,7 & 1821 & 73,3 & 2483 & 100,0 & 0,0005 \\
\hline \multirow{4}{*}{$\begin{array}{l}\text { Perspectiva de } \\
\text { trab. e financ. } \\
\text { após formatura }\end{array}$} & $\begin{array}{l}\text { Realização prof. e } \\
\text { financeira }\end{array}$ & 338 & 26,0 & 964 & 74.0 & 1302 & 54,0 & \\
\hline & $\begin{array}{l}\text { Relização prof. e } \\
\text { não financeira }\end{array}$ & 200 & 27,5 & 527 & 72,5 & 727 & 30,1 & \\
\hline & $\begin{array}{l}\text { Realização financ. } \\
\text { e não prof. }\end{array}$ & 53 & 25,0 & 159 & 75,0 & 212 & 8,8 & \\
\hline & $\begin{array}{l}\text { Sem realização } \\
\text { prof. ou financ. }\end{array}$ & 52 & 30,2 & 120 & 69,8 & 172 & 7,1 & \\
\hline Total & & 643 & 26.6 & 1770 & 73,4 & 2413 & 100,0 & 0,5689 \\
\hline \multirow{5}{*}{$\begin{array}{l}\text { Desempenho } \\
\text { no último } \\
\text { semestre }\end{array}$} & Passou direto & 337 & 24,3 & 1047 & 75,7 & 1384 & 56,3 & \\
\hline & Passou d/ recup. & 100 & 33,7 & 197 & 66,3 & 297 & 12,1 & \\
\hline & Passou $c$ depend. & 163 & 31,3 & 357 & 68,7 & 520 & 21,1 & \\
\hline & Repetiu & 106 & 26,4 & 78 & 73,6 & 106 & 4,3 & \\
\hline & Outro & 152 & 17.8 & 125 & 82,2 & 152 & 6,2 & \\
\hline Total & & 2459 & 26,6 & 1804 & 73,4 & 2459 & 100,0 & 0.0001 \\
\hline \multirow{10}{*}{$\begin{array}{l}\text { Atividade } \\
\text { quando falta às } \\
\text { aulas }\end{array}$} & Não falta & 64 & 15,8 & 342 & 84,2 & 406 & 17,9 & \\
\hline & Cinema/Clube & 29 & 31,9 & 62 & 68,1 & 91 & 4,0 & \\
\hline & Estuda em casa & 68 & 22,0 & 241 & 78,0 & 309 & 13,6 & \\
\hline & Estuda na USP & 17 & 12,2 & 122 & 87,8 & 139 & 3,1 & \\
\hline & Não faz nada & 43 & 41,0 & 62 & 59,0 & 105 & 4,6 & \\
\hline & Só quando doente & 43 & 17,8 & 199 & 82,2 & 242 & 10,7 & \\
\hline & Trabalha & 71 & 26,8 & 194 & 73,2 & 265 & 11,7 & \\
\hline & Dorme/Descansa & 152 & 34,9 & 283 & 65,1 & 435 & 19,2 & \\
\hline & $\mathrm{CA}^{+} / \mathrm{CEPEUSP}^{++}$ & 72 & 47,7 & 79 & 52,3 & 151 & 6,7 & \\
\hline & Outros & 36 & 29.3 & 87 & 70.7 & 123 & 5,4 & \\
\hline Total & & 595 & 26,3 & 1671 & 73,7 & 2266 & 100,0 & $<0,0001$ \\
\hline
\end{tabular}

$\mathrm{p}^{*}$ : nivel descritivo do teste de associação de Pearson. Na realização do teste foi excluída a categoria 'ignorado'. +: $\mathrm{CA}=$ Centro Acadêmico / $\mathrm{DA}=$ Diretório Acadêmico

+ : CEPEUSP $=$ Centro de Práticas Esportivas da USP 
Tabela $4 \mathbf{b}$ - Número e porcentagem de estudantes universitários da USP, segundo o uso de droga e características da vida acadêmica (1996)

\begin{tabular}{|c|c|c|c|c|c|c|c|c|}
\hline \multirow[t]{2}{*}{ Variável } & \multirow[t]{2}{*}{ Categoria } & \multicolumn{2}{|c|}{ Usa } & \multicolumn{2}{|c|}{ Não Usa } & \multicolumn{2}{|c|}{ Total } & \multirow[t]{2}{*}{$p^{*}$} \\
\hline & & $\mathbf{n}$ & $\%$ & $\mathbf{n}$ & $\%$ & $\mathbf{n}$ & $\%$ & \\
\hline $\begin{array}{l}\text { Lugares que } \\
\text { freqüenta na } \\
\text { universidade }\end{array}$ & $\begin{array}{l}\text { CADA }^{+} \\
\text {CEPEUSP } \\
\text { Biblioteca } \\
\text { Lanchonete } \\
\text { Outros }\end{array}$ & $\begin{array}{c}151 \\
159 \\
69 \\
147 \\
36\end{array}$ & $\begin{array}{l}45.6 \\
28,9 \\
13.0 \\
26,1 \\
20,2\end{array}$ & $\begin{array}{l}180 \\
392 \\
461 \\
416 \\
142\end{array}$ & $\begin{array}{l}54,4 \\
71,1 \\
87,0 \\
73,9 \\
79,8\end{array}$ & $\begin{array}{l}331 \\
551 \\
530 \\
563 \\
178\end{array}$ & $\begin{array}{c}15,4 \\
25,6 \\
24,6 \\
26,1 \\
8,3\end{array}$ & \\
\hline Total & & 562 & 26,1 & 1591 & 73,9 & 2153 & 100,0 & $<0,0001$ \\
\hline $\begin{array}{l}\text { Satisfeito com } \\
\text { escolha } \\
\text { profissional } \\
\text { Total }\end{array}$ & $\begin{array}{l}\text { Sim } \\
\text { Não }\end{array}$ & $\begin{array}{c}535 \\
96 \\
631\end{array}$ & $\begin{array}{l}25.8 \\
31,4 \\
\\
26,5\end{array}$ & $\begin{array}{c}1539 \\
210 \\
\\
1749\end{array}$ & $\begin{array}{l}74,2 \\
68,6 \\
73,5\end{array}$ & $\begin{array}{c}2074 \\
306 \\
2380\end{array}$ & $\begin{array}{l}87,1 \\
12,9 \\
100,0\end{array}$ & 0.0391 \\
\hline $\begin{array}{l}\text { Pensou em } \\
\text { abandonar o curso }\end{array}$ & $\begin{array}{l}\text { Sim } \\
\text { Não } \\
\text { Ainda pensa }\end{array}$ & $\begin{array}{c}203 \\
395 \\
36\end{array}$ & $\begin{array}{l}30,0 \\
24,7 \\
29,3\end{array}$ & $\begin{array}{c}474 \\
1204 \\
87\end{array}$ & $\begin{array}{l}70,0 \\
75,3 \\
70,7\end{array}$ & $\begin{array}{c}677 \\
1599 \\
123\end{array}$ & $\begin{array}{c}28,2 \\
66,7 \\
5,1\end{array}$ & \\
\hline Total & & 634 & 26,4 & 1765 & 73,6 & 2399 & 100.0 & 0,0252 \\
\hline $\begin{array}{l}\text { Em qual ano } \\
\text { pensou em } \\
\text { abandonar o curso }\end{array}$ & $\begin{array}{l}1^{\circ} \text { ano } \\
2^{\circ} \text { ano } \\
3^{\circ} \text { ano } \\
4^{\circ} \text { ano } \\
5^{\circ} \text { ano } \\
6^{\circ} \text { ano }\end{array}$ & $\begin{array}{l}85 \\
57 \\
45 \\
08 \\
02 \\
01\end{array}$ & $\begin{array}{l}30,4 \\
26.9 \\
34,4 \\
25.0 \\
22,0 \\
25,0\end{array}$ & $\begin{array}{l}195 \\
155 \\
86 \\
24 \\
07 \\
03\end{array}$ & $\begin{array}{l}69,6 \\
73,1 \\
65,6 \\
75,0 \\
77,8 \\
75,0\end{array}$ & $\begin{array}{c}280 \\
212 \\
131 \\
32 \\
09 \\
04\end{array}$ & $\begin{array}{c}41,9 \\
31,7 \\
19,6 \\
4,8 \\
1.3 \\
0,6\end{array}$ & \\
\hline Total & & 198 & 29,6 & 470 & 70,4 & 668 & 100,0 & 0,7242 \\
\hline
\end{tabular}

$\mathrm{p}^{*}:$ nivel descritivo do teste de associação de Pearson. Na realização do teste foi excluída a categoria 'ignorado $+: \mathrm{CA}=$ Centro Acadêmico / DA=Diretório Acadêmico

$++:$ CEPEUSP $=$ Centro de Práticas Esportivas da USP

Como seria de se esperar, com base em resultados de outros estudos, foram encontradas diferenças entre usuários e não usuários de drogas, relacionadas às variáveis referentes ao rendimento escolar. $\mathrm{O}$ grupo de usuários apresentou uma chance aumentada de não fazer os trabalhos 
escolares, ficar de recuperação e dependência, e ter um desempenho escolar mais para o fraco ou insuficiente, do que para o bom ou excelente. Quanto à satisfação com a escolha profissional, observou-se maior insatisfação no grupo que usa droga. Os resultados mostram uma forte associação entre o uso de droga e os lugares que os alunos freqüentam na universidade. Os usuários são mais assíduos aos centros acadêmicos e diretórios $(45,6 \%)$, seguidos pelos centros esportivos $(28,9 \%)$ e lanchonetes $(26,1 \%)$. O lugar menos freqüentado por esse grupo é a biblioteca $(13,0 \%)$.

\subsubsection{Amigos}

Duas das variáveis agrupadas nesse tópico e apresentadas na tabela 5 não mostraram associação com o uso de droga: dificuldade em fazer novos amigos $(p=0,3455)$ e sentir-se rejeitado por amigos ou por outros da mesma idade $(\mathrm{p}=0,9053)$.

É interessante notar que os usuários de droga julgam-se pessoas mais facilmente influenciáveis pelos amigos que os não-usuários. Dentro do esperado, verificou-se que os usuários têm muito mais amigos que fazem uso freqüente de álcool e outras drogas do que amigos que não fazem esse uso. 
Tabela 5 - Número e porcentagem de estudantes universitários da USP, segundo o uso de droga e características do grupo de amigos(1996)

\begin{tabular}{|c|c|c|c|c|c|c|c|c|}
\hline \multirow[t]{2}{*}{ Variável } & \multirow[t]{2}{*}{ Categoria } & \multicolumn{2}{|c|}{ Usa } & \multicolumn{2}{|c|}{ Não Usa } & \multicolumn{2}{|c|}{ Total } & \multirow[t]{2}{*}{$\mathbf{p}^{*}$} \\
\hline & & $\mathbf{n}$ & $\%$ & $\mathbf{n}$ & $\%$ & $\mathbf{n}$ & $\%$ & \\
\hline $\begin{array}{l}\text { Dificuldade de } \\
\text { fazer novos amigos }\end{array}$ & $\begin{array}{l}\text { Sim } \\
\text { Não }\end{array}$ & $\begin{array}{l}102 \\
540\end{array}$ & $\begin{array}{l}24,8 \\
27,0\end{array}$ & $\begin{array}{c}310 \\
1459\end{array}$ & $\begin{array}{l}75,2 \\
73,0\end{array}$ & $\begin{array}{c}412 \\
1999\end{array}$ & $\begin{array}{l}17,1 \\
82,9\end{array}$ & \\
\hline Total & & 642 & 26,6 & 1769 & 73,4 & 2411 & 100,0 & 0,3455 \\
\hline $\begin{array}{l}\text { Sentir-se rejeitado } \\
\text { por amigos }\end{array}$ & $\begin{array}{l}\text { Sim } \\
\text { Não }\end{array}$ & $\begin{array}{c}51 \\
591\end{array}$ & $\begin{array}{l}27,0 \\
26,6\end{array}$ & $\begin{array}{c}138 \\
1632\end{array}$ & $\begin{array}{l}73,0 \\
73,4\end{array}$ & $\begin{array}{c}189 \\
2223\end{array}$ & $\begin{array}{c}7,8 \\
92,2\end{array}$ & \\
\hline Total & & 642 & 26,6 & 1770 & 73,4 & 2412 & 100,0 & 0,9053 \\
\hline $\begin{array}{l}\text { Facilmente } \\
\text { influenciável }\end{array}$ & $\begin{array}{l}\text { Sim } \\
\text { Não }\end{array}$ & $\begin{array}{c}98 \\
542\end{array}$ & $\begin{array}{l}34,0 \\
25,6\end{array}$ & $\begin{array}{l}190 \\
1577\end{array}$ & $\begin{array}{l}66,0 \\
74,4\end{array}$ & $\begin{array}{c}288 \\
2119\end{array}$ & $\begin{array}{l}12,0 \\
88,0\end{array}$ & \\
\hline Total & & 640 & 26,6 & 1767 & 73,4 & 2407 & 100,0 & 0,0023 \\
\hline $\begin{array}{l}\text { Amigos/uso } \\
\text { freqüente de álcool }\end{array}$ & $\begin{array}{l}\text { Sim } \\
\text { Não }\end{array}$ & $\begin{array}{l}399 \\
250\end{array}$ & $\begin{array}{l}38,2 \\
19,2\end{array}$ & $\begin{array}{c}645 \\
1055\end{array}$ & $\begin{array}{l}61,6 \\
80,8\end{array}$ & $\begin{array}{l}1044 \\
1305\end{array}$ & $\begin{array}{l}44,4 \\
55,6\end{array}$ & \\
\hline Total & & 649 & 27,6 & 1700 & 72,4 & 2349 & 100,0 & $<0,0001$ \\
\hline $\begin{array}{l}\text { Amigos/uso } \\
\text { freqüente de drogas }\end{array}$ & $\begin{array}{l}\text { Sim } \\
\text { Não }\end{array}$ & $\begin{array}{l}396 \\
271\end{array}$ & $\begin{array}{l}49,3 \\
15,9\end{array}$ & $\begin{array}{l}407 \\
1432\end{array}$ & $\begin{array}{l}50,7 \\
84,1\end{array}$ & $\begin{array}{c}803 \\
1703\end{array}$ & $\begin{array}{l}32,0 \\
68,0\end{array}$ & \\
\hline Total & & 667 & 26,6 & 1839 & 73,4 & 2506 & 100,0 & $<0,0001$ \\
\hline
\end{tabular}

\subsubsection{Lazer}

Analisando-se os resultados apresentados na tabela 6 não se encontrou associação estatisticamente significativa entre o uso de droga e a quantidade de horas livres disponíveis nos dias úteis da semana $(\mathrm{p}=0,1349)$. Já a quantidade de horas livres durante o fim de semana $(p<0,0001)$ e o que 
faz nessas horas $(p<0,0001)$ mostrou forte associação com o uso: quanto mais horas livres durante o fim de semana, maior o uso. Dos alunos que dispõem de todo o tempo livre nos fins de semana, $32,0 \%$ relatam o uso de droga, enquanto que, dentre aqueles que possuem menos de uma hora por dia nos fins de semana, apenas $11,1 \%$ disseram fazer uso.

Tabela 6 - Número e porcentagem de estudantes universitários da USP, segundo o uso de droga e características relacionadas ao lazer (1996)

\begin{tabular}{|c|c|c|c|c|c|c|c|c|}
\hline \multirow[t]{2}{*}{ Variável } & \multirow[t]{2}{*}{ Categoria } & \multicolumn{2}{|c|}{ Usa } & \multicolumn{2}{|c|}{ Não Usa } & \multicolumn{2}{|c|}{ Total } & \multirow[t]{2}{*}{$\mathbf{p}^{*}$} \\
\hline & & $\mathbf{n}$ & $\%$ & $\mathbf{n}$ & $\%$ & $\mathbf{n}$ & $\%$ & \\
\hline \multirow{5}{*}{$\begin{array}{l}\text { Horas livres } \\
\text { nos dias úteis }\end{array}$} & Nenhuma & 64 & 22,4 & 222 & 77,6 & 286 & 11,5 & \\
\hline & Até 2 hs & 168 & 25,5 & 490 & 74,5 & 658 & 26,5 & \\
\hline & De 2 a 4 hs & 255 & 28,7 & 634 & 71,3 & 889 & 35,8 & \\
\hline & De 4 a 6 hs & 113 & 25,6 & 329 & 74,4 & 442 & 17,8 & \\
\hline & Mais de 6 hs & 64 & 30.8 & 144 & 69,2 & 208 & 8,4 & \\
\hline Total & & 664 & 26,7 & 1819 & 73,3 & 2483 & 100,0 & 0.1349 \\
\hline \multirow{4}{*}{$\begin{array}{l}\text { Horas livres } \\
\text { nos fins de } \\
\text { semana }\end{array}$} & Todo tempo & 315 & 32,0 & 668 & 68,0 & 983 & 39,6 & \\
\hline & Algumas hs/dia & 341 & 23,7 & 1096 & 76,3 & 1437 & 57,9 & \\
\hline & - de I h/dia & 04 & 11.1 & 32 & 88,9 & 36 & 1,4 & \\
\hline & Nenhuma hora & 04 & 14,3 & 24 & 85,7 & 28 & 1,1 & \\
\hline Total & & 664 & 26,7 & 1820 & 73,3 & 2484 & 100,0 & $<0,0001$ \\
\hline Atividades nas & Igreja & 03 & 6,7 & 42 & 93,3 & 45 & 2,2 & \\
\hline \multirow[t]{7}{*}{ horas livres } & Sai/Viaja & 195 & 27,9 & 505 & 72,1 & 700 & 34,5 & \\
\hline & Esportes & 74 & 28,6 & 185 & 71,4 & 259 & 12,8 & \\
\hline & & 46 & 17,8 & 213 & 82,2 & 259 & 12,8 & \\
\hline & Atividades culturais & 83 & 31,3 & 182 & 68,7 & 265 & 13,1 & \\
\hline & Bares/Festas & 73 & 50.7 & 71 & 49,3 & 144 & 7,1 & \\
\hline & Leitura & 28 & 14,6 & 164 & 85,4 & 192 & 9,5 & \\
\hline & Outros & 28 & 17,1 & 136 & 82,9 & 164 & 8,1 & \\
\hline Total & & 530 & 26,1 & 1498 & 73,9 & 2028 & 100,0 & $<0,0001$ \\
\hline Dedica tempo & Sim & 296 & 30,2 & 683 & 69,8 & 979 & 39.6 & \\
\hline $\begin{array}{l}\text { satisfatório às } \\
\text { atividades }\end{array}$ & Não & 366 & 24,5 & 1127 & 75,5 & 1493 & 60,4 & \\
\hline Total & & 662 & 26,8 & 1810 & 73,2 & 2472 & 100,0 & 0,0017 \\
\hline
\end{tabular}


Para as atividades com as quais os estudantes preenchem as horas livres, 'ir à igreja' mostrou relação com uma chance menor de uso $(6,7 \%)$, enquanto 'freqüentar bares e festas' apresentou a maior associação com o uso (50,7\%). O estudo revelou que os usuários ocupam mais o tempo com atividades fora de casa, como sair, viajar, praticar esportes e participar de eventos culturais do que com atividades mais caseiras, como assistir televisão ou se dedicar à leitura. Enquanto o grupo que fez uso de droga se mostrou satisfeito com a freqüência com que pratica essas atividades, os que não usam se mostraram mais insatisfeitos.

\subsubsection{Vida Sexual}

Na tabela 7 são apresentados os resultados referentes à vida sexual dos alunos que fizeram parte da amostra estudada. Não mostraram associação com o uso de droga as variáveis: gostaria de mais informações sobre DST's e AIDS ( $\mathrm{p}=0,0505$ ) e importância do uso de preservativo $(\mathrm{p}=0,1406)$.

Quanto à freqüência com que faz uso de preservativo, a maior chance entre os usuários é de 'um uso esporádico' $(33,1 \%)$, seguido por 'usar sempre' $(28,2 \%)$ e 'nunca usar' $(16,3 \%)$. Os motivos referidos para não usar o preservativo, no grupo de usuários foram: não manter relações 
sexuais $(9,6 \%)$, ter parceiro fixo $(29,0 \%)$ e outros motivos $(47,8 \%)$. Incluídos em outros motivos estavam: 'não gosto', 'é caro', 'esqueço na hora H', 'não vou pegar doença nenhuma'e 'recusa do parceiro'.

Tabela 7 - Número e porcentagem de estudantes universitários da USP, segundo o uso de droga e características da vida sexual (1996)

\begin{tabular}{|c|c|c|c|c|c|c|c|c|}
\hline \multirow[t]{2}{*}{ Variável } & \multirow[t]{2}{*}{ Categoria } & \multicolumn{2}{|c|}{ Usa } & \multicolumn{2}{|c|}{ Não Usa } & \multicolumn{2}{|c|}{ Total } & \multirow[t]{2}{*}{$\mathbf{p}^{*}$} \\
\hline & & $\mathbf{n}$ & $\%$ & $\mathbf{n}$ & $\%$ & $\mathbf{n}$ & $\%$ & \\
\hline \multirow{2}{*}{$\begin{array}{l}\text { Quer mais informações } \\
\text { sobre DST's e AIDS }\end{array}$} & Sim & 398 & 25,4 & 1167 & 74,6 & 1565 & 65,0 & \\
\hline & Não & 245 & 29,1 & 596 & 70,9 & 841 & 35,0 & \\
\hline Total & & 643 & 26.7 & 1763 & 73,3 & 2406 & 100,0 & 0,0505 \\
\hline \multirow{2}{*}{$\begin{array}{l}\text { Acha importante o uso } \\
\text { de preservativo }\end{array}$} & Sim & 635 & 26.6 & 1748 & 73.4 & 2383 & 98,8 & \\
\hline & Não & 04 & 14,3 & 24 & 85.7 & 28 & 1,2 & \\
\hline Total & & 639 & 26,5 & 1772 & 73,5 & 2411 & 100,0 & 0,1406 \\
\hline \multirow[t]{3}{*}{ Faz uso de preservativo } & Sempre & 362 & 28,2 & 923 & 71,8 & 1285 & 55,8 & \\
\hline & Nunca & 68 & 16,3 & 349 & 83,7 & 417 & 18.1 & \\
\hline & Às vezes & 199 & 33,1 & 402 & 66,9 & 601 & 26,1 & \\
\hline Total & & 629 & 27,3 & 1674 & 72,7 & 2303 & 100,0 & $<0,0001$ \\
\hline \multirow{4}{*}{$\begin{array}{l}\text { Motivo para não usar } \\
\text { preservativo }\end{array}$} & Usa sempre & 251 & 27,9 & 650 & 72,1 & 901 & 44,4 & \\
\hline & Parceiro fixo & 180 & 29,0 & 440 & 71,0 & 620 & 30,6 & \\
\hline & Não faz sexo & 33 & 9,6 & 312 & 90,4 & 345 & 17,0 & \\
\hline & Outros & 77 & 47,8 & 84 & 52,2 & 161 & 7,9 & \\
\hline Total & & 541 & 26,7 & 1486 & 73,3 & 2027 & 100,0 & $<0,0001$ \\
\hline
\end{tabular}

\subsubsection{Atitudes}

Nas tabelas 8a e 8b são apresentadas as atitudes de alunos 
quanto ao uso experimental e uso regular de álcool, maconha, cocaína, crack, tranqüilizantes, anfetaminas e inalantes. A questão foi colocada perguntando-se ao aluno se ele aprova ou desaprova que qualquer pessoa experimente as drogas acima relacionadas. Ainda com referência às mesmas drogas foi perguntado se ele aprova ou desaprova que qualquer pessoa faça uso delas regularmente.

Todas essas variáveis mostraram forte associação com o uso de droga. Com relação à experimentação, a maior porcentagem de usuários encontra-se entre os que aprovam o uso de cocaína ( $62 \%$ ), seguida pelos que aprovam o uso de inalantes $(58,5 \%)$, de $\operatorname{crack}(52,7 \%)$ e de anfetaminas $(52,6 \%)$. É interessante observar que, nesse grupo, o menor índice de uso é encontrado entre os que aprovam o uso de álcool (30,3\%),seguido por aqueles que aprovam o uso de tranqüilizantes $(40,0 \%)$.

Quando se passa do uso experimental para o uso regular, a menor porcentagem de usuários continua a ser a dos que aprovam o uso de álcool $(38,3 \%)$, seguida pela dos usuários que aprovam o uso de tranqüilizantes $(41,1 \%)$, enquanto que as maiores porcentagens de usuários estão entre aqueles que aprovam o uso de maconha $(70,8 \%)$, seguidos dos que aprovam o uso de cocaína $(60,9 \%)$ e de inalantes $(53,6 \%)$. 
Tabela 8a - Número e porcentagem de estudantes universitários da USP, segundo o uso de droga e atitudes quanto ao uso experimental de algumas drogas (1996)

\begin{tabular}{|c|c|c|c|c|c|c|c|c|}
\hline \multirow[t]{2}{*}{ Variável } & \multirow[t]{2}{*}{ Categoria } & \multicolumn{2}{|c|}{ Usa } & \multicolumn{2}{|c|}{ Não Usa } & \multicolumn{2}{|c|}{ Total } & \multirow[t]{2}{*}{$\mathbf{p}^{*}$} \\
\hline & & n & $\%$ & $\mathbf{n}$ & $\%$ & $\mathbf{n}$ & $\%$ & \\
\hline \multirow{2}{*}{$\begin{array}{l}\text { Experimentar } \\
\text { álcool }\end{array}$} & Aprova & 625 & 30,3 & 1441 & 69,7 & 2066 & 84,5 & \\
\hline & Desaprova & 29 & 7,6 & 351 & 92,4 & 380 & 15,5 & \\
\hline Total & & 654 & 26,7 & 1792 & 73,3 & 2446 & 100,0 & $<0,0001$ \\
\hline \multirow{2}{*}{$\begin{array}{l}\text { Experimentar } \\
\text { maconha }\end{array}$} & Aprova & 539 & 47,7 & 590 & 52,3 & 1129 & 46,3 & \\
\hline & Desaprova & 107 & 8,2 & 1203 & 91,8 & 1310 & 53,7 & \\
\hline Total & & 646 & 26,5 & 1793 & 73,5 & 2439 & 100,0 & $<0,0001$ \\
\hline \multirow{2}{*}{$\begin{array}{l}\text { Experimentar } \\
\text { cocaína }\end{array}$} & Aprova & 178 & 62,0 & 109 & 38,0 & 287 & 11,8 & \\
\hline & Desaprova & 469 & 21,8 & 1678 & 78,2 & 2147 & 88,2 & \\
\hline Total & & 647 & 26,6 & 1787 & 73,4 & 2434 & 100,0 & $<0,0001$ \\
\hline \multirow{2}{*}{$\begin{array}{l}\text { Experimentar } \\
\text { crack }\end{array}$} & Aprova & 68 & 52,7 & 61 & 47,3 & 129 & 5,3 & \\
\hline & Desaprova & 578 & 25,1 & 1724 & 74,9 & 2302 & 94,7 & \\
\hline Total & & 646 & 26.6 & 1785 & 73,4 & 2431 & 100,0 & $<0,0001$ \\
\hline \multirow{2}{*}{$\begin{array}{l}\text { Experimentar } \\
\text { tranqüilizantes }\end{array}$} & Aprova & 222 & 40,0 & 333 & 60,0 & 555 & 23,0 & \\
\hline & Desaprova & 418 & 22,5 & 1443 & 77,5 & 1861 & 77,0 & \\
\hline Total & & 640 & 26,5 & 1776 & 73,5 & 2416 & 100,0 & $<0,0001$ \\
\hline \multirow{2}{*}{$\begin{array}{l}\text { Experimentar } \\
\text { anfetaminas }\end{array}$} & Aprova & 180 & 52,6 & 162 & 47,4 & 342 & 14,2 & \\
\hline & Desaprova & 461 & 22,4 & 1600 & 77,6 & 2061 & 85,8 & \\
\hline Total & & 641 & 26,7 & 1762 & 73,3 & 2403 & 100,0 & $<0,0001$ \\
\hline \multirow{2}{*}{$\begin{array}{l}\text { Experimentar } \\
\text { inalantes }\end{array}$} & Aprova & 245 & 58,5 & 174 & 41,5 & 419 & 17.4 & \\
\hline & Desaprova & 395 & 19,8 & 1597 & 80,2 & 1992 & 82,6 & \\
\hline Total & & 640 & 26,5 & 1771 & 73,5 & 2411 & 100,0 & $<0,0001$ \\
\hline
\end{tabular}


Tabeła 8b - Número e porcentagem de estudantes universitários da USP, segundo o uso de droga e atitudes quanto ao uso regular de algumas drogas (1996)

\begin{tabular}{|c|c|c|c|c|c|c|c|c|}
\hline \multirow[t]{2}{*}{ Variável } & \multirow[t]{2}{*}{ Categoria } & \multicolumn{2}{|c|}{ Usa } & \multicolumn{2}{|c|}{ Não Usa } & \multicolumn{2}{|c|}{ Total } & \multirow[t]{2}{*}{$\mathbf{p}^{\star}$} \\
\hline & & $\mathbf{n}$ & $\%$ & $\mathbf{n}$ & $\%$ & $\mathbf{n}$ & $\%$ & \\
\hline $\begin{array}{l}\text { Uso regular de } \\
\text { álcool }\end{array}$ & $\begin{array}{l}\text { Aprova } \\
\text { Desaprova }\end{array}$ & $\begin{array}{l}339 \\
312\end{array}$ & $\begin{array}{l}38,3 \\
20,1\end{array}$ & $\begin{array}{c}546 \\
1238\end{array}$ & $\begin{array}{l}61,7 \\
79,9\end{array}$ & $\begin{array}{c}885 \\
1550\end{array}$ & $\begin{array}{l}36,6 \\
63,7\end{array}$ & \\
\hline Total & & 651 & 26,7 & 1784 & 73,3 & 2435 & 100,0 & $<0,0001$ \\
\hline $\begin{array}{l}\text { Uso regular de } \\
\text { maconha }\end{array}$ & $\begin{array}{l}\text { Aprova } \\
\text { Desaprova }\end{array}$ & $\begin{array}{l}291 \\
354\end{array}$ & $\begin{array}{l}70,8 \\
17,5\end{array}$ & $\begin{array}{c}120 \\
1669\end{array}$ & $\begin{array}{l}29,2 \\
82,5\end{array}$ & $\begin{array}{c}411 \\
2023\end{array}$ & $\begin{array}{l}16,9 \\
83,1\end{array}$ & \\
\hline Total & & 645 & 26.5 & 1789 & 73,5 & 2434 & 100.0 & $<0.0001$ \\
\hline $\begin{array}{l}\text { Uso regular de } \\
\text { cocaina }\end{array}$ & $\begin{array}{l}\text { Aprova } \\
\text { Desaprova }\end{array}$ & $\begin{array}{c}28 \\
619\end{array}$ & $\begin{array}{l}60.9 \\
25.9\end{array}$ & $\begin{array}{c}18 \\
1772\end{array}$ & $\begin{array}{l}39.1 \\
74.1\end{array}$ & $\begin{array}{c}46 \\
2391\end{array}$ & $\begin{array}{r}1.9 \\
98.1\end{array}$ & \\
\hline Total & & 647 & 26.5 & 1790 & 73,5 & 2437 & 100,0 & $<0,0001$ \\
\hline $\begin{array}{l}\text { Uso regular de } \\
\text { crack }\end{array}$ & $\begin{array}{l}\text { Aprova } \\
\text { Desaprova }\end{array}$ & $\begin{array}{c}11 \\
635\end{array}$ & $\begin{array}{l}45,8 \\
26,3\end{array}$ & $\begin{array}{c}13 \\
1776\end{array}$ & $\begin{array}{l}54,2 \\
73,7\end{array}$ & $\begin{array}{c}24 \\
2411\end{array}$ & $\begin{array}{c}1,0 \\
99,0\end{array}$ & \\
\hline Total & & 646 & 26.5 & 1789 & 73.5 & 2435 & 100.0 & 0.0313 \\
\hline $\begin{array}{l}\text { Uso regular de } \\
\text { tranqüilizantes }\end{array}$ & $\begin{array}{l}\text { Aprova } \\
\text { Desaprova }\end{array}$ & $\begin{array}{c}44 \\
600\end{array}$ & $\begin{array}{l}41,1 \\
25,9\end{array}$ & $\begin{array}{c}63 \\
1719\end{array}$ & $\begin{array}{l}58.9 \\
74.1\end{array}$ & $\begin{array}{c}107 \\
2319\end{array}$ & $\begin{array}{c}4,4 \\
95,6\end{array}$ & \\
\hline Total & & 644 & 26,5 & 1782 & 73.5 & 2426 & 100,0 & 0.0005 \\
\hline $\begin{array}{l}\text { Uso regular de } \\
\text { anfetaminas }\end{array}$ & $\begin{array}{l}\text { Aprova } \\
\text { Desaprova }\end{array}$ & $\begin{array}{c}34 \\
611\end{array}$ & $\begin{array}{l}50,0 \\
26,0\end{array}$ & $\begin{array}{c}34 \\
1740\end{array}$ & $\begin{array}{l}50,0 \\
74,0\end{array}$ & $\begin{array}{c}68 \\
2351\end{array}$ & $\begin{array}{c}2,8 \\
97,2\end{array}$ & \\
\hline Total & & 645 & 26,7 & 1774 & 73,3 & 2419 & 100,0 & $<0,0001$ \\
\hline $\begin{array}{l}\text { Uso regular de } \\
\text { inalantes }\end{array}$ & $\begin{array}{l}\text { Aprova } \\
\text { Desaprova }\end{array}$ & $\begin{array}{c}30 \\
615\end{array}$ & $\begin{array}{l}53,6 \\
26,0\end{array}$ & $\begin{array}{c}26 \\
1749\end{array}$ & $\begin{array}{l}46,4 \\
74,0\end{array}$ & $\begin{array}{c}56 \\
2364\end{array}$ & $\begin{array}{c}2,3 \\
97,7\end{array}$ & \\
\hline Total & & 645 & 26,7 & 1775 & 73,3 & 2420 & 100,0 & $<0,0001$ \\
\hline
\end{tabular}




\subsubsection{Opiniões}

Na tabela 9, visualiza-se o que pensam os alunos no que se refere ao problema de dependência de álcool e de outras drogas. Não foi encontrada diferença significativa entre os dois grupos, com relação a considerar ou não o problema da dependência como um problema de saúde $(\mathrm{p}=0,5609)$, nem sobre a opinião deles sobre a cura, melhora ou piora dos alcoolistas $(\mathrm{p}=0,6094)$.

A opinião do grupo de usuários é bem mais otimista e irrealista que a do grupo de não-usuários quanto ao desenvolvimento do problema da dependência de outras drogas. Entre os que consideram que a maioria dos dependentes de droga se curam, encontramos $38,0 \%$ de usuários, decrescendo respectivamente para a consideração de melhora por $33,5 \%$, de não melhora por $27,2 \%$, até a piora que é considerada por apenas $19,7 \%$ dos usuários. Condizente com este resultado, o uso de droga apareceu mais associado a 'não querer informações sobre $\mathrm{o}$ assunto, nem se interessar por ajudar pessoas que tenham o problema'.

Quando perguntados sobre quem eles procurariam em primeiro lugar se tivessem dúvidas relacionadas ao problema de álcool e drogas, 'amigos e colegas da faculdade' e 'professores'foram as primeiras escolhas no grupo de usuários (respectivamente, $36,3 \%$ e $28,4 \%$ ). Por outro lado, 'pais' e 'líder religioso' foram as opções mais freqüentes no grupo de nãousuários, correspondendo a $85,5 \%$ e $80,0 \%$, respectivamente. Para os alunos 
que fazem uso de droga, conversar sobre esse assunto com os pais seria a última escolha (14,5\%), atrás até de líder religioso $(20,0 \%)$.

Tabela 9 - Número e porcentagem de estudantes universitários da USP, segundo o uso de droga e opiniōes relacionadas ao uso de drogas (1996)

\begin{tabular}{|c|c|c|c|c|c|c|c|c|}
\hline \multirow[t]{2}{*}{ Variável } & \multirow[t]{2}{*}{ Categoria } & \multicolumn{2}{|c|}{ Usa } & \multicolumn{2}{|c|}{ Não Usa } & \multicolumn{2}{|c|}{ Total } & \multirow[t]{2}{*}{$\mathbf{p}^{*}$} \\
\hline & & $\mathbf{n}$ & $\%$ & $\mathbf{n}$ & $\%$ & $\mathbf{n}$ & $\%$ & \\
\hline \multirow{3}{*}{$\begin{array}{l}\text { Dependência de } \\
\text { droga é problema } \\
\text { de saúde } \\
\text { Total }\end{array}$} & Sim & 566 & 26,4 & 1579 & 73,6 & 2145 & 86,8 & \\
\hline & Não & 91 & 27,9 & 235 & 72.1 & 326 & 13,2 & \\
\hline & & 657 & 26,6 & 1814 & 73,4 & 2471 & 100,0 & 0,5609 \\
\hline \multirow{4}{*}{$\begin{array}{l}\text { A maioria dos } \\
\text { alcoolistas }\end{array}$} & Se curam & 34 & 28,3 & 86 & 71,7 & 120 & 4,9 & \\
\hline & Melhoram & 169 & 25,3 & 500 & 74,7 & 669 & 27,6 & \\
\hline & Não melhoram & 322 & 27,1 & 867 & 72,9 & 1189 & 49,0 & \\
\hline & Pioram & 109 & 24.4 & 338 & 75.6 & 447 & 18,4 & \\
\hline Total & & 634 & 26,1 & 1791 & 73,9 & 2425 & 100,0 & 0,6094 \\
\hline \multirow{4}{*}{$\begin{array}{l}\text { A maioria dos } \\
\text { dependentes de } \\
\text { droga }\end{array}$} & Se curam & 35 & 38,0 & 57 & 62,0 & 92 & 3,8 & \\
\hline & Melhoram & 155 & 33,5 & 308 & 66,5 & 463 & 19,1 & \\
\hline & Não melhoram & 273 & 27,2 & 732 & 72,8 & 1005 & 41,4 & \\
\hline & Pioram & 171 & 19.7 & 696 & 80.3 & 867 & 35.7 & \\
\hline Total & & 634 & 26,1 & 1793 & 73,9 & 2427 & 100,0 & $<0.0001$ \\
\hline \multirow{6}{*}{$\begin{array}{l}\text { Quem procuraria } \\
1^{\circ} \text { se tivesse } \\
\text { dúvidas sobre } \\
\text { álcool e drogas }\end{array}$} & Professores & 25 & 28,4 & 63 & 71,6 & 88 & 3,7 & \\
\hline & Amigos/Colegas & 275 & 36,3 & 483 & 63,7 & 758 & 31,9 & \\
\hline & Pais & 56 & 14,5 & 331 & 85,5 & 387 & 16,3 & \\
\hline & Profissionais & 99 & 26,3 & 278 & 73,7 & 377 & 15,9 & \\
\hline & Lider religioso & 05 & 20,0 & 20 & 80,0 & 25 & 1,1 & \\
\hline & Livros científicos & 175 & 23,6 & 568 & 76,4 & 743 & 31,2 & \\
\hline Total & & 635 & 26.7 & 1743 & 73,3 & 2378 & 100,0 & $<0,0001$ \\
\hline \multirow{4}{*}{$\begin{array}{l}\text { Em relação a } \\
\text { álcool e drogas, } \\
\text { gostaria de }\end{array}$} & Mais informações & 186 & 27.5 & 491 & 72,5 & 677 & 27,6 & \\
\hline & Ajudar pessoas & 87 & 29,0 & 213 & 71,0 & 300 & 12,2 & \\
\hline & As duas coisas & 139 & 20,0 & 556 & 80,0 & 695 & 28,3 & \\
\hline & Nenhuma das duas & 240 & 30,7 & 543 & 69,3 & 783 & 31,9 & \\
\hline Total & & 652 & 26,6 & 1803 & 73,4 & 2455 & 100,0 & $<0,0001$ \\
\hline
\end{tabular}

$\mathrm{p}^{*}$ : nível descritivo do teste de associação de Pearson. Na realização do teste foi excluida a categoria 'ignorado'. 


\subsubsection{Uso pessoal de drogas}

Em relação ao uso de droga feito pelo próprio aluno, observase na tabela 10 a existência de uma forte associação do uso de tabaco e do uso de álcool ( $p<0,0001$ para ambos) com o de outras drogas, assim como dentre os alunos que referiram ter usado drogas antes de ingressar na universidade, dos quais, $66,5 \%$ referiram fazer uso atual (no período do estudo) $(\mathrm{p}<0,0001)$. $\mathrm{Na}$ comparação entre os grupos observa-se uma diferença significativa no que se refere ao envolvimento em acidente de carro após o uso de alguma droga, inclusive o álcool $(\mathrm{p}<0,0001)$.

Tabela 10 - Número e porcentagem de estudantes universitários da USP, segundo o uso de droga e informações relacionadas ao uso pessoal de droga (1996)

\begin{tabular}{|c|c|c|c|c|c|c|c|c|}
\hline \multirow[t]{2}{*}{ Variável } & \multirow{2}{*}{$\begin{array}{l}\text { Categor } \\
\text { ia }\end{array}$} & \multicolumn{2}{|c|}{ Usa } & \multicolumn{2}{|c|}{ Não Usa } & \multicolumn{2}{|c|}{ Total } & \multirow[t]{2}{*}{$\mathbf{p}^{\star}$} \\
\hline & & $\mathbf{n}$ & $\%$ & $\mathbf{n}$ & $\%$ & $\mathbf{n}$ & $\%$ & \\
\hline \multirow{2}{*}{$\begin{array}{l}\text { Usou álcool nos últimos } 12 \\
\text { meses }\end{array}$} & Sim & 634 & 31,7 & 1364 & 68,3 & 1998 & 82,0 & \\
\hline & Não & 31 & 7,1 & 407 & 92,9 & 438 & 18,0 & \\
\hline Total & & 665 & 27,3 & 1771 & 72,7 & 2436 & 100,0 & $<0,0001$ \\
\hline \multirow{2}{*}{$\begin{array}{l}\text { Usou tabaco nos últimos } 12 \\
\text { meses }\end{array}$} & Sim & 358 & 57.6 & 264 & 42,4 & 622 & 26,9 & \\
\hline & Não & 283 & 16,7 & 1410 & 83,3 & 1693 & 73,1 & \\
\hline Total & & 641 & 27,7 & 1674 & 72,3 & 2315 & 100,0 & $<0,0001$ \\
\hline \multirow{2}{*}{$\begin{array}{l}\text { Experimentou drogas antes } \\
\text { de entrar na USP }\end{array}$} & Sim & 387 & 66,5 & 195 & 33,5 & 582 & 26,4 & \\
\hline & Não & 254 & 15,7 & 1368 & 84,3 & 1622 & 73,6 & \\
\hline Total & & 641 & 29,1 & 1563 & 70,9 & 2204 & 100,0 & $<0,0001$ \\
\hline \multirow{2}{*}{$\begin{array}{l}\text { Envolveu-se em acidente de } \\
\text { carro após uso de drogas }\end{array}$} & Sim & 41 & 61.2 & 26 & 38,8 & 67 & 3,0 & \\
\hline & Não & 596 & 27,8 & 1550 & 72,2 & 2146 & 97,0 & \\
\hline Total & & 637 & 28,8 & 1576 & 71,2 & 2213 & 100,0 & $<0,0001$ \\
\hline
\end{tabular}




\subsection{Variáveis de risco associadas ao uso de droga}

Para se elaborar um modelo de regressão logística para os fatores de risco de uso de droga, fez-se inicialmente a análise univariada para a seleção das variáveis que entrariam no processo de modelagem multivariada. $\mathrm{O}$ resultado da análise univariada é apresentado no anexo 5, e as variáveis selecionadas, separadas pelos tópicos, encontram-se nas tabelas 11 a e 11 b. As demais variáveis não foram testadas por não terem apresentado significância estatística na análise univariada.

Tabela 11a - Relação das variáveis escolhidas para elaboração do modelo multivariado, segundo os tópicos: atitudes, opiniões e uso de drogas

\begin{tabular}{llc}
\hline Tópico & Variável & $\mathbf{p}^{\star}$ \\
\hline Atitudes e opiniões com álcool & A quem perguntar sobre álcool e drogas & $<0,0001$ \\
e drogas & Experimentar álcool & $<0,0001$ \\
& Experimentar maconha & $<0,0001$ \\
& Experimentar cocaína & $<0,0001$ \\
& Experimentar crack & $<0,0001$ \\
& Experimentar tranqüilizantes & $<0,0001$ \\
Experimentar anfetaminas & $<0,0001$ \\
& Experimentar inalantes & $<0,0001$ \\
& Uso regular de maconha & $<0,0001$ \\
& Uso regular de cocaína & $<0,0001$ \\
Uso regular de álcool & $<0,0001$ \\
& Uso regular de anfetaminas & 0,0001 \\
& Uso regular de tranqüilizantes & 0,0025 \\
& Uso regular de inalantes & 0,0001 \\
& Opinião sobre dependência de drogas & $<0,0001$ \\
& Ter informação e/ou ajudar pessoas & 0,0001 \\
\hline Uso de drogas & Uso de álcool & $<0,0001$ \\
& Uso de tabaco & $<0,0001$ \\
& Experimentou drogas antes de entrar na USP & $<0,0001$ \\
& Envolveu-se em acidente de carro após uso de drogas & $<0,0001$
\end{tabular}

$\mathrm{p}^{*}$ : nível descritivo do teste de associação de Pearson. 
Tabela 11b - Relação das variáveis escolhidas para elaboração do modelo multivariado, segundo os tópicos: perfil do aluno, família, curso universitário, vida acadêmica, amigos, lazer, vida sexual.

\begin{tabular}{|c|c|c|}
\hline Tópico & Variável & $\mathbf{p}^{*}$ \\
\hline Perfil do Aluno & $\begin{array}{l}\text { Moradia } \\
\text { Religião } \\
\text { Pratica religião } \\
\text { Idade } \\
\text { Sexo } \\
\text { Trabalha } \\
\text { Estado Civil } \\
\text { Pessoa Confiável }\end{array}$ & $\begin{array}{c}<0,0001 \\
<0,0001 \\
<0,0001 \\
0,0008 \\
0,0014 \\
0,0069 \\
<0,0211 \\
<0,0001\end{array}$ \\
\hline Familia & $\begin{array}{l}\text { Escolaridade do pai } \\
\text { Escolaridade da mãe } \\
\text { Renda familiar } \\
\text { Mãe/uso freqüente de álcool } \\
\text { Irmão/uso freqüente de álcool } \\
\text { Pai/uso freqüente de drogas } \\
\text { Mãe/uso freqüente de drogas } \\
\text { Irmão/uso freqüente de drogas } \\
\text { Situação marital }\end{array}$ & $\begin{array}{l}<0,0001 \\
<0,0001 \\
<0,0001 \\
<0,0001 \\
<0,0001 \\
<0,0001 \\
<0,0001 \\
<0,0001 \\
0,0003\end{array}$ \\
\hline Curso Universitário & $\begin{array}{l}\text { Área } \\
\text { Unidade }\end{array}$ & $\begin{array}{l}<0,0001 \\
<0,0001\end{array}$ \\
\hline Vida Acadêmica & $\begin{array}{l}\text { Lugares que freqüenta na USP } \\
\text { Execução de trab. acadêmicos } \\
\text { Desempenho escolar } \\
\text { Julgamento do desemp. escolar } \\
\text { Pensou abandonar curso } \\
\text { Atividades na falta às aulas }\end{array}$ & $\begin{array}{c}<0,0001 \\
<0,0001 \\
0,0003 \\
0,0006 \\
0,0397 \\
<0,0001 \\
\end{array}$ \\
\hline Amigos & $\begin{array}{l}\text { Amigos/uso freqüente de drogas } \\
\text { Amigos/uso freqüente de álcool } \\
\text { Facilmente influenciável }\end{array}$ & $\begin{array}{c}<0,0001 \\
<0,0001 \\
0,0100\end{array}$ \\
\hline Lazer & $\begin{array}{l}\text { Horas livres nos fins de semana } \\
\text { Atividades nas horas livres } \\
\text { Pratica atividades em tempo } \\
\text { satisfatório }\end{array}$ & $\begin{array}{c}<0,0001 \\
<0,0001 \\
0,0022\end{array}$ \\
\hline Vida Sexual & $\begin{array}{l}\text { Usa preservativo } \\
\text { Motivo de não uso do } \\
\text { preservativo }\end{array}$ & $\begin{array}{l}<0,0001 \\
<0,0001\end{array}$ \\
\hline
\end{tabular}

$\mathrm{p}^{*}$ : nível descritivo do teste de associação de Pearson. 
O anexo 6 contém o detalhamento, passo a passo, do desenvolvimento dos modelos multivariados finais. São apresentadas apenas as categorias que foram de risco estatisticamente significativo.

Optamos por usar, como indicador de risco, a odds ratio, ou razão de chances, usado para calcular a força de associação entre o fator de risco e a ocorrência do evento (uso de droga). A chance e a probabilidade são termos ligeiramente diferentes, mas ambos usados para expressar as possibilidades de ocorrência de um evento. Enquanto a probabilidade compara o número de casos favoráveis com o número de casos possíveis, a chance compara o número de casos favoráveis com o de casos desfavoráveis. Este indicador foi usado inicialmente como uma medida aproximada do risco relativo, porém, mais recentemente, considera-se a odds ratio, ela própria, uma medida de risco, com vantagens sobre o risco relativo, dentre elas, a de poder ser calculada para qualquer tipo de estudo epidemiológico (DANIEL 1995; PEREIRA 1995).

\subsubsection{Características pessoais}

O modelo multivariado final para a caracterização do perfil do aluno usuário de droga na USP está apresentado na tabela 12. Neste modelo consideram-se fatores independentes para o uso de droga a prática da 
religião, a faixa etária, o sexo, o trabalho, a forma de moradia e o principal confidente.

A aplicação do modelo propiciou revelar que mesmo possuindo uma religião, aqueles alunos que não a praticam tem 1,6 vezes mais chance de fazer uso de droga, quando comparados com os religiosos praticantes.

Tabela 12 - Modelo multivariado final das variáveis associadas ao risco de uso de droga para características pessoais dos alunos da USP

\begin{tabular}{llccc}
\hline \multicolumn{1}{c}{ Variável } & \multicolumn{1}{c}{ Categoria } & OR & IC $_{\mathbf{9 s}}$ & P \\
\hline \multirow{2}{*}{ Religioso praticante } & Não & 1,6 & {$[1,3 ; 2,0]$} & $, 0,0001$ \\
& Sim & 1,0 & - & - \\
\hline \multirow{2}{*}{ Faixa Etária } & $15-19$ & 1,5 & {$[1,1 ; 2,1]$} & 0,0220 \\
& $20-24$ & 1,7 & {$[1,3 ; 2,2]$} & 0,0002 \\
& 25 ou + & 1,0 & - & - \\
\hline \multirow{2}{*}{ Sexo } & Masculino & 1,4 & {$[1,2 ; 1,7]$} & 0,0003 \\
& Feminino & 1,0 & - & - \\
\hline \multirow{2}{*}{ Mora com } & Amigos/Só & 1,9 & {$[1,2 ; 3,1]$} & 0,0079 \\
& Conjuge & 1,0 & - & - \\
\hline \multirow{2}{*}{ Trabalho remunerado } & Sim & 1,3 & {$[1,1 ; 1,6]$} & 0,0037 \\
& Não & 1,0 & - & - \\
\hline \multirow{2}{*}{ Principal confidente } & Terapeuta & 3,6 & {$[1,9 ; 7,0]$} & 0,0001 \\
& Amigos & 2,8 & {$[2,2 ; 3,6]$} & $<0,0001$ \\
& Irmão & 2,1 & {$[1,4 ; 3,1]$} & 0,0003 \\
& Namorado & 1,5 & {$[1,1 ; 2,0]$} & 0,0072 \\
& Pais & 1,0 & - & - \\
\hline
\end{tabular}

$+: \mathrm{OR}=$ odds ratio 
Alunos da USP, na faixa etária de 15 a 19 anos têm 1,5 vezes mais chance de usar drogas do que aqueles com 25 anos ou mais; esta chance aumenta para 1,7 vezes, em relação aos alunos com idades entre 20 e 24 anos.

Quanto ao sexo, estudantes do sexo masculino têm 1,4 vezes mais chance de usar droga, quando comparados com o grupo do sexo feminino.

O fato de o aluno exercer atividade remunerada associa-se a uma maior chance $(\mathrm{OR}=1,3)$ de uso, em relação àqueles que não trabalham.

Dentre os estudantes, aqueles que vivem só ou com amigos têm 1,9 vezes mais chance de usar droga, quando comparados com aqueles que vivem com o cônjuge.

Para os estudantes, aqueles que escolhem como confidentes os terapeutas são os que têm o maior risco associado ao uso de droga $(\mathrm{OR}=3,6)$; seguem-se os que elegem os amigos, irmão e namorado(a), com riscos respectivos de 2,8,2,1 e 1,5 vezes maior do que o grupo que escolhe os pais como principais confidentes. 


\subsubsection{Características do ambiente familiar}

Para o modelo multivariado final das características do ambiente familiar dos alunos da USP relacionadas ao uso de droga, são apresentadas 9 variáveis de risco na tabela 13 .

A escolaridade dos pais aparece como um fator que influencia o uso de droga. Filhos de pais com grau superior de instrução têm 1,7 vezes mais chance de usar droga; mesmo que o nível de instrução do pai seja o segundo grau, já existe um risco maior - de 1,5 vezes - quando comparados com aqueles, cujo pai, no máximo, chegou a concluir o primeiro grau. Quando a mãe possuía nível superior, o risco de uso de droga foi de 1,6 vezes maior que o daqueles cujas mães só estudaram até o primeiro grau.

Filhos de famílias com renda mensal superior a 40 salários mínimos têm 1,4 mais chances de usar droga do que aqueles pertencentes a uma família de menor poder aquisitivo, com renda de até 20 salários mínimos.

Filhos de mães que fazem uso freqüente de álcool estão 2,1 vezes mais em risco de usar droga, do que aqueles cujas mães não usam. $O$ mesmo acontece para os que têm irmãos com uso freqüente de álcool, com um risco 1,5 vezes maior do que os alunos cujos irmãos não fazem uso freqüente de álcool.

Os maiores fatores de risco aparecem relacionados à existência de familiares que fazem uso freqüente de drogas. Estudantes com pai que 
faz uso de drogas têm 2,5 vezes mais chance de usar droga do que os que têm pai que não usa. Se o uso freqüente de drogas é feito pela mãe, o risco é de 1,7 vezes mais do que os universitários cujas mães não fazem uso. Já o estudante que tenha algum irmão que faça uso de droga tem o seu risco de usar elevado para 3,3, comparado com os que não tem irmãos que façam uso.

Tabela 13 - Modelo multivariado final das variáveis associadas ao risco de uso de droga para características do ambiente familiar dos alunos da USP

\begin{tabular}{|c|c|c|c|c|}
\hline Variável & Categoria & $\mathbf{O} \mathbf{R}^{++}$ & $I_{9 \mathrm{S \%}}$ & $\mathbf{p}$ \\
\hline Escolaridade do pai & $\begin{array}{l}\text { Superior } \\
2^{\circ} \text { grau } \\
1^{\circ} \text { grau }\end{array}$ & $\begin{array}{l}1,7 \\
1,5 \\
1,0 \\
\end{array}$ & $\begin{array}{c}{[1,2 ; 2,4]} \\
{[1,0 ; 2,1]} \\
-\end{array}$ & $\begin{array}{c}0,0011 \\
0,0417 \\
-\end{array}$ \\
\hline Escolaridade da mãe & $\begin{array}{l}\text { Superior } \\
1^{\circ} \text { grau }\end{array}$ & $\begin{array}{l}1,6 \\
1,0\end{array}$ & {$[1,2 ; 2,1]$} & 0.0033 \\
\hline Renda familiar & $\begin{array}{l}+40 \mathrm{sm}^{+} \\
\text {até } 20 \mathrm{sm}\end{array}$ & $\begin{array}{l}1,4 \\
1,0 \\
\end{array}$ & $\begin{array}{c}{[1,0 ; 1,8]} \\
-\end{array}$ & $\begin{array}{c}0,0124 \\
- \\
\end{array}$ \\
\hline Mãe faz uso freqüente de álcool & $\begin{array}{l}\text { Sim } \\
\text { Não }\end{array}$ & $\begin{array}{l}2,1 \\
1,0\end{array}$ & $\begin{array}{c}{[1,3 ; 3,4]} \\
-\end{array}$ & $\begin{array}{c}0,0011 \\
- \\
\end{array}$ \\
\hline Irmão faz uso freqüente de álcool & $\begin{array}{l}\text { Sim } \\
\text { Não }\end{array}$ & $\begin{array}{l}1,5 \\
1,0 \\
\end{array}$ & $\begin{array}{c}{[1,1 ; 2,1]} \\
-\end{array}$ & $\begin{array}{c}0,0054 \\
- \\
\end{array}$ \\
\hline Pai faz uso freqüente de droga & $\begin{array}{l}\text { Sim } \\
\text { Não }\end{array}$ & $\begin{array}{l}2,5 \\
1,0\end{array}$ & $\begin{array}{c}{[1,2 ; 5,3]} \\
-\end{array}$ & $\begin{array}{c}0,0113 \\
-\end{array}$ \\
\hline Mãe faz uso freqüente de droga & $\begin{array}{l}\text { Sim } \\
\text { Não }\end{array}$ & $\begin{array}{l}1,7 \\
1,0\end{array}$ & $\begin{array}{c}{[1,1 ; 2,8]} \\
-\end{array}$ & $\begin{array}{c}0,0222 \\
-\end{array}$ \\
\hline Irmão faz uso freqüente de droga & $\begin{array}{l}\text { Sim } \\
\text { Não }\end{array}$ & $\begin{array}{l}3,3 \\
1,0 \\
\end{array}$ & $\begin{array}{c}{[2,3 ; 4,7]} \\
-\end{array}$ & $\begin{array}{c}<0,0001 \\
-\end{array}$ \\
\hline Pais & $\begin{array}{l}\text { Separados } \\
\text { Pai ou mãe falecidos }\end{array}$ & $\begin{array}{l}1,5 \\
1,0\end{array}$ & $\begin{array}{c}{[1,0 ; 2,3]} \\
-\end{array}$ & $\begin{array}{c}0,0369 \\
-\end{array}$ \\
\hline
\end{tabular}

$+: \mathrm{sm}=$ salário mínimo

$++:$ OR $=$ odds ratio 
Outro fator de risco independente para o uso de droga é a situação marital dos pais. Filhos de pais separados têm 1,5 vezes mais chance de usar droga, comparado com os que têm, pelo menos, um dos pais falecidos. Filhos de pais que moram juntos não apresentaram risco significativo, quando comparados com aqueles, cujos pais já faleceram.

\subsubsection{Características da vida acadêmica}

Para a elaboração deste modelo, cujos resultados estão apresentados na tabela 14 , juntaram-se as variáveis de dois dos tópicos iniciais: curso universitário e vida acadêmica. Constatou-se que são fatores independentes para o uso de droga o curso em que o aluno está matriculado, os lugares dentro da universidade freqüentados pelos alunos, a finalização de trabalhos acadêmicos, o desempenho escolar do último semestre e como se ocupa o aluno quando falta às aulas.

Assim, olhando para os cursos nos quais o aluno está matriculado, pode-se dividi-los em três grupos de, respectivamente, baixo, médio e alto risco para uso de droga, quando comparados com o curso do Instituto de Matemática e Estatística (IME). Como já explicado anteriormente, a escolha do IME como categoria de referência desta variável 
ocorreu por ser essa a unidade que apresentou o menor índice de uso de droga. Dentro dos mais baixos índices de risco estão incluídos: a Escola de Enfermagem (EE) - 2,9; o Instituto de Física (IF) - 3,0; a Escola Politécnica (EP) - 3,3; a Faculdade de Direito (FD) - 3,6; e a Faculdade de Economia e Administração (FEA ) - 3,8. Outras oito unidades mostraram que seus alunos têm um risco médio associado ao uso de droga, sempre comparados aos alunos do IME. Neste grupo encontram-se: Faculdade de Medicina (FM) - 4,5; Faculdade de Ciências Farmacêuticas (FCF) - 4,9; Faculdade de Medicina Veterinária e Zootecnia (FMVZ) - 5,0; Faculdade de Odontologia (FO) - 5,3; Faculdade de Educação (FE) - 5,3; Escola de Comunicações e Artes (ECA) - 5,4; Faculdade de Filosofia, Letras e Ciências Humanas (FFLCH) - 5,9; Instituto Agronômico e Geofísico (IAG) - 6,0.

Um grupo, com cinco unidades, destaca-se como sendo o mais associado ao uso de droga: Faculdade de Arquitetura e Urbanismo (FAU) 8,1; Instituto de Psicologia (IP) - 9,0; Escola de Educação Física e Esporte (EEFE) - 9,9; Instituto de Biociências (IB) - 10,6; e Instituto de Geociências (IG) - 10,9.

Das 21 unidades pesquisadas, apenas duas - o Instituto de Química (IQ) e a Faculdade de Saúde Pública (FSP) - tiveram a mesma chance do aluno ser usuário de droga que a referência IME, razão pela qual não aparecem na tabela. 
Tabela 14 - Modelo multivariado final das variáveis associadas ao risco de uso de droga para características da vida acadêmica dos alunos da USP

\begin{tabular}{|c|c|c|c|c|}
\hline Variável & Categoria & $\mathbf{O R}^{+1+}$ & $1 C_{95 \%}$ & $\mathbf{p}$ \\
\hline Unidade & $\begin{array}{l}\text { IG (E) } \\
\text { IB (B) } \\
\text { EEFE (B) } \\
\text { IP (B) } \\
\text { FAU (H) } \\
\text { IAG (E) } \\
\text { FFLCH (H) } \\
\text { ECA (H) } \\
\text { FE (H) } \\
\text { FO (B) } \\
\text { FMVZ (B) } \\
\text { FCF (B) } \\
\text { FM (B) } \\
\text { FEA (H) } \\
\text { FD (H) } \\
\text { EP (E) } \\
\text { IF (E) } \\
\text { EE (B) } \\
\text { IME (E) } \\
\end{array}$ & $\begin{array}{l}10,9 \\
10,6 \\
9,9 \\
9,0 \\
8,1 \\
6,0 \\
5,9 \\
5,4 \\
5,3 \\
5,3 \\
5,0 \\
4,9 \\
4,5 \\
3,8 \\
3,6 \\
3,3 \\
3,0 \\
2,9 \\
1,0 \\
\end{array}$ & $\begin{array}{r}{[4,0 ; 29,8]} \\
{[4,8 ; 23,3]} \\
{[4,3 ; 23,0]} \\
{[3,8 ; 21,4]} \\
{[3,4 ; 19,7]} \\
{[1,8 ; 20,5]} \\
{[2,7 ; 12,6]} \\
{[2,2 ; 13,5]} \\
{[1,5 ; 17,9]} \\
{[2,4 ; 11,8]} \\
{[2,1 ; 11,9]} \\
{[2,1 ; 11,0]} \\
{[2,1 ; 9,7]} \\
{[1,7 ; 8,4]} \\
{[1,6 ; 8,1]} \\
{[1,6 ; 6,9]} \\
{[1,3 ; 6,9]} \\
{[1,1 ; 7,5]} \\
\end{array}$ & $\begin{array}{c}<0,0001 \\
<0,0001 \\
<0,0001 \\
<0,0001 \\
<0,0001 \\
0,0037 \\
<0,0001 \\
0,0003 \\
0,0077 \\
<0,0001 \\
0,0003 \\
0,0001 \\
0,0001 \\
0,0008 \\
0,0020 \\
0,0013 \\
0,0080 \\
0,0257 \\
- \\
\end{array}$ \\
\hline Ocupação quando falta às aulas & $\begin{array}{l}\mathrm{CA}^{+} / \mathrm{CEPEUSP}^{++} \\
\text {Dorme/Fica ocioso } \\
\text { Cinema/Clube } \\
\text { Trabalha } \\
\text { Estuda em casa } \\
\text { Estuda na faculdade }\end{array}$ & $\begin{array}{l}3,9 \\
3.2 \\
2,6 \\
2,3 \\
2,0 \\
1,0\end{array}$ & $\begin{array}{c}{[2,1 ; 7,4]} \\
{[1,8 ; 5,6]} \\
{[1,3 ; 5,2]} \\
{[1,3 ; 4,3]} \\
{[1,1 ; 3,6]} \\
-\end{array}$ & $\begin{array}{c}<0,0001 \\
<0,0001 \\
0,0078 \\
0,0056 \\
0,0264 \\
-\end{array}$ \\
\hline $\begin{array}{l}\text { Lugares freqüentados na USP } \\
\text { (não por exigência do curso) }\end{array}$ & $\begin{array}{l}\text { Centro acadêmico } \\
\text { Centro Esportivo } \\
\text { Lanchonete } \\
\text { Biblioteca }\end{array}$ & $\begin{array}{l}4,8 \\
2,4 \\
2,1 \\
1,0\end{array}$ & $\begin{array}{c}{[3,3 ; 6,9]} \\
{[1,7 ; 3,4]} \\
{[1,5 ; 3,0]} \\
-\end{array}$ & $\begin{array}{c}<0,0001 \\
<0,0001 \\
<0,0001 \\
-\end{array}$ \\
\hline $\begin{array}{l}\text { Tem deixado de fazer trabalhos } \\
\text { acadêmicos no último ano }\end{array}$ & $\begin{array}{l}\text { Sim } \\
\text { Não }\end{array}$ & $\begin{array}{l}1,7 \\
1,0\end{array}$ & {$[1,3 ; 2,2]$} & $\begin{array}{c}0,0001 \\
-\end{array}$ \\
\hline $\begin{array}{l}\text { Desempenho escolar no último } \\
\text { semestre }\end{array}$ & $\begin{array}{l}\text { Passou com dependência } \\
\text { Passou direto }\end{array}$ & $\begin{array}{l}1,4 \\
1,0\end{array}$ & {$[1,0 ; 1,8]$} & 0,0211 \\
\hline
\end{tabular}

+: $\mathrm{CA}=$ Centro Acadêmico

$++:$ CEPEUSP $=$ Centro de Práticas Esportivas da USP

$+H:$ OR $=$ odds ratio 
irem às aulas têm uma chance 2,0 vezes maior de uso de droga que aqueles que faltam às aulas para estudar na faculdade. Esta chance aumenta para 2,3 vezes para aqueles que faltam para trabalhar; 2,6 para os que vão ao cinema ou ao clube; 3,2 vezes para os que ficam dormindo ou ociosos e chega a 3,9 para os alunos que ficam nos centros acadêmicos ou esportivos.

Alguns dos lugares freqüentados pelos alunos na universidade apresentam um risco relacionado ao uso de droga, quando comparados com 'freqüentar a biblioteca'. Novamente verifica-se que os alunos que freqüentam os centros e diretórios acadêmicos têm 4,8 vezes mais chance de fazer uso. Este risco cai para 2,4 para os alunos que costumam ir ao CEPEUSP ou a outros lugares para prática esportiva na universidade. Freqüentar a lanchonete também tem um risco associado de 2,1.

Alunos que deixaram de fazer trabalhos acadêmicos no ano anterior à coleta dos dados têm uma chance 1,7 vezes maior de fazer uso que aqueles alunos que não deixaram de entregar seus trabalhos.

O desempenho do aluno no último semestre mostrou relação com o uso de droga. Verificou-se um risco aumentado de usar droga para alunos que passaram de ano, mas ficaram com alguma dependência em relação ao semestre anterior $(\mathrm{OR}=1,4)$, quando comparados aos que passaram direto em todas as disciplinas. Repetir de ano não constituiu fator de risco significativo quando comparado a passar direto. 


\subsubsection{Características da vida social}

Neste modelo final, com os resultados apresentados na tabela 15 , incluíram-se as variáveis relacionadas ao grupo de amigos, ao lazer e à vida sexual de alunos da USP. Aparecem como fatores independentes para o uso de droga 'ter amigos que façam uso freqüente de drogas', 'considerarse facilmente influenciável pelos amigos', 'a quantidade de horas livres nos fins de semana', 'as atividades praticadas como lazer', e 'a satisfação com o tempo dedicado à prática dessas atividades' .

Alunos que referiram ter amigos que usam droga com freqüência têm 5,1 vezes mais chance de também fazerem uso de droga do que aqueles cujo grupo de amigos não usa droga. O risco de usar droga é 1,5 vezes maior para aqueles alunos que se consideram influenciáveis pelos amigos, quando comparados com os que não se julgam facilmente influenciáveis.

Estudantes que, durante os fins de semana, dispõem de todo o tempo livre estão 2,6 vezes mais em risco de uso de droga, se comparados àqueles que têm menos de duas horas por fim de semana. $\mathrm{O}$ risco de usar droga varia com o tipo de atividade que o aluno diz praticar durante suas horas de lazer. Assim, o estudante que referiu gostar de sair e viajar apresentou um risco associado de 4,4; para aquele que gosta de praticar esportes o risco aumenta para 4,6; já o que prefere realizar atividades 
culturais tem um risco de 6,0 , enquanto que a preferência para 'freqüentar bares e festas', aumenta o risco para 11,1. Todos esses riscos foram comparados à ocupação de freqüentar a igreja. Os jovens que se mostraram satisfeitos com o tempo que dedicam a essas atividades apresentaram um risco de uso de droga de 1,3 , um pouco maior que aqueles que não mostraram essa satisfação.

Tabela 15 - Modelo multivariado final das variáveis associadas ao risco de uso de droga para características da vida social dos alunos da USP

\begin{tabular}{llccc}
\hline \multicolumn{1}{c}{ Variável } & \multicolumn{1}{c}{ Categoria } & OR $^{+}$ & IC $_{95 \%}$ & $\mathbf{P}$ \\
\hline \multirow{2}{*}{ Amigos fazem uso freqüente de drogas } & Sim & 5,1 & {$[4,2 ; 6,2]$} & $<0,0001$ \\
& Não & 1,0 & - & - \\
\hline Influenciável pelos amigos & Sim & 1,5 & {$[1,1 ; 2,0]$} & 0,0041 \\
& Não & 1,0 & - & - \\
\hline Horas livres no fim de semana & Todo o tempo & 2,6 & {$[1,2 ; 5,8]$} & 0,0169 \\
& Menos que 1 h/dia & 1,0 & - & - \\
\hline Principais atividades nas horas livres & Bares/Festas & 11,1 & {$[3,1 ; 39,6]$} & 0,0002 \\
& Culturais & 6,0 & {$[1,7 ; 21,0]$} & 0,0050 \\
& Esportivas & 4,6 & {$[1,3 ; 16,3]$} & 0,0162 \\
& Sai/Viaja & 4,4 & {$[1,3 ; 15,0]$} & 0,0190 \\
& Igreja & 1,0 & - & - \\
\hline Satisfação com o tempo dedicado a & Sim & 1,3 & {$[1,1 ; 1,6]$} & 0,0078 \\
essas atividades & Não & 1,0 & - & - \\
\hline +: OR = odds ratio & & & &
\end{tabular}

$+: \mathrm{OR}=$ odds ratio 


\subsubsection{Características de atitudes, opiniões e uso pessoal}

Oito variáveis permaneceram nesse modelo multivariado final, como pode ser visto na tabela 16. Mostraram-se independentes para o uso de droga: a pessoa procurada para esclarecer dúvidas sobre álcool e drogas, usar álcool e tabaco, ter experimentado droga antes de entrar na universidade, ter-se envolvido em acidente de trânsito após o uso de álcool ou de qualquer outra droga, opinião sobre o uso experimental e regular de maconha, e sobre o uso experimental de inalantes.

Os estudantes que informaram procurar professores para o esclarecimento de dúvidas relacionadas a álcool e outras drogas têm 2,3 vezes mais risco de usar droga quando comparados àqueles que referiram buscar os esclarecimentos com seus pais. Se, ao invés de professores, os procurados forem os amigos e colegas, o risco diminui para 1,6.

Alunos que informaram fazer uso de álcool têm 1,6 vezes mais chance de usar drogas comparado com os que não fazem uso de álcool, enquanto que fazer uso de tabaco aumenta em 3,4 vezes a chance de uso de droga, em relação aos alunos que não usam tabaco. A chance de usar droga cresce 5,0 vezes para o grupo que experimentou drogas, exceto álcool e tabaco, antes de entrar na universidade, quando comparado com o grupo dos que não o fizeram. 
Tabela 16 - Modelo multivariado final das variáveis associadas ao risco de uso de droga para atitudes, opiniões e uso pessoal dos alunos da USP

\begin{tabular}{|c|c|c|c|c|}
\hline Variável & Categoria & $\mathbf{O R}^{+}$ & $1 \mathrm{C}_{98 \%}$ & $\mathbf{p}$ \\
\hline Dúvidas relacionadas a álcool e drogas & $\begin{array}{l}\text { Professores } \\
\text { Amigos/Colegas } \\
\text { Pais }\end{array}$ & $\begin{array}{l}2,3 \\
1,6 \\
1,0\end{array}$ & $\begin{array}{l}{[1,2 ; 4,5]} \\
{[1,1 ; 2,5]} \\
-\end{array}$ & $\begin{array}{l}0.0110 \\
0,0158 \\
-\end{array}$ \\
\hline Uso de álcool & $\begin{array}{l}\text { Sim } \\
\text { Não }\end{array}$ & $\begin{array}{l}1,6 \\
1.0\end{array}$ & {$[1,0 ; 2,5]$} & $\begin{array}{l}0,0342 \\
-\end{array}$ \\
\hline Uso de tabaco & $\begin{array}{l}\text { Sim } \\
\text { Não }\end{array}$ & $\begin{array}{l}3,4 \\
1.0\end{array}$ & {$[2,7 ; 4,4]$} & $\begin{array}{l}<0,0001 \\
-\end{array}$ \\
\hline $\begin{array}{l}\text { Experimentou drogas antes de entrar na } \\
\text { universidade }\end{array}$ & $\begin{array}{l}\text { Sim } \\
\text { Não }\end{array}$ & $\begin{array}{l}5,0 \\
1,0\end{array}$ & {$[3,8 ; 6,5]$} & $<0.0001$ \\
\hline $\begin{array}{l}\text { Envolveu-se em acidente de trânsito } \\
\text { após uso de alguma droga }\end{array}$ & $\begin{array}{l}\text { Sim } \\
\text { Não }\end{array}$ & $\begin{array}{l}2.9 \\
1.0\end{array}$ & {$[1.5 ; 5.4]$} & $\begin{array}{l}0.0013 \\
-\end{array}$ \\
\hline Experimentar maconha & $\begin{array}{l}\text { Aprova } \\
\text { Desaprova }\end{array}$ & $\begin{array}{l}2.7 \\
1.0\end{array}$ & {$[2.0 ; 3.6]$} & $\begin{array}{l}<0.0001 \\
-\end{array}$ \\
\hline Experimentar inalantes & $\begin{array}{l}\text { Aprova } \\
\text { Desaprova }\end{array}$ & $\begin{array}{l}2.1 \\
1.0\end{array}$ & {$[1.5 ; 2,8]$} & $\begin{array}{l}<0,0001 \\
-\end{array}$ \\
\hline Uso regular de maconha & $\begin{array}{l}\text { Aprova } \\
\text { Desaprova }\end{array}$ & $\begin{array}{l}3.2 \\
1.0\end{array}$ & $\mid 2.4 ; 4.41$ & $\begin{array}{l}<0.0001 \\
-\end{array}$ \\
\hline
\end{tabular}

$+: O R=$ odds ratio

Existe um risco 2,9 vezes maior de uso de droga para jovens que já estiveram envolvidos em acidente de trânsito após o uso de álcool ou qualquer outra droga em relação a jovens que nunca estiveram envolvidos nesse tipo de situação.

Os alunos que aprovam o uso experimental de maconha e de inalantes têm uma chance maior de uso de droga, respectivamente 2,7 e 2,1, 
quando comparados com aqueles que desaprovam a experimentação dessas drogas. Aprovar o uso regular de maconha expõe 3,2 vezes mais ao uso de droga, que desaprovar esse uso.

\subsubsection{Características gerais}

Como última etapa, decidiu-se avaliar conjuntamente, num único modelo (tabelas $17 \mathrm{a}$ e $17 \mathrm{~b}^{7}$ ), todas as variáveis que foram significativas nos 5 modelos anteriores. Desta forma, 17 fatores foram considerados independentes para o uso de drogas: ter amigos que façam uso freqüente de drogas, ser influenciável pelos amigos, estar satisfeito com o tempo que dedica ao lazer, praticar alguma atividade remunerada, ter pai e mãe que façam uso freqüente de drogas, fazer uso de tabaco, ter usado drogas antes de entrar na USP, ter-se envolvido em acidente de carro após uso de álcool e outras drogas, quem procura quando tem dúvidas sobre álcool e drogas, a unidade da USP em que está matriculado, lugares que freqüenta na universidade, deixar de fazer trabalhos acadêmicos, aproveitamento escolar recente, o que pensa sobre uma pessoa experimentar maconha, experimentar inalantes, ou usar regularmente maconha.

\footnotetext{
${ }^{7}$ A tabela 17 b é continuação da tabela $17 \mathrm{a}$.
} 
Assim, o estudo revelou que alunos que tenham amigos que usem droga com freqüência têm 2,1 vezes mais chance de também fazer uso de droga que aqueles cujo grupo de amigos não usa droga. $\mathrm{O}$ risco de usar droga é 1,8 vezes maior para aqueles alunos que se consideram influenciáveis pelos amigos, quando comparados com os que não se julgam facilmente influenciáveis. Aqueles estudantes que estão satisfeitos com o tempo gasto com suas atividades de lazer têm uma chance aumentada $(1,4$ vezes) de usar drogas quando comparados com os que não estão satisfeitos com o tempo dedicado ao lazer. Os alunos que praticaram alguma atividade remunerada também tiveram um risco aumentado de 1,4 vezes, em relação aos que não exerceram atividades remuneradas.

Estudantes, cujos pais fazem uso regular de drogas, mostraramse mais em risco de usar drogas, com um risco maior quando o uso é feito pelo pai ( 3,9 vezes), do que pela mãe ( 2,6 vezes). Jovens que usam tabaco apresentam 3,5 vezes mais chance de usar drogas que os que não fumam, e aqueles que usaram drogas antes de entrarem na universidade apresentaram 5,2 vezes mais risco para usar, em relação àqueles que não fizeram esse uso prévio.

Os estudantes que informaram procurar resolver suas dúvidas referentes a álcool e drogas com professores apresentaram 3,1 vezes mais chance de usar drogas, e os que disseram procurar as respostas com seus colegas, 1,7 vezes mais chance do que aqueles que tentam sanar suas 
dúvidas com seus pais.

Tabela 17a - Modelo multivariado final geral das variáveis associadas ao risco de uso de drogas para alunos da USP

\begin{tabular}{|c|c|c|c|c|}
\hline Variável & Categoria & $\mathbf{O R}^{+}$ & $1 C_{95 \%}$ & $\mathbf{p}$ \\
\hline Mãe c/ uso freqüente de drogas & $\begin{array}{l}\text { Sim } \\
\text { Não }\end{array}$ & $\begin{array}{l}2,6 \\
1,0\end{array}$ & {$[1,3 ; 5,2]$} & 0,0073 \\
\hline Pai c/ uso freqüente de drogas & $\begin{array}{l}\text { Sim } \\
\text { Não }\end{array}$ & $\begin{array}{l}3,9 \\
1,0\end{array}$ & {$[1,3 ; 11,6]$} & 0,0153 \\
\hline Amigos/uso freqüente de drogas & $\begin{array}{l}\text { Sim } \\
\text { Não }\end{array}$ & $\begin{array}{l}2,1 \\
1,0\end{array}$ & $\begin{array}{c}{[1,6 ; 2,7]} \\
-\end{array}$ & $<0,0001$ \\
\hline Influenciável pelos amigos & $\underset{\text { Não }}{\text { Sim }}$ & $\begin{array}{l}1,8 \\
1,0\end{array}$ & {$[1,2 ; 2.7]$} & 0,0023 \\
\hline Satisfeito $\mathrm{c} /$ tempo de lazer & $\begin{array}{l}\text { Sim } \\
\text { Não }\end{array}$ & $\begin{array}{l}1,4 \\
1,0\end{array}$ & {$[1,0 ; 1.8]$} & 0,023 \\
\hline Uso de tabaco & $\begin{array}{l}\text { Sim } \\
\text { Não }\end{array}$ & $\begin{array}{l}3,5 \\
1,0\end{array}$ & $\begin{array}{c}{[2,6 ; 4,7]} \\
-\end{array}$ & $<0,0001$ \\
\hline $\begin{array}{l}\text { Usou drogas antes de entrar na } \\
\text { USP }\end{array}$ & $\begin{array}{l}\text { Sim } \\
\text { Não }\end{array}$ & $\begin{array}{l}5,2 \\
1,0 \\
\end{array}$ & {$[3,8 ; 7,1]$} & $<0,0001$ \\
\hline $\begin{array}{l}\text { Envolveu-se em acidente após uso } \\
\text { de qualquer droga }\end{array}$ & $\begin{array}{l}\text { Sim } \\
\text { Não }\end{array}$ & $\begin{array}{l}2,1 \\
1,0\end{array}$ & $\begin{array}{c}{[1,1 ; 4,2]} \\
-\end{array}$ & 0,0285 \\
\hline Experimentar maconha & $\begin{array}{l}\text { Aprova } \\
\text { Desaprova }\end{array}$ & $\begin{array}{l}2,4 \\
1,0\end{array}$ & {$[1,7 ; 3,3]$} & $<0,0001$ \\
\hline Experimentar inalantes & $\begin{array}{l}\text { Aprova } \\
\text { Desaprova }\end{array}$ & $\begin{array}{l}2,0 \\
1,0\end{array}$ & $\begin{array}{c}{[1,5 ; 2,9]} \\
-\end{array}$ & $<0,0001$ \\
\hline Usar regularmente maconha & $\begin{array}{l}\text { Aprova } \\
\text { Desaprova }\end{array}$ & $\begin{array}{l}2,6 \\
1,0\end{array}$ & $\begin{array}{c}{[1,8 ; 3,7]} \\
-\end{array}$ & $<0,0001$ \\
\hline
\end{tabular}

+: $\mathrm{OR}=$ odds ratio 
Tabela 17b - Modelo multivariado final geral das variáveis associadas ao risco de uso de drogas para alunos da USP

\begin{tabular}{|c|c|c|c|c|}
\hline Variável & Categoria & $\mathbf{O R}^{+}$ & $\mathrm{IC}_{95 \%}$ & $\mathbf{p}$ \\
\hline \multirow{2}{*}{ Deixa de fazer trabalhos do curso } & Sim & 1,5 & {$[1,0 ; 2,1]$} & 0,0284 \\
\hline & Não & 1.0 & - & - \\
\hline \multirow[t]{2}{*}{ Aproveitamento escolar no semestre } & Passou $\mathrm{d}$ dependência & 1,5 & {$[1,0 ; 2,2]$} & 0,0271 \\
\hline & Passou direto & 1,0 & - & - \\
\hline \multirow{3}{*}{$\begin{array}{l}\text { Quem procura quando tem dúvidas } \\
\text { sobre drogas }\end{array}$} & Professores & 3,1 & {$[1,4 ; 6,7]$} & 0,0034 \\
\hline & Amigos/Colegas & 1,7 & {$[1,1 ; 2,8]$} & 0,0213 \\
\hline & Pais & 1,0 & - & - \\
\hline \multirow[t]{2}{*}{ Atividade remunerada } & Sim & 1,4 & {$[1.0 ; 1,9]$} & 0,0526 \\
\hline & Não & 1,0 & - & - \\
\hline \multirow{4}{*}{$\begin{array}{l}\text { Lugares que freqüenta na } \\
\text { universidade }\end{array}$} & Centro Acadêmico & 2,8 & {$[1,7 ; 4,7]$} & $<0,0001$ \\
\hline & Centro Esportivo & 1,7 & {$[1,1 ; 2,8]$} & 0,0176 \\
\hline & Lanchonete & 1,7 & {$[1,1 ; 2,6]$} & 0,0225 \\
\hline & Biblioteca & 1,0 & - & - \\
\hline \multirow[t]{13}{*}{ Unidade } & $\mathrm{IB}(\mathrm{B})$ & 7,4 & {$[2,6 ; 21,1]$} & 0,0002 \\
\hline & EEFE (B) & 6,4 & {$[2,1 ; 20,0]$} & 0,0012 \\
\hline & $\mathrm{FO}(\mathrm{B})$ & 5,4 & {$[1,9 ; 15,4]$} & 0,0015 \\
\hline & FFLCH $(\mathrm{H})$ & 4,9 & {$[1,8 ; 13,1]$} & 0,0016 \\
\hline & FM (B) & 4,6 & {$[1,7 ; 12,4]$} & 0,0029 \\
\hline & FMVZ (B) & 4,2 & {$[1,3 ; 13,6]$} & 0,0158 \\
\hline & ECA & 4,0 & {$[1,2 ; 13,7]$} & 0,0264 \\
\hline & IG (E) & 3,8 & {$[1,0 ; 14,3]$} & 0,0479 \\
\hline & IP (B) & 3,5 & {$[1,1 ; 10,8]$} & 0,0295 \\
\hline & FEA (H) & 3.5 & {$[1,2 ; 9,9]$} & 0,0196 \\
\hline & FCF (B) & 3,0 & {$[1,0 ; 8,8]$} & 0,0415 \\
\hline & $E P(E)$ & 2,8 & {$[1,1 ; 7,3]$} & 0,0309 \\
\hline & IME (E) & 1,0 & - & - \\
\hline
\end{tabular}

+: $\mathrm{OR}=$ odds ratio

Ter-se envolvido em acidente de carro após o uso de álcool e drogas traz um risco associado de 2,1 para o uso de drogas. Ter uma atitude favorável à experimentação de maconha traz um risco de uso de drogas de 2,4 , aumentando para 2,6 se favorável ao uso regular dessa mesma droga. 
Ser favorável à experimentação de inalantes também eleva esse risco para 2,0 .

Detectou-se a existência de risco associado ao uso de drogas, com variações que dependeram da unidade freqüentada pelo aluno, tomando como referência os alunos do curso de Matemática e Estatística (IME), que apresentaram o menor índice de uso de droga. As doze unidades que apareceram por ordem decrescente de risco foram: Instituto de Biociências (IB) - 7,4; Escola de Educação Física e Esporte (EEFE) - 6,4; Faculdade de Odontologia (FO) - 5,4; Faculdade de Filosofia, Letras e Ciências Humanas (FFLCH) -4,9; Faculdade de Medicina (FM) - 4,6; Faculdade de Medicina Veterinária e Zootecnia (FMVZ) - 4,2; Escola de Comunicações e Artes (ECA) - 4,0; Instituto de Geociências (IG) - 3,8; Instituto de Psicologia (IP) - 3,5; Faculdade de Economia e Administração (FEA ) - 3,5; Faculdade de Ciências Farmacêuticas (FCF) - 3,0; Escola Politécnica (EP) - 2,8.

Alguns dos lugares da universidade freqüentados pelos alunos, fora da exigência das atividades acadêmicas, apresentam um risco relacionado ao uso de droga, quando comparados com a freqüência à biblioteca. Freqüentar centros e diretórios acadêmicos têm um risco associado de 2,8, caindo para 1,7 para os alunos que costumam ir para o centro esportivo da universidade ou para a lanchonete.

Deixar de fazer trabalhos acadêmicos eleva em 1,5 vezes a chance de fazer uso de drogas, comparada com a dos alunos que não deixam de entregar seus trabalhos. Para o desempenho do aluno no último semestre 
há um risco aumentado de 1,5 vezes para usar droga em alunos que passaram de ano, mas ficaram com alguma dependência, em relação ao semestre anterior, quando comparados aos que passaram direto. 


\section{DISCUSSĀO}

\subsection{Introdução}

Este projeto faz parte de uma linha de pesquisa, voltada para a compreensão de fatores que protegem do uso ou favorecem o uso de drogas por jovens brasileiros. Considera-se pertinente, na continuidade das investigações, voltar o olhar para as duas drogas lícitas, álcool e tabaco que, no caso do álcool, é de longe a droga mais usada e abusada em praticamente todo o mundo (WHO 1994). Dentre as drogas ilícitas seria interessante pesquisar mais detalhadamente a maconha, uma das mais usadas por jovens de nosso país e bastante controvertida, mesmo entre cientistas e profissionais da área (HALL e SOLOWIJ 1998; WEBB et al. 1997).

O presente estudo baseou-se em dados coletados por autorelato, o que implica a possibilidade de erros involuntários ou intencionais, incluindo medidas sub-estimadas de uso de droga (SZALAY et al. 1996). Possivelmente, os $20 \%$ da amostra, que não responderam ao questionário, também contribuam para uma sub-estimação dos usuários, pois se supõe que, entre os não-respondentes, possa haver uma proporção maior de 
usuários do que entre os respondentes (WEBB et al. 1997; CASPAR 1992; ANDRADE et al. 1997b). A par dessas ressalvas, o procedimento metodológico utilizado - coleta de dados por meio de questionários de autopreenchimento - vem sendo o mais comumente empregado na área. Dispõese de uma quantidade considerável de trabalhos que mostram a validade e acurácia desse método, especialmente quando garantido o anonimato, como no presente estudo (IVIS e ADLAF 1999; PRENDERGAST 1994; KHAVARI 1993; NEWCOMB et al. 1986; SCHOBER et al. 1992; TURNER et al. 1992).

A comparação entre os diversos estudos existentes na área fica prejudicada pelas diferenças metodológicas encontradas entre eles. Segundo PRENDERGAST (1994), em sua recente revisão de literatura sobre o uso de drogas em estudantes universitários, as principais diferenças são as medidas de uso (quantidade e freqüência), a definição de droga, o número de substâncias pesquisadas, a especificação da amostra, o tipo de análise, e o formato usado para exposição dos dados. No presente trabalho, ficou bastante marcada a dificuldade de comparação com outros estudos nacionais, pela escassez de levantamentos epidemiológicos na população brasileira, assim como de investigações voltadas, principalmente, a fatores associados ao uso.

Mesmo reconhecendo essas limitações, os dados disponíveis sugerem que a prevalência de uso de drogas ilícitas entre jovens brasileiros é menor que aquela apresentada pela juventude americana, canadense e de 
alguns países desenvolvidos do continente europeu. É maior, porém, que os índices existentes em alguns países da América Latina e México (LATIMER et al. 1999; DEITOS et al. 1998; JOHNSTON et al. 1998; ANDRADE et al. 1997a; ANDRADE et al. 1997b; GALDUROZ et al., 1996; WEBB et al. 1997; ANDRADE et al. 1995; VILLA 1995; WHO 1994; MAGALHÃES et al. 1989; QUEIPO et al. 1988). Em muitos países verifica-se a tendência de um aumento no uso de drogas ilícitas, com o padrão se tornando, cada vez mais, o uso de múltiplas substâncias, com diversas combinações de drogas (WHO 1994). Para a maioria dos países, inclusive o Brasil, a maconha é a substância ilícita mais consumida por estudantes universitários (PRENDERGAST 1994; ANDRADE et al. 1997b).

O período de jovem adulto, caracterizado pelo final da segunda década até o início da quarta década de vida, e do qual a população universitária é um importante sub-grupo, tem sido, nos Estados Unidos, o período de maior uso para muitas drogas (JOHNSTON et al. 1998).

A entrada nessa fase caracteriza uma importante transição no desenvolvimento emocional, com o jovem saindo da adolescência e entrando na fase adulta. É um período em que o jovem passa a assumir papéis adultos e desenvolve responsabilidades e habilidades sociais (SLOBODA e DAVID 1997). Nessa passagem, a busca maior é por uma identidade própria, na qual o jovem surja enquanto individuo único e diferenciado de outros, principalmente de seus pais, que exerceram, até então, a influência mais forte e importante. É nesta época que, para muitos, 
ocorre a saida da casa dos pais, o início de envolvimentos amorosos mais estáveis, a formação de um novo grupo de amigos, restando poucos ou nenhum dos amigos anteriores, e o começo da vida profissional e da obtenção de recursos econômicos através do próprio trabalho. Para grande parte dos estudantes universitários, somam-se a novidade e o desafio das pressões da vida acadêmica e do ambiente universitário. Ser bem aceito nesse ambiente é sinônimo de sucesso pessoal para muitos deles, e é nesse contexto que se deve refletir sobre o fato de o consumo de álcool e outras substâncias psicoativas ser considerado como uma norma de conduta amplamente tolerada pela comunidade universitária (PRENDERGAST 1994).

WEBB e seus colegas (1997) ficaram surpresos ao encontrarem um índice elevado de estresse e ansiedade em universitários ingleses, comparável com índices de ansiedade clínica em pacientes psiquiátricos. Embora não tenham encontrado associação entre os níveis de estresse e o consumo de drogas, esta é uma relação que mereceria pesquisas mais aprofundadas com universitários, dado que estudos recentes com ratos e dependentes de drogas têm encontrado relações entre o uso de drogas e o estresse (KREEK e KOOB 1998; BOWERSOX 1996). Dados americanos evidenciam a existência de uma prevalência maior de uso e abuso de álcool entre universitários, que entre os seus pares não universitários (JOHNSTON et al. 1993).

PRENDERGAST (1994) alerta que: "o padrão de consumo, 
as atitudes e os comportamentos relativos ao uso de álcool e drogas pelos estudantes universitários são importantes não apenas para os próprios estudantes, mas também para toda a sociedade. Os estudantes de hoje serão os legisladores, formadores de opinião, indicadores de estilo e controladores da mídia de amanhã. Eles irão, portanto, influenciar desproporcionalmente (o destaque é nosso) o comportamento de uso de álcool e drogas da nação." (p.111).

Uma última observação se faz necessária, antes da discussão propriamente dita dos modelos encontrados. É a explicação do porquê optamos pelo método de regressão logística múltipla para análise de nossos dados. Claro que um dos motivos é o favorecimento, através desse método, da análise de grande número de variáveis, buscando neutralizar o efeito de confusão entre elas. Mas, o principal motivo é que consideramos o uso de droga como produto de múltiplos fatores, sendo que nenhum deles pode ser responsável ou explicar, de maneira exaustiva, o uso/não uso de drogas. A análise multivariada é "a extensão matemática lógica para o modelo de rede de causas" e auxilia na estimativa das contribuições relativas dos diversos fatores que compõem o modelo (PEREIRA 1995, p.392).

Também a procura inicial de fatores de risco e de proteção ao uso de drogas acabou dando prioridade ao risco, pois foram escolhidas, 
como referências (baseline) para a análise estatística, as categorias de menor índice de uso de drogas. Esta situação teria se invertido se as categorias de referência fossem escolhidas entre aquelas de maior índice de uso.

Para finalizar esta introdução, o importante é que não se perca de vista, em momento algum, a complexidade e multi-determinação dos fatores em cada grupo estudado, e ainda, que em um estudo de prevalência como este, não se pode garantir a antecedência do fator de risco, pois tanto as informações sobre o efeito estudado - uso de drogas - quanto dos supostos fatores causais são coletadas no mesmo momento.

\subsection{Características pessoais}

Observando-se as características pessoais de nossa amostra, o perfil de maior risco corresponderia ao aluno do sexo masculino, com idade entre 20 e 24 anos, morando só ou com amigos, exercendo algum tipo de trabalho remunerado, não praticante de religião, e que considera seu terapeuta a pessoa de maior confiança para confidências. De um modo geral este perfil é concordante com os dados existentes na literatura.

$\mathrm{O}$ fato de os estudantes do sexo masculino de nossa amostra apresentarem um risco aumentado de uso de drogas, em relação às 
estudantes do sexo feminino, mostrou-se semelhante aos dados encontrados amplamente na literatura (JOHNSTON et al. 1998; PRENDERGAST 1994; KUMPFER 1992; D’ASSUMPÇÃO 1988). Embora as pesquisas indiquem um uso maior em indivíduos do sexo masculino, as diferenças de uso entre homens e mulheres variaram de droga para droga (PRENDERGAST 1994), para o que maiores explicações poderiam se situar na dimensão de influências sociais e culturais (SCHALL et al. 1992). SZALAY e colegas (1996) constataram, para o uso de maconha, alta vulnerabilidade às influências ambientais por parte dos homens, enquanto que as mulheres se mostraram muito resistentes aos fatores do ambiente.

A investigação sobre padrões de iniciação, permanência e cessação de uso, para diversas classes de drogas, em jovens adultos, vem revelando que o risco de uso inicial de álcool, tabaco e diversas drogas ilícitas atinge seu máximo aos 18 anos, decrescendo, a partir daí, e terminando aos vinte e poucos anos para as drogas lícitas - álcool e tabaco e, também, para a maconha. A exceção fica para a cocaína, cujos índices de iniciação aumentam após os 19 anos, permanecendo até bem próximo dos trinta; a partir dessa idade, a maior parte dos que iniciam o uso o fazem com drogas psicoativas de prescrição (CHEN e KANDEL 1995; KANDEL e LOGAN 1984; YAMAGUCHI e KANDEL 1984).

$\mathrm{O}$ que o presente estudo revela - lembrando que $80 \%$ dos alunos estudados se encontravam na faixa entre 15 e 24 anos - é uma população quase toda em risco, constituindo o período que mereceria maior 
atenção, aquele correspondente à entrada na universidade até o final do primeiro ano.

A escolha do terapeuta como a pessoa mais confiável para esclarecimentos sobre álcool e drogas sugere, inicialmente, que esses alunos que já estavam se submetendo a um processo psicoterapêutico no período de estudo, seriam pessoas com mais conflitos que os seus pares, que não fazem psicoterapia. A psicoterapia implica um esforço de tempo, de dinheiro e de disposição para se lidar com sentimentos dolorosos, a tal ponto que somente uma situação bastante incômoda pareceria justificar ao jovem tal investimento. Este fator suscita, ainda, a hipótese de uma dificuldade em relacionamentos que envolvam um grau maior de intimidade, como aqueles com os pais ou com os parceiros. Restaria, então, o relacionamento com o terapeuta, bastante próximo, porém profissional e sem o desenvolvimento de intimidade fora do setting terapêutico. Restaria, ainda, o relacionamento com o grupo de amigos, que pode apenas ser um agrupamento de jovens solitários, sem nenhum, ou quase nenhum laço de amizade, intimidade, e confiança (WINNICOT 1982).

A presença de religiosidade implicando, não apenas ter uma religião, mas também a prática dos rituais e preceitos religiosos, mostrou-se um fator diferencial para o uso de droga. Fato este em concordância com diversas pesquisas nacionais e internacionais (CRONIN 1995; PRENDERGAST 1994; NAZAR-BEUTELSPACHER et al. 1994; KHAVARI 1993; BACHMAN et al. 1988; D'ASSUMPÇÃO 1988 ). 
HADEN e EDMUNDSON (1991), pesquisando fatores motivacionais que antecedem ao uso de drogas entre universitários, encontraram que estudantes usam drogas mais por razões pessoais que devido a razões sociais, exceção feita para o uso de álcool. Este dado reforça nossa hipótese de o aluno com maiores conflitos internos ser mais vulnerável ao uso de droga, e também corrobora o fato de que o uso de álcool deve ser analisado e abordado de forma diferenciada do uso de outras drogas.

Ao se observar as características pessoais dos alunos da população desse estudo, em risco mais elevado para o uso de drogas, é possível traçar um paralelo com o adolescente em busca de sua independência, numa fase em que, para isto, ainda é necessário o distanciamento de seu envolvimento familiar: ele não mora com sua família, não partilha seus problemas mais íntimos com os pais, e busca ter o seu próprio dinheiro. Desta forma, supõe estar livre das inferências familiares e ser responsável pelos seus próprios atos.

"A sociedade em que vivemos, com seu quadro de violência e destruição, não oferece garantias suficientes de sobrevivência e cria uma nova dificuldade para o desprendimento. $O$ adolescente, cujo destino é a busca de ideais e de figuras ideais para identificar-se, depara-se com a violência e o poder e também os usa." (ABERASTURY 1984, p.19). 
É nesse quadro que o fator religião poderia estar sendo situado, como um agravante ou atenuante para o uso de droga, pois os alunos praticantes de alguma religião, qualquer que seja, pertencem a um grupo com valores e normas estabelecidos e compartilhados, enquanto que os não praticantes estão soltos na atual estrutura social caótica, justapostos com outros pares, com os quais compartilham mais a ausência do que a presença de normas e valores comuns. Ou ainda criam, eles próprios, regras e valores comuns ao grupo, e, muitas vezes, diferentes e destoantes das normas aceitas pela sociedade. Essa idéia é concordante com o estudo de CRONIN (1995), que obteve uma associação negativa entre o uso de droga e a dedicação do indivíduo a valores religiosos, independente da religião professada pelo estudante universitário. Em 1921, o próprio FREUD (1972) já colocava a religiosidade como a busca de apoio ao sentimento de solidão e desamparo do indivíduo crescido que, quando na mais tenra infầncia, recorria ao sentimento de onipotência para proteger-se da incapacidade e fraqueza que lhe eram inerentes.

O risco aumentado de uso de droga para os alunos que vivem sozinhos ou com amigos aparece em outros trabalhos, mas, principalmente, relacionados ao consumo de álcool (PRENDERGAST 1994). Duas situações para universitários que não vivem com a família poderiam ser melhor investigadas: a de alunos, cujas famílias moram em outra cidade, $\mathrm{e}$ que por este motivo, se vêem obrigados a sair da casa dos pais, com vivências estressantes de solidão e separação; e a de alunos que optam por 
sair da casa dos pais como uma forma de liberdade e independência, o que, para os imaturos, poderia ser interpretado como oposição e rebeldia.

Estudantes que têm um trabalho remunerado estarem mais em risco para o uso de drogas pode parecer inicialmente uma contradição, e, de fato, na literatura é colocada de forma controvertida, com estudos em que aqueles que trabalham usam menos (D'ASSUMPÇÃO 1988), e outros em que ter um trabalho aparece como variável significativa para o uso de droga (MILLER e MILLER 1997; NAZAR-BEUTELSPACHER et al. 1994). Ter o seu próprio dinheiro pode significar a liberdade para escolher como gastálo e, principalmente, para agir de acordo com os seus próprios valores. Segundo ABERASTURY (1984), "os pais costumam usar a dependência econômica como poder sobre o filho, o que cria um abismo e um ressentimento entre as duas gerações"(p.17). Novamente a inexperiência e ausência de maturidade poderiam estar tendo um influente papel na busca da independência econômica.

\subsection{Características do ambiente familiar}

Dentro daquilo que se consideram, neste estudo, características relacionadas ao ambiente familiar, obtive-se um perfil de risco para os estudantes provenientes de familias mais abastadas, cujos pais tenham maior 
nível de escolaridade e sejam separados. Além disso, vemos um risco aumentado quando membros da família fazem uso freqüente de álcool ou de drogas, com exceção para uso freqüente de álcool pelo pai.

A literatura é quase unanimemente concordante com o aumento do risco de uso de drogas em famílias com história de uso e abuso de álcool e drogas (MOSS et al. 1998; JACKSON et al. 1997; HOPS et al. 1996; SWAN 1995; BLACKSON et al. 1994; MOLINA et al. 1994; PRENDERGAST 1994; KHAVARI 1993; KUMPFER 1992; STABENAU 1992; HAWKINS et al. 1992).

Apesar de tantas evidências, NAZAR-BEUTELSPACHER e colaboradores (1994), em estudo retrospectivo com adolescentes mexicanos de áreas urbanas, encontraram, assim como neste estudo, que o consumo de álcool pelo pai não teve associação positiva com o consumo de drogas de adolescentes. Por outro lado, outros estudos vêm reforçar a importância do consumo paterno de álcool, concluindo que este tem um impacto maior no uso de drogas de seus filhos, muito mais que o uso de álcool pela mãe (SWAN 1995). Devido a alta porcentagem de alunos, cujo pai faz uso freqüente de álcool - quase $20 \%$ - na população deste estudo, e as decorrentes implicações preventivas, sugere-se futura investigação sobre tal associação.

Lembrando que: (1) tanto Freud, quanto seus seguidores, consideravam que a relação dos pais com o filho, desde os primeiros anos de vida, constitui um ponto central para a compreensão do desenvolvimento 
posterior do adulto; (2) "as conseqüências da carência paterna são tão graves quanto as da carência materna"(ABERASTURY e SALAS 1991), é possível considerar que o uso de álcool e de drogas por familiares necessariamente influenciará na qualidade do relacionamento e dos vínculos estabelecidos entre os membros da família.

$\mathrm{Na}$ literatura, além das já descritas, muitas outras variáveis foram objetos de estudo para explicar a relação entre o uso de álcool e drogas pelos pais e/ou irmãos e o aumento de vulnerabilidade do indivíduo. MOLINA e colaboradores (1994), investigando os fatores associados ao uso de drogas em filhos de alcoolistas e filhos de não alcoolistas, encontraram que a dificuldade para exercer uma vigilância paterna (saber onde o filho está e com quem) influenciava no uso de droga de seus filhos, para ambos os grupos. Resultado semelhante foi obtido por SMITH e colaboradores (1995), que encontraram na vigilância dos pais, um fator para proteção contra o uso de drogas dos filhos.

HAWKINS e colaboradores (1992), em estudo sobre jovens de alto risco, constataram que, dentre os fatores de risco associados à família, estão: alcoolismo na família; pais que não conseguem estabelecer limites, valores e normas claras de comportamento, e que dão punições excessivamente severas ou inconsistentes; e pais que usam drogas, ou que são tolerantes com o uso de drogas de seus filhos.

D'ASSUMPÇÃO (1988), em seu estudo com estudantes universitários de Minas Gerais, encontrou uma correlação entre o uso de 
drogas e a qualidade do relacionamento entre os pais, e observou ainda que o relacionamento com a mãe é mais importante na associação com o uso de drogas, mais do que o relacionamento com o pai.

Um estudo de âmbito nacional, realizado na Colômbia em 1993, encontrou, dentre os fatores de risco para consumo de cocaína, a má comunicação familiar, o consumo de droga por familiares, o abuso de álcool na família, o recebimento de castigos injustos, e existência de irmão consumidor de drogas ( VILLA 1995).

YAMAGUCHI e KANDEL (1984) concluíram que o uso de drogas pela mãe é um dos fatores de risco para a progressão de uso de drogas de prescrição em mulheres.

KHAVARI (1993) mostra que irmãos mais velhos podem exercer, tanto uma influência inibitória, quanto uma encorajadora em seus irmãos mais novos, no que se refere ao uso de drogas.

Quaisquer que sejam os aspectos familiares que influenciam no uso de drogas, deve-se lembrar, também, a vulnerabilidade herdada geneticamente, objeto de estudo em trabalhos desenvolvidos com irmãos, meio irmãos, irmãos gêmeos e crianças adotadas (KUMPFER 1992).

Este estudo encontrou um risco aumentado para uso de drogas em alunos cujos pais são separados, quando comparados a alunos que tem, pelo menos, um dos pais já falecidos. DUNCAN e colaboradores (1997) encontraram maior uso de droga entre familiares, em famílias em que o jovem vive sozinho com um dos pais, ou junto com padrasto ou madrasta. 
Já o estudo de BACHMAN e colaboradores (1988) não atribuiu grande importância para este fator, quando comparado com fatores relacionados ao estilo de vida e à experiência.

Assim como em outro estudo (JOHNSTON et al. 1998), no presente trabalho a escolaridade dos pais foi considerada um bom indicador do nível sócio-econômico da família, o que vem reforçar a associação positiva encontrada entre risco de uso e familias de classes sociais mais elevadas. Na literatura são relatadas algumas evidências de que o risco para o uso de drogas aumenta em filhos de pais mais educados ou com rendimentos mais elevados (JOHNSTON et al. 1998; PRENDERGAST 1994; BACHMAN et al. 1988). A literatura, no entanto, não esclarece suficientemente essa relação que, nos Estados Unidos, poderia ser explicada pela ênfase dada às variáveis raça e diferenças regionais, muito mais do que à variável classe social. Além do mais, comparações podem ser perigosas se se pensar na enorme diferença entre a distribuição de renda no Brasil e nos países "desenvolvidos". Uma possível explicação, mais condizente com a nossa realidade de país e de cidade, é a de que a população deste estudo, composta por universitários da USP - tida como um dos vestibulares mais concorridos e dificeis do país - deve ter estudado, em sua grande maioria, em boas escolas, o que na atualidade significam escolas particulares e caras. Assim, alunos provenientes de camadas sociais de baixa renda e com pais portadores de baixo nível de escolaridade, tendo estudado em escolas públicas deterioradas, de antemão estão colocados em situação desigual, 
com menores chances de ingressarem na USP, diante de um processo competitivo de seleção. Isso requer deles o desenvolvimento de qualidades especiais como dedicação, esforço, perseverança e responsabilidade em seu processo educacional, para possibilitar seu acesso à universidade pública, por mais paradoxal que pareça. Estudantes com estes atributos possivelmente se enquadrariam no grupo de não-usuários de drogas.

\subsection{Características do ambiente social}

Quando se leva em conta as características da vida social, o perfil de risco aumentado para uso de drogas é o do aluno que se considera influenciável por seu grupo de amigos, os quais costumam fazer uso de drogas; dedica todo o fim de semana para o seu lazer, freqüentando com assiduidade bares e festas, e satisfeito com o tempo que dedica a essas atividades.

A influência de amigos que usam drogas constitui um dos mais consistentes indicadores de risco encontrados na literatura (MILLER e MILLER 1997; VILLA 1995; YAMAGUCHI e KANDEL 1984). Quanto maior o número de amigos que fazem uso de drogas, maior o risco de uso (NAZAR-BEUTELSPACHER et al. 1994). A literatura mostra que, mesmo quando o jovem provém de famílias bem estruturadas e sem a constatação 
de outros fatores de risco, apenas o fato de ficar em companhia de amigos que usam drogas já aumenta o risco de uso (HAWKINS et. al 1992).

Pesquisa com estudantes universitários espanhóis constatou que a maioria dos jovens foram apresentados às drogas pelo círculo de amigos que tendiam a consumi-las em grupo (QUEIPO et al. 1988). Da mesma forma, ter amigos que desaprovam o uso de drogas funciona como inibitório ao uso (KHAVARI 1993), enquanto que a dedicação e o tempo gasto na companhia de amigos correlaciona-se positivamente com o uso (NAZAR-BEUTELSPACHER et al. 1994).

De forma geral, os alunos da amostra deste estudo referiram ter o costume de viajar ou sair em seu tempo livre de fim de semana, mas gostariam de um tempo maior para dedicar-se a essas atividades. Já os alunos usuários informaram costumar ir a bares e festas, declarando-se satisfeitos com o tempo que dedicam a suas atividades preferidas. Uma possivel contribuição para o entendimento desses resultados é o estudo de SZALAY et al.(1996), que mostra diferenças na percepção de diversão, para usuários e não-usuários de droga. Segundo esse estudo, estudantes universitários com uso freqüente de droga associam divertir-se com beber, cerveja, bar, drogas e 'ficar de cabeça feita'. Já para os não-usuários divertir-se está mais relacionado a filmes, jogos e bate-papo.

É, no entanto, a satisfação com o tempo dedicado ao lazer o que mais chama a atenção no perfil de risco do modelo agora considerado.. Usufruir de todo o fim de semana para o lazer e estar satisfeito com isso, 
parecem fatos pouco freqüentes, na época atual e em uma cidade com as características de São Paulo, onde o tempo para realizar aquilo que se quer e aquilo que se necessita é, geralmente, insuficiente. Supõe-se estar diante de um grupo bastante irresponsável e imaturo, do ponto de vista do desenvolvimento emocional, que não se perturba com as obrigações e deveres por fazer. Há indicações de estarem muito mais voltados à satisfação de suas próprias necessidades e desejos, do que conectados com as responsabilidades impostas pela realidade. Fica-se, no entanto, sem saber se esse funcionamento psíquico provém de uma deficiência no desenvolvimento, ou é basicamente provocado por um estado mental decorrente do uso de droga. É claro que essas duas possibilidades não são excludentes, podendo haver uma superposicão, isto é, o uso de drogas por um indivíduo emocionalmente imaturo, enfatizando apenas o prazer, sem nenhuma culpa pelas obrigações adiadas e não resolvidas. Segundo a literatura, o uso de pequenas quantidades de drogas pode aumentar as probabilidades de relato de satisfação na vida porque esse uso é associado a socializar e divertir-se, enquanto a abstinência completa pode refletir um estilo de vida rígido ou estar ligada ao uso medicinal de certas drogas, decorrentes de problemas de saúde (CLIFFORD et al. 1991). 


\subsection{Características da vida acadêmica}

Uma das características encontradas, relacionadas à vida acadêmica do aluno, e que compõe o perfil de maior risco para o uso de droga, é a do estudante com prejuízo em seu rendimento escolar, que deixou de entregar trabalhos curriculares, e não conseguiu passar direto em todas as disciplinas. Alguns estudos na literatura mostram a associação existente entre o risco de uso de droga e o desempenho escolar, principalmente notas baixas de avaliação (BACHMAN et al. 1988; BOTVIN e TORTU 1988). Em contrapartida, o fator bom desempenho escolar é apresentado como um dos fatores que protegem contra o uso de droga (SMITH et al. 1995). Esses dados da literatura vêm de encontro à idéia presente neste trabalho, de que não é um fator isolado que aumenta o risco de uso ou protege contra esse mesmo risco, e sim, um conjunto de fatores que compõem uma circunstância mais ou menos favorável à ocorrência do evento (uso de droga).

O estudo de BACHMAN e colaboradores (1988), já citado anteriormente, constatou também uma alta correlação entre 'cabular' aula e uso de maconha. Os resultados deste estudo revelam que faltar às aulas não só é um fator associado ao risco, mas ainda, que este risco varia de acordo com o quê o aluno faz quando não vai à aula. Os maiores riscos encontrados foram para estudantes que ficam dormindo ou ociosos, e para 
aqueles que ficam nos centros acadêmicos ou vão para o centro de esportes.

A freqüência aos centros ou diretórios acadêmicos (CAs e DAs) merece discussão mais detalhada e contextualizada, uma vez que aparece com certa consistência nos resultados deste trabalho, permanecendo, inclusive, no modelo geral final.

Os CAs e DAs tiveram, assim como toda a Universidade de São Paulo, uma grande importância na época da ditadura militar (19641984). Eram espaços em que os alunos podiam se reunir para discutir, principalmente sobre os rumos políticos do país. A oposição ao regime e aos militares era amplamente justificada pela brutalidade da censura e perseguição a todos que deles discordavam, e compartilhada por boa parte dos intelectuais da época. Os espaços dos centros eram, então, preenchidos por uma atividade política e intelectual intensa, com constantes reuniões, grupos de estudo e discussões de idéias. Havia, ainda, uma tácita proteção à inviolabilidade deste espaço por professores e autoridades da comunidade universitária contrários à situação, esforçando-se o quanto podiam para que todo o campus ficasse protegido da entrada de policiais.

No período de transição política, em que o país foi se democratizando e a perseguição abrandando, os CAs foram perdendo este caráter de lugar de conspiração das causas justas e se tornando um espaço para os "rebeldes sem causa". Não poderiam a manutenção do espaço como intocável (território livre), conjugada a um esvaziamento de propósitos, serem responsáveis pelo elevado risco de uso de drogas para os alunos que 
lá ficam?

Além disso a maioria dos centros possui um bar próprio, onde é permitida a venda de bebidas alcoólicas, assim como o é nas lanchonetes de quase todas as unidades da USP. SCHALL e colaboradores (1992) mostraram em seu estudo que estudantes que vivem numa universidade, cuja cultura pressiona para o beber, onde beber bastante é bem aceito e onde as bebidas e os lugares para beber são bem acessíveis, tenderão a beber mais.

Pergunta-se se estas características também não contribuiriam para um aumento no risco de uso de drogas. Para responder a essa indagação, uma pesquisa desenvolvida por BELL e colaboradores (1997) constatou que universidades com bares em seu campus, e permanecer mais tempo com amigos em situações sociais, são fatores que aumentam o risco para o uso de maconha.

Outra variável consistente nos resultados deste trabalho, e que também permanece no modelo final, é a unidade que o aluno freqüenta. Muitos outros estudos, em vários países, encontraram diferentes padrões de uso e riscos associados a diferentes cursos e áreas do conhecimento (BRENES et al. 1986; QUEIPO et al. 1988; SCHALL et al. 1992; WEBB et al. 1997; ANDRADE et al. 1997a). Essa consistência não se mantém no momento em que olha quais os cursos e áreas de maiores e menores prevalências e ou riscos, pois não há consenso entre os diferentes estudos. A maior concordância entre eles, incluindo-se este, seria quanto às áreas, 
aparecendo uma tendência maior de consumo nas áreas de ciências biológicas e humanas, e menor na área de ciências exatas.

O estudo de WEBB e colaboradores (1997) sugere que grandes proporções de mulheres, em determinadas unidades, contribuam para alguns dos resultados. Esta hipótese dificilmente se aplicaria a este estudo, diante dos resultados obtidos, pois, como explicaríamos a diferença de risco associado para os alunos de enfermagem e os de psicologia? Ambos são cursos com predominância de mulheres e os estudantes de psicologia apresentaram um risco três vezes maior que os de enfermagem.

Ao mesmo tempo, haveria de concordar à medida que este mesmo estudo dilui a importância do curso, e privilegia o estilo de vida e as atitudes que, numa visão mais dialética, vão determinar e serem determinados pela escolha do curso. Como exemplo disso, dentre as motivações para o uso de drogas, amplamente apontadas pela literatura, aparecem o desejo de alterar a consciência, da exploração de si-mesmo, ou do aprimoramento da experiência sensorial (PRENDERGAST 1994), motivos estes que poderiam ser altamente valorizados pelo estudante de psicologia, cujo objeto de estudo é a mente humana, e altamente desvalorizados pelos estudantes de outros cursos que visem a um conhecimento mais exato e objetivo da realidade.

Nessa linha de raciocínio, considera-se oportuno sugerir a realização de estudo de natureza qualitativa no IME, que aparece como a unidade da USP com o menor risco de uso de droga e também de uso de 
álcool (QUEIROZ et al. 1999). Que fatores protegeriam os alunos dessa unidade? Seria interessante incluir no estudo sugerido, pesquisa das três unidades que apresentaram cerca de dez vezes mais risco para o uso de droga (IG, IB e EEFE) em relação ao IME, na busca de fatores específicos da cultura da unidade, que estariam favorecendo o uso de drogas.

No caso de estudantes da Escola de Educação Física e Esporte, sugere-se, também, o desenvolvimento de investigação qualitativa detalhada, pois os resultados revelam risco aumentado para os estudantes que freqüentam o centro esportivo. Diante dessa constatação algumas dúvidas e preocupações ganham relevo, em especial duas que são aqui apresentadas: 1. Incluir/excluir, incentivar/desestimular a prática de esportes em programas de prevenção de drogas? 2. Que comportamento e modelo podem ser esperados desses estudantes, que em futuro próximo, serão os professores da juventude brasileira, em escolas e academias?

Reforçando essas preocupações e corroborando os resultados aqui obtidos, estudo comparando jovens atletas e não-atletas constatou tendência de aumento do risco de uso e abuso de álcool em atletas e, ainda, que estes bebem mais freqüentemente que os não-atletas (RAINEY et al. 1996). 


\subsection{Atitudes, opiniões, e uso pessoal de drogas}

Anteriormente já se fez referência aos benefícios que os métodos de análise qualitativa podem trazer às pesquisas na área de drogas. É porém neste item, relacionado a atitudes, opiniões e percepções, que os beneficios podem ser mais evidentes (IVIS e ADLAF 1999; LAMBERT et al 1995).

No geral, o perfil de risco ao uso de drogas obtido a partir dos resultados deste estudo vem confirmar os dados existentes na literatura, no que se refere à constatação de que o uso de álcool e de tabaco são fatores de risco para o uso de drogas (DEITOS et al. 1998; MILLER e MILLER 1997; SLOBODA e DAVID 1997; WEBB et al. 1997; JOHNSTON et al. 1993; VILLA et al. 1995; NAZAR-BEUTELSPACHER et al. 1994; SCHALL et al. 1992; QUEIPO et al. 1988; YAMAGUCHI e KANDEL 1984).

Alguns dos estudos citados apontam uma progressão no consumo de drogas, movendo-se do uso ilegal das drogas legais como tabaco, álcool e inalantes, para o uso de drogas ilegais, começando, geralmente, pela maconha. Esta seqüência de uso é compatível com a facilidade de obtenção destas referidas drogas e até mesmo com a aceitação da sociedade, principalmente com relação ao álcool e ao tabaco. Isto não quer dizer que fumar ou beber sejam as causas do uso posterior de outras 
drogas, porém é motivo de preocupação, quando se toma conhecimento de alguns números impressionantes, que foram obtidos de uma análise dos dados do censo americano, mostrando que quem já usou álcool ou tabaco alguma vez na vida, tem 65 vezes mais risco de usar maconha, em relação àquele que nunca fumou ou bebeu. E o risco de passar para a cocaína é 104 vezes maior para quem usou maconha, pelo menos uma vez na vida, do que para aquele que nunca a usou (SLOBODA e DAVID 1997).

Neste estudo, o aluno que experimentou drogas antes de entrar na universidade apresentou 5 vezes mais risco de uso de drogas e, a cada 3 destes alunos, 2 são usuários e 1 não-usuário. Em concordância com estes resultados, estudos mostram que experimentar drogas mais cedo na vida aumenta o risco associado ao uso e às conseqüências deste uso (WEBB et al. 1997; PRENDERGAST 1994; BRENES et al. 1986; YAMAGUCHI e KANDEL 1984).

Outro resultado encontrado e fartamente respaldado pela literatura é a associação existente entre o risco de usar determinadas drogas e a percepção que o jovem tem das conseqüências que este uso possa lhe trazer (JOHNSTON et al. 1998; ANDRADE et al 1997a; MESQUITA et al 1995; BACHMAN et al. 1988; BOTVIN e TORTU 1988). Um aumento nos índices de desaprovação e de percepção de danos, geralmente tende a levar a menores índices de uso. O estudo de MESQUITA e colaboradores (1995), feito com estudantes de medicina da própria USP, mostra que os alunos saem do curso pouco informados e com preconceitos não desfeitos, 
impossibilitados de relacionar corretamente o uso de algumas drogas, entre elas, as mais comumente usadas (álcool, tabaco, inalantes e maconha), às correspondentes complicações bio-psico-sociais delas decorrentes. Resultados deste estudo mostraram que alunos que referiram aprovar a experimentação de inalantes e o uso experimental e regular da maconha têm um risco aumentado para o uso de drogas. Isto também ocorre para os que já se envolveram em acidentes de carro após o uso de drogas, comprovando a tendência do jovem de se perceber pouco vulnerável às consequiências de comportamento de risco (BOTVIN e TORTU 1988).

Considera-se pertinente uma atenção especial à maconha, pela difusão de seu uso - que deixou de ser restrito a certos grupos marginais e está se tornando comum/"normal" entre a juventude - pelo fácil acesso, preços relativamente baixos e variados mitos e desinformação existentes (HALL e SOLOWIJ 1998; WEBB et al. 1997; YAMAGUCHI e KANDEL 1984).

Entre nós o risco da maconha é pouco percebido. Estudantes de medicina da USP aceitam o uso de maconha, pois não acham que ela cause problemas de saúde ou sociais (MESQUITA et al. 1995). Enquanto isso, estudos americanos mostram que o acesso à informação sobre riscos e conseqüências do uso da maconha, pode levar a mudanças de crenças e atitudes, e à redução do uso e da procura por esta droga (LO e GLOBETTI 1995; BACHMAN et al. 1988).

Analisando os resultados encontrados, verifica-se que 
universitários não-usuários percebem o risco para o uso de crack e de cocaína, mas não desaprovam muito o uso de tranqüilizantes, o que pode ser perigoso se se considerar a leitura de alguns autores que colocam as drogas prescritas como substitutas das ilegais, em individuos de idade mais madura. Ainda entre os não-usuários, apurou-se que um em cada dez dos universitários que participaram deste estudo não vêem a dependência de drogas como problema de saúde e, para aqueles que acreditam que os dependentes de drogas pioram, apenas metade pensa o mesmo sobre o dependente de álcool. Nosso parecer é de que estes dados justificam ações educativas-informativas voltadas para toda a comunidade uspiana estudantil, e não apenas para os grupos de maior risco.

\subsection{Características gerais}

Neste modelo final, foram testadas todas as variáveis que compuseram os modelos anteriormente apresentados, permanecendo apenas aquelas variáveis com força suficiente, mesmo quando controladas para todos os outros fatores. Em termos numéricos, das 33 variáveis dos modelos anteriores, restaram apenas 17 , sendo uma delas referente às características pessoais, duas, às características familiares, três, às características sociais, quatro, à vida acadêmica, e sete, às opiniões e atitudes do aluno. Esta 
distribuição de variáveis nas diversas categorias, sugere duas hipóteses: 1 . Que as atitudes, crenças e opiniões dos jovens teriam maior importância na determinação do risco associado ao uso, do que os outros aspectos considerados; 2. Que o instrumento utilizado seja mais adequado para avaliar atitudes, crenças, opiniões e características da vida acadêmica, do que para caracterizar aspectos sociais, familiares ou pessoais do aluno. Mais uma vez, reforça-se a importância de um estudo de análise qualitativa que, a partir de entrevistas com estudantes, seu grupo de amigos e seus familiares, poderia trazer dados para maior compreensão do problema.

As variáveis demográficas, como sexo, idade, escolaridade dos pais e renda familiar não estão mais presentes neste modelo geral, mas o que chama atenção, de forma particular, é a ausência consistente da influência do uso de álcool no modelo; tanto do uso pessoal, quanto do uso freqüente feito pela mãe e pelo irmão, variáveis que apareciam nos modelos anteriores, desapareceram neste. Todas estas variáveis, que mostraram importância no relacionamento com o uso de droga quando tomadas isoladamente, isto é, na análise univariada, e mesmo nos modelos multivariados mais específicos, perderam esta posição na presença de outros fatores, presentes em modelos diferentes.

$\mathrm{O}$ interesse deste modelo subordina-se à idéia de que o conjunto de fatores de risco tem maior influência para predizer o risco, do que cada um dos fatores isoladamente. Esta é também a observação de SCHEIER e colaboradores (1994), para os quais quanto maior o número de 
fatores de risco encontrados no indivíduo, maior sua vulnerabilidade para o uso de drogas.

Muitas vezes, pesquisas sobre o risco de uso de drogas identificam fatores que não passíveis de serem modificados por intervenções preventivas, como é o caso de alguns aspectos demográficos ou da história familiar do indivíduo (CLIMENT et al. 1989). Apenas para exemplificar, não se pode, mediante intervenções preventivas dirigidas à população de estudantes universitários, modificar o sexo ou a idade deles, bem como alterar a renda familiar, a escolaridade dos pais ou seu status marital, e muito menos condições da infância de alguns desses estudantes, que cresceram em lares com pelo menos um dos pais alcoolistas. Neste estudo, e em particular, neste modelo final geral, os fatores encontrados são passíveis de modificações mediante intervenções sociais e educativas. Este fato torna os resultados obtidos, apropriados para subsidiar o desenvolvimento de ações e estratégias preventivas na área temática, objeto do presente estudo. 


\section{CONCLUSÕES}

Em nossas conclusões, colocamos em destaque a interdependência dos múltiplos fatores encontrados.

Nosso perfil de risco seria o aluno que fuma, trabalha, já fez uso de drogas antes de entrar na universidade, considera-se influenciável pelos amigos, está satisfeito com o tempo que dedica ao seu lazer e também já esteve envolvido em acidente de carro após o uso de alguma droga. Seus pais e amigos usam drogas com freqüência. Na universidade ele pertence a um curso da área de biológicas, mais provavelmente biologia ou educação física, costuma freqüentar o centro acadêmico, não faz todos os trabalhos curriculares e acaba passando de ano, mas com dependência em alguma matéria. Não vê nenhum problema em outros experimentarem maconha ou inalantes, e mesmo em usarem maconha regularmente. Quando tem dúvidas sobre drogas, costuma procurar informações com seus professores. 


\section{SUGESTÕES}

Ao término deste estudo, gostaríamos de apresentar duas sugestões para o prosseguimento do processo investigativo das condições de risco para o uso de drogas entre estudantes da USP.

A primeira delas seria a realização de estudos de análise qualitativa. Enquanto as pesquisas quantitativas revelam uma fotografia de determinado fenômeno, num tempo e espaço definidos, a pesquisa qualitativa permite maior riqueza e detalhamento das circunstâncias existentes neste dado instante, ampliando a compreensão do fenômeno em estudo.

A segunda seria uma proposta de estudo prospectivo, com o acompanhamento de estudantes por um período de cinco anos (ou equivalente ao tempo de duração do curso), no sentido de medir possíveis alterações decorrentes de estratégias preventivas aplicadas no campus da USP. Este estudo nos daria ainda, através da observação e medição dos eventos se sucedendo no tempo, maior acurácia na explicação do fenômeno estudado. 


\section{REFERÊNCIAS BIBLIOGRÁFICAS}

Aberastury A. $\mathrm{O}$ adolescente e a amizade. In: Aberastury A, Knobel M. Adolescência normal. $3^{\mathrm{a}}$ ed. Porto Alegre: Artes Médicas; 1984.

Aberastury A, Salas EJ. A paternidade: um enfoque psicanalítico. $3^{\mathrm{a}} \mathrm{ed}$. Porto Alegre: Artes Médicas; 1991.

Andrade AG, Bassit AZ, Mesquita AM, Fukushima JT, Gonçalves EL. Prevalência do uso de drogas entre alunos da Faculdade de Medicina da Universidade de São Paulo (1991-93). Rev ABP-APAL 1995; 17(2): 41-6.

Andrade AG, Bassit AZ, Kerr-Corrêa F, Tonhon AP, Boskovitz EP, Cabral $\mathrm{M}$, et al. Fatores de risco associados ao uso de drogas na vida entre estudantes de medicina do Estado de São Paulo. Rev ABP-APAL 1997a; 19(4): 117-26.

Andrade AG, Queiroz S, Villaboim RCM, Cesar CLG, Alves MCGP, Bassit AZ. Uso de álcool e drogas entre alunos de graduação da Universidade de São Paulo (1996). Rev ABP-APAL 1997b; 19(2): 53-9.

Bachman JG, Johnston LD, O'Malley PM, Humphrey RH. Explaining the recent decline on marijuana use: diferentiating the effects of perceived risks, disapproval, and general lifestyle factors. J Health So Behav 1988; 29 (March): 92-112.

Bell R, Wechsler H, Johnston LD. Correlates of college student marijuana use: results of a US national survey. Addiction 1997; 92(5): 571-81.

Blackson T, Tarter R. Individual, family, and peer affiliation factors predisposing to early-age onset of alcohol and drug use. Alcohol Clin Exp Res 1994; 18(4): 813-21. 
Boskovitz EP, Cruz ETN, Chiaravalloti Neto F, Moraes MS, Paiva Neto JV, Avila LA et al. Uso de drogas entre estudantes universitários em São José do Rio Preto. Rev Psiquiatr Clín. 1995; 22:87-93.

Botvin GJ, Tortu S. Preventing adolescent substance abuse through life skills trainning. In: Price RH, Cowen EL, Lorion RP, Ramos-McKay J, editors. Fourteen ounces of prevention. Washington, DC: American Psychological Association; 1988. p. 98-110.

Bowersox JA. Anxiety and stress found to promote cocaine use in rats.

NIDA Notes [on line] 1996; 11(4):[3 telas]. Available from $<$ http://www.nida.nih.gov/NIDA_Notes/NNVOL11N4/ Anxiety html> [1997 Nov 27].

Brenes LFV, Hammes MF, Solé MTV, Hein R, Ramil KAA. Drogas ilícitas entre universitários. Rev Assoc Méd Rio Grande do Sul 1986; 30(2): 1403.

Bucher R, Totugui ML. Conocimiento y uso de drogas entre alunos de Brasília. Acta Psiquiatr Psicol Am Lat 1988; 34: 113-26.

Bucher R. Drogas e drogadição no Brasil. Porto Alegre: Artes Médicas; 1992.

Carlini E.A, Carlini-Cotrim B, Silva-Filho AR. Sugestões para programas de prevenção ao abuso de drogas no Brasil. São Paulo: CEBRID/Escola Paulista de Medicina; 1990.

Carlini EA. Medicamentos, drogas e saúde. São Paulo: Hucitec/ Sobravime; 1995.

Carvalho FV. Drug use among university students in the State of São Paulo, Brazil. Bull Narc 1986; 38: 37-9.

Caspar RA. Follow-up of nonrespondents in 1990. In: Turner CF, Lessler JT, Gfroerer JC, editors. Survey measurement of drug use methodological studies. Rockville: National Institute on Drug Abuse; 1992. p.155-73. 
Chen K, Kandel DB. The natural history of drug use from adolescence to the mid-thirties in a general population samples. Am J Public Health 1995; 85(1): 41-7.

Clifford PR, Edmundson EW, Koch WR, Dodd BG. Drug use and life satisfaction among college students. Int J Addic 1991; 26(1): 45-53.

Climent CE, Aragón LV, Plutchic R. Predicción del riesgo de uso de drogas por parte de estudiantes de secundaria. Bol Oficina Sanit Panam 1989; 107(6): 568-75.

Cronin C. Religiosity, religious affiliation, and alcohol and drug use among american college students living in Germany. Int J Addic 1995 Jan; 30(2): 231-8.

Daniel WW. Biostatistics: a foundation for analysis in the health sciences. $6^{\text {th }}$ ed.Singapore: John Wiley \& Sons; 1995.

D'Assumpção EA. Um perfil do uso de drogas entre estudantes universitários. Folha Med 1988; 97(5-6): 309-12.

Deitos FT, Santos RP, Pasqualotto AC, Segat FM, Guillande S, Benvegnú LA. Prevalência do consumo de tabaco, álcool e drogas ilícitas em estudantes de uma cidade de médio porte no sul do Brasil. Inf Psiquiátr 1998; 17(1): 11-6.

Delpirou A, Labrousse A. Coca Coke: produtores, consumidores, traficantes e governantes. São Paulo: Brasiliense; 1988.

Duncan TE, Duncan SC, Alpert A, Hops H, Stoolmiller M, Muth NB. Latent variable modeling of longitudinal and multilevel substance use data. Multiv Behav Res 1997; 32: 275-318.

Enciclopédia Barsa. São Paulo: Enciclopédia Britânica Editores; 1964. Bebidas alcoólicas; v.3, p. 73-5.

Freud S. Obras completas. Trad. Torres LLB. 3a. ed. Madrid: Biblioteca Nueva; 1972. Psicologia de las masas y analisis del yo; p. 2563-610. 
Galduróz JCF, D'Almeida V, Carvalho V, Carlini EA. III levantamento sobre o uso de drogas entre estudantes de 10. e 20. graus em 10 capitais brasileiras - 1993. São Paulo: CEBRID/Depto. de Psicobiologia/ Escola Paulista de Medicina; 1994.

Galduróz JCF, Noto AR, Nappo SA. O consumo de drogas na cidade de São Paulo em 1987,1989 e 1993. TEMAS 1996; 52: 275-85.

Gorenstein C. Uso de psicoestimulantes e energizantes por universitários. Rev Assoc Méd Bras 1983; 29: 45-6.

Greenspan SI. Psychopathology and adaptation in infancy and early childhood. New York: International University Press; 1980 (Clinical Infant Reports, 1).

Grinspoon L, Bakalar JB. Cocaine: une drogue et son évolution sociale. Paris: Éd. L'Étincelle; 1978.

Haden TL, Edmundson EW. Personal and social motivations as predictors of substance use among college students. J Drug Educ 1991; 21(4): 303-12.

Hall W, Solowij N. Adverse effects of cannabis. Lancet 1998; 352:1611-6.

Hawkins JD, Catalano RF, Miller JY. Risk and protective factors for alcohol and other drug problems in adolescence and early adulthood: implications for substance abuse prevention. Psychol Bull 1992; 112: 64-105.

Hops H, Duncan TE, Duncan SC, Stoolmiller M. Parent substance use as a predictor of adolescent use: a six-year lagged analysis. Ann Behav Med 1996; 18(3): 157-64.

Ivis F, Adlaf E. A comparison of trends in drug use among students in the USA and Ontario, Canada:1975-1997. Drugs Educ Prev Policy 1999; 6(1): 17-27.

Jackson C, Henriksen L, Dickinson D, Levine DW. Early use of alcohol and tobacco: relation to child competence and parental behavior. Am J Public Health 1997; 87: 359-64. 
Johnston LD, O'Malley PM, Bachman JG. National Survey Results on Drug Use from the Monitoring the Future Study, 1975-1992. Rockville, MD: National Institute on Drug Abuse; 1993. v2: College students and young adults.

Johnston LD, O'Malley PM, Bachman JG. National Survey Results on Drug Use from the Monitoring the Future Study, 1975-1997. Rockville, MD: National Institute on Drug Abuse; 1998. v 1: Secondary school students.

Kandel DB, Logan JA. Patterns of drug use from adolescence to young adulthood: I. Periods of risk for initiation, continued use, and discontinuation. Am J Public Health 1984; 74(7): 660-6.

Khavari KA. Interpersonal influences in college students initial use of alcohol and drugs - The role of friends, self, parents, doctors, and dealers. Int J Addict 1993 Mar; 28(4): 377-88.

Kessler RC, Mc Gonagle KA, Zhao S, Nelson CB, Hughes M, Eshleman S, et al. Lifetime and 12-month prevalence of DSM-III-R psychiatric disorders in the United States. Arch Gen Psychiatry 1994; 51: 8-19.

Kreek MJ, Koob GF. Drug dependence: stress and dysregulation of brain reward pathways. Drug Alcohol Depend 1998; 51: 23-47.

Kujawski GM. Ortega y Gasset: a aventura da razão. São Paulo: Moderna; 1994.

Kumpfer KL, DeMarsh J. Family environmental and genetic influences on children's future chemical dependency. J Child Contemp Soc 1985; 18(12): 49-91.

Kumpfer KL .Prevention of alcohol and drug abuse: a critical review of risk factors and prevention strategies. In: Shaffer D, Philips I, Enzer NB, editors. Prevention of mental disorders, alcohol, and other drug use in children and adolescents. Rockville: DHHS; 1992. p.309-71. (OSAP Prevention Monograph, 2). 
Lambert EY, Ashery RS, Needle RH, editors. Qualitative methods in drug abuse and HIV research. Rockville: National Institute on Drug Abuse; 1995. Introduction; p. 1-5.

Latimer B, Vasques M, Cortes LAP, Garrido AFZ, Winters K, Botzet A. drug use among school-based youth in Mexico: predictors of problem severity and POSIT screening. [Presented at College on Problems Dependence (CPDD) - Sixty-first Annual Scientific Meeting; 1999 June 1217, Acapulco, Mexico].

Leukefeld CG, Bukoski WJ, editors. An introduction to drug abuse prevention intervention research: methodological issues. Rockville: NIDA; 1991. p. 1-6.

Lins e Silva T. Produção e consumo de drogas no contexto sócio-político contemporâneo. In: Bastos FI, Gonçalves O, organizadores. Só socialmente: os fatores psicoativos nas relações humanas através dos tempos. Rio de Janeiro: Relume-Dumará; 1992. p. 51-6.

Lo CC, Globetti G. The effects of internal and external control factors on college students marijuana use and cessation of use. J Drug Educ 1995; 25(4): 357-77.

Lozano A. Menores estão mais violentos em São Paulo. Folha de São Paulo 1996 julho 26; cad 3: 1.

Magalhães MP, Barros RS, Oliveira RC, Azevedo RB, Almeida SP, Silva MTA. Padrões de freqüência do uso da maconha por estudantes universitários. Rev ABP-APAL 1989; 11(1): 35-40.

Magalhães MP, Barros RS, Silva MTA. Uso de drogas entre universitários: a experiência com maconha como fator delimitante. Rev ABP-APAL 1991; 13 (3): 97-104.

Mesquita AM, Andrade AG, Anthony JC. Alcohol and drug use among medical students at the University of São Paulo, Brazil. [Apresentado na Association for Medical Education and Research in Substance Abuse National Conference; 1992 nov 13; Bethesda, USA]. 
Mesquita AMC, Butaretchi HA, Castel S, Andrade AG. Estudantes da Faculdade de Medicina da Universidade de São Paulo: uso de substâncias psicoativas em 1991. Rev ABP-APAL 1995; 17(2): 47-54.

Miller DS, Miller TQ. A test of socioeconomic status as a predictor of initial marijuana use. Addic Behav 1997; 22(4): 479-89.

Molina B, Chassin L, Curran P. Comparisons of mechanisms underlying substance use for early adolescent children of alcoholics and controls. J Stud Alcohol 1994; 55(3): 269-75.

Moss HB, Bonicatto S, Kirisci L, Girardelli AM, Murrelle L. Substance abuse and associated psychosocial problems among Argentina adolescents: sex, heterogeneity and familial transmission. Drug Alcohol Depend 1998; 52(3): 221-30.

Murad JE. Drug abuse among students in the State of Minas Gerais, Brazil. Bull on Narc 1979; 31: 49-58.

[NIDA] National Institute on Drug Abuse. National Household Survey on Drug Abuse: Population Estimates 1991. Washington,DC: US Government Printing Office; 1992.

Nazar-Beutelspacher A, Tapia-Conyer R, Villa-Romero A, Leon-Alvarez G, Medina-Mora ME, Savatierra-Izaba B. Factores asociados al consumo de drogas en adolescentes de áreas urbanas de México. Salud Publica Mex 1994; 36: 646-54.

Newcomb MD, Maddahian E, Bentler PM. Risk factor for drug use among adolescents: concurrent and longitudinal analyzes. Am J Public Health 1986; 76(5): 525-31.

Oetting ER, Beauvais F. Common elements in youth drug use: peer cluster and other psychosocial factors. In: Peele $S$, editor. Visions of addiction. Lexington: DC Health; 1988.

[OMS] Organização Mundial de Saúde. Reagindo aos problemas das drogas e do álcool na comunidade. São Paulo: Livraria Editora Santos; 1992. 
Pereira MG. Epidemiologia: teoria e prática. Rio de Janeiro: Guanabara Koogan; 1995.

Plotnik R. Utilização de psicotrópicos por estudantes universitários. Rev Pesq Méd 1986; 20: 109-13.

Prendergast ML. Substance use and abuse among college students: a review of recent literature. J Addic Coll Health 1994; 43(Nov): 99-113.

Queipo D, Alvarez FJ, Velasco A. Drug consumption among university students in Spain. Br J Addic 1988; 83: 91-8.

Queiroz S, Rosenburg CP, Andrade AG. Fatores associados ao uso de álcool em estudantes de graduação da Universidade de São Paulo. In: Anais do 6o. Congresso Paulista de Saúde Pública; 1999. Out:17-20; Águas de Lindóia. p.7.

Rainey CJ, McKeown RE, Sargent RG, Valois RF. Patterns of tobacco and alcohol use among sedentary, exercising, non athletic, and athletic youth. $\mathbf{J}$ School Health 1996; 66(1): 27-32.

Ray O, Ksir C. Drugs, society and human behavior.6th. ed. St. Louis: Mosby-Year Book; 1993.

Schall M, Kemeny A, Maltzman I. Factors associated with alcohol use in university students. J Stud Alcohol 1992; 53(2): 122-36.

Scheier LM, Newcomb M, Skager R. Protection and vulnerability to adolescent drug use: latent variable-models of three age groups. J Drug Educ 1994; 24(1): 49-82.

Schober SE, FeCaces M, Pergamit MR, Branden L. Effect of mode of administration on reporting of drug use in the National Longitudinal Survey. In: Turner CF, Lessler JT, Gfroerer JC, editors. Survey measurement of drug use: methodological studies. Rockville: National Institute on Drug Abuse; 1992. p.267-76. 
Sloboda Z, David SL. Preventing drug use among children and adolescents: a research-based guide. $2^{\text {nd }}$ ed. Rockville, MD: National Institute on Drug Abuse; 1997.

Smart RG, Hughes P, Johnston LD, Anumonye A, Khant U, Mora MEM, et al. A methodology for student drug-use surveys. Geneva: WHO Offset Publication; 1980.

Smith C, Lizotte AJ, Thormberry TP, Krohn MD. Resilient youth: identifying factors that prevent high-risk youth from engaging in delinquency and drug use. In: Hagan J, editor. Delinquency and disrepute in the life course. Greenwich, CT: JAI Press; 1995. p. 217-47.

Stabenau JR. Is risk for substance abuse unitary? J Nerv Ment Dis 1992; 180(9): 583-8.

Swan N. Early childhood behavior and temperament predict later substance use. NIDA Notes [on line] 1995; 10(1):[5 telas]. Available from $<$ http://165.112.78.61/NIDA_Notes/NNVOL10N1/ Earlychild html $>$ [1998 April 9].

Szalay LB, Inn A, Doherty KT. Social influences: effects of the social environment on the use of alcohol and other drugs. Subst Use Misuse 1996; 31(3): 343-73.

Turner CF, Lessler JT, Gfroerer JC, editors. Survey measurement of drug use: methodological studies. Rockville: National Institute on Drug Abuse; 1992. Future directions for research and practice; p. 299-306.

Villa JAP, director. Estudio National de Salud Mental y Consumo de Substancias Psicoactivas - Colombia 1993. 2a. ed. Santafé de Bogotá: Ministerio de Salud; 1995.

Webb E, Ashton H, Kelly P, Kamali F. Patterns of alcohol consumption, smoking and illicit drug use in British university students: interfaculty comparisons. Drug Alcohol Depend 1997; 47: 145-53. 
Winnicott DW. O ambiente e os processos de maturação: estudos sobre a teoria do desenvolvimento emocional. Trad. de ICS Ortiz. Porto Alegre: Artes Médicas; 1982.

[WHO] World Health Organization. Adolescents, drugs and prevention setting an international agenda: report and recommendations Geneva; 1994.

Yamaguchi K, Kandel DB. Patterns of drug use from adolescence to young adulthood: III. Predictors of progression. Am J Public Health 1984; 74(7): 673-81.

Zanini AC, Moraes ECF, Akerman B, Aizenstein M, Salgado PET. Concept and use of psychoactive drugs among university students in the São Paulo area. Drug Forum 1977; 6: 85-99. 


\section{ANEXOS}


ANEXO 1 
Distribuição da amostra ${ }^{1}$ por área e unidades ( $n$ total da amostra $=$ 3539).

\begin{tabular}{|c|c|c|}
\hline Área & Unidade & $\mathbf{n}$ \\
\hline Humanas $^{2}$ & $\begin{array}{l}\text { ECA } \\
\text { FAU } \\
\text { FD } \\
\text { FEA } \\
\text { FE } \\
\text { FFLCH }\end{array}$ & $\begin{array}{l}97 \\
71 \\
170 \\
224 \\
184 \\
495\end{array}$ \\
\hline Total & & 1241 \\
\hline Exatas $^{3}$ & $\begin{array}{l}\text { EP } \\
\text { IAG } \\
\text { IF } \\
\text { IG } \\
\text { IME } \\
\text { IQ }\end{array}$ & $\begin{array}{l}603 \\
22 \\
197 \\
38 \\
185 \\
55\end{array}$ \\
\hline Total & & 1198 \\
\hline Biológicas $^{4}$ & $\begin{array}{l}\text { EEFE } \\
\text { EE } \\
\text { FCF } \\
\text { FM } \\
\text { FMVZ } \\
\text { FO } \\
\text { FSP } \\
\text { IB } \\
\text { IP }\end{array}$ & $\begin{array}{l}105 \\
79 \\
179 \\
317 \\
94 \\
168 \\
30 \\
145 \\
81\end{array}$ \\
\hline Total & & 1100 \\
\hline
\end{tabular}

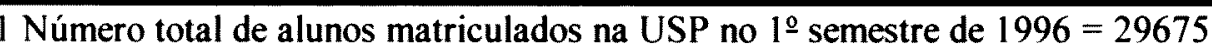

2 Número total de alunos matriculados na área de humanas no $1^{10}$ semestre de $1996=17167$

3 Número total de alunos matriculados na área de exatas no $1^{\circ}$ semestre de $1996=7270$

4 Número total de alunos matriculados na área de biológicas no $1^{\circ}$ semestre de $1996=5238$ 
ANEXO 2 


\section{POPULACÃO DI: I:SIUDO IE I:STIMADORES}

A população de estudo constitue-se dos alunos matriculados em 1996 nos cursos de graduação da Universidade São Paulo, em unidades localizadas no municipio de São Paulo.

Para fins de elaboração do plano de amostragem, foi fixada como meta prioritária do estudo estimar as proporções desses alunos que fizeram uso de alcool, de tabaco e de drogas sem orientação médica, considerando a frequência desse uso eın três niveis: durante a vida, no último ano e no mês.

Tais proporções devem ser estimadas separadaınente nas 3 áreas em que se dividem os cursos da USP ( Ciências Humanas, Exatas e Biológicas), significando que essas áreas constituem-se domínios de estudo.

Em cada uma delas o estimador a ser utilizado é

$$
p_{h}=\frac{\sum_{i}^{n} y_{h t}}{n_{h}}
$$

sendo $y_{i}=1$ se $i$-ésimo aluno da área $h$ tiver usado a droga em estudo

yhi $=0$ caso contrário

nı é o número de alınos da área $h$

Para o conjunto das áreas. o esti nador passa \& ser

$$
\begin{gathered}
p=\sum_{R} W_{h} \cdot m_{h} \\
W_{h}=\frac{N_{h}}{N}
\end{gathered}
$$

onde $\mathrm{N}_{h}$ è o número de alunos matriculı dos na área $\mathrm{h}$

$\mathrm{N}$ é o número total de alunos 
Após a realização das entrevistas, os alunos de cada área serão agrupados segundo 3 variáveis. Primeiramente por periodo (diurno e noturno); em seguida todos serão novamente divididos por sexo (feminino e masculino) e finalmente por ano de ingresso (até ---- e após ---). Para cada um desses 6 grupos, serão calculadas as proporções de interesse, utilizando os estimadores para subclasses, abaixo mencionados,

$$
p_{h g}=\frac{\sum_{i}^{m l} y h g i}{m h g}
$$

sendo yhgi $=1$ se $i$-ésimo aluno da área $h$, grupo g tiver usado a droga em estudo

ylıj $=0$ caso contrário

migg é o número de alunos da área $\mathrm{h}$, grupo $\mathrm{g}$

Para todo o grupo g. independente da área

$$
\begin{aligned}
& p_{g}=\sum_{\mathcal{L}} W_{h} \cdot p_{1 g} \\
& W_{h}=\frac{M_{h}}{M}
\end{aligned}
$$

onde $\mathrm{Mh}_{\mathrm{h}}$ o número de alunos da área h pertencentes ao grupo de interesse (leminino / masculino; diurno / noturno; que ingressaram até ---- / após ----)

$\mathrm{M}$ é o número total de alunos pertencentes ao grupo de interesse 


\section{TAMANHO DA AMOSTRA.}

Para determinar o número de alunos a serem estrevistados em cada área, fixou-se que a diferença absoluta (erro de amostragem) entre uma particular proporção obtida pela amostra e o seu valor na população não deveria exceder 0,05 . Optou-se por considerar, para fins de cálculo do tamanho da amostra, que a proporção a ser estimada equivale a . $50 \%$, valor que determina o maior tamanho possivel da amostra, pois algumas das estimativas obtidas em estudo piloto aproximaram-se desse patamar.

O número inicial de alunos a serem sorteados em cada uma das áreas é dado por,

$$
n o=\frac{p(1-p)}{(d / z)^{2}}
$$

onde p é a proporção de alunos que: fazem uso da droga em estudo

d é a diferença máxima aceitável entre a proporção obtida na amostra e a populacional

$z$ é o valor correspondente ao nivel de significância de $5 \%$ na distribuição Normal reduzida

Com os valores já definidos,

$$
n o=\frac{0,5 * 0,5}{(0,05 / 1,96)^{2}}=384
$$

Uma vez que espera-se obter, em cada área, um numero de entrevistas que permita conhecer as estimativas para grupos de ahunos segundo sexo, periodo e ano de ingresso, o tamanho da amostra acima determinado deve ser dividido por 0,37 , que corresponde ao menor percentual de alunos segundo esses grupos.

$$
\mathbf{n}=384 / 0,37=1038
$$

Para compensar possiveis perdas de unidades sorteadas, pelo não comparecimento do aluno para responder ao questionário ou pela necessidade de anulaq̆a de questões nele contidas, será sorteado um numero maior de alunos. Admitindo-se que as perdas sejam de $20 \%$, esse numero corresponde a 1298 .

Considerando as 3 áreas, o número total de alunos a serem entrevistados é 3114 e a serem sorteados é $\mathbf{3 8 9 4}$. 


\section{SORTEIO}

A amostragem a ser utilizada é a estratificada por área (Humanas, Exatas e Biológicas), com partilha igual, sendo a fração de amostragem dada por,

$$
\mathrm{fh}=\frac{\mathrm{nh}}{\mathrm{Nh}}
$$

onde nh é o número de alunos amostrados na área $h$

Nh é o número de alunos matriculados na área $h$

Os alunos serão selecionados por sorteio sistemático, tendo como intervalos de amostragem os valores 13,832; 6,612 e 4,375 nas áreas de Humanas, Exatas e Biológicas, respectivamente, e estratificados após a seleção segundo sexo, periodo de estudo e ano de ingresso.

\section{PRECISÃo dOS ESTIMADORES}

0 erro de amostragem de qualquer proporção estimada será calculado por $1,96 \times \operatorname{var}(p)$, sendo a variância de $p$ dada pelas expressões abaixo.

4.I Dentro de cada área $h$ e dentro de cada grupo g, segundo sexo. periodo e ano de ingresso.

$$
\begin{aligned}
& \operatorname{var}\left(p_{h g}\right)=(1-f) \frac{\text { She }^{2}}{\text { ming }} \\
& \text { Shg }^{2}=\frac{\text { mhg } \cdot \text { phrg }\left(1-p_{h g}\right)}{m_{\text {ig }}-1}
\end{aligned}
$$

estando phrg, mhr e findefinidos nas expressões (4)e (2) 
4.2 Dentro de cada área, para o conjunto de alunos

$$
\operatorname{var}(\text { phg })=\frac{1-f_{h}}{n h} \sum_{g} W_{h g} S g^{2}+\frac{1-f h}{n h} \sum_{g} W_{h g}\left(1-W_{h g}\right) \frac{S_{h g}^{2}}{n_{h g}}
$$

$W_{h}=\frac{\text { Nhg }}{N_{h}}$

onde Nhg é o número de alunos matriculados que pertencem à área $h$, grupo $g$ Nh é o número de alunos matriculados

4.3 Para cada grupo g, no conjunto das áreas

$\operatorname{var}\left(p_{B}\right)=\sum_{R} \frac{M h^{2}}{M} \cdot \operatorname{var}($ phg $)$

estando Mh e M definidos em(3)

4.4 Para o conjunto de alunos de todas as áreas

$\operatorname{var}(p)=\sum_{2} \frac{\mathrm{Nh}^{2}}{N} \cdot \operatorname{var}\left(p_{h}\right)$

estando Nhe N definidos em (1) 
ANEXO 3 


\section{QUESTIONÁRIO}

\section{INSTRUÇÕES PARA O PREENCHIMENTO}

1.Este questionário visa colher informações sobre atitudes e uso de drogas dos alunos da USP.

2. Todas as respostas são confidenciais e o preenchimento deste questionário é anônimo.

3.A sua sinceridade nas respostas é muito importante, assim como o preenchimento de todas as questões. Porém, se não souber responder uma questão - ou se não se sentir a vontade para respondê-la - deixe-a em branco.

4. Em cada questão deverá ser assinalada somente uma alternativa, salvo onde estiver indicado: "é possível assinalar mais de uma alternativa".

5. O tempo necessário para preenchimento do questionário é de aproximadamente 20 minutos.

6. Preencha individualmente.

7. Ao acabar de respondê-lo, coloque na urna que se encontra no local.

8. Sua participação é de extrema importância para a realização deste estudo.

9. Muito obrigado pela colaboração! 
1. Seu curso pertence a área de (na dúvida, consulte a tabela na contra capa)

1. ( ) humanas

2. ( ) biológicas

3. ( ) exatas

2. Coloque a sigla de sua unidade (consulte tabela na contra capa):

3. Coloque o ano em que ingressou na USP: (199

4. Ano que está cursando:

1. ( ) 1‥ ano

2. ( ) $2 \stackrel{\circ}{\circ}$ ano

3. ( ) $3^{\circ}$. ano

4. ( ) 4\% ano

5. ( ) $5^{\text {o. ano }}$

6. ( ) $6^{2}$. ano

5. Periodo que está cursando:

1. ( ) Diurno (matutino, vespertino, integral)

2. ( ) Noturno

6. Sexo:

1. ( ) masculino

2. ( ) feminino

7. Idade:

1. ( ) $15-19$

2. ( ) $20-24$

3. ( ) $25-29$

4. ( ) $30 \mathrm{ou}+$

8. Seu estado civil atual é:

1. ( ) Solteiro

2. ( ) Casado/vive junto

3. ( ) Outro

9. Você mora:

1. ( ) Pais/outros familiares

2. ( ) Cônjuge/companheiro(a)

3. ( ) Amigos/república

4. ( ) Sozinho

5. ( ) CRUSP

6. ( ) Outro 
10. Você tem religião ?

$$
\begin{aligned}
& \text { 1. ( ) Sim } \\
& \text { 2. ( ) Não }
\end{aligned}
$$

11. Você pratica sua religião?

$$
\begin{aligned}
& \text { 1. ( ) Sim } \\
& \text { 2. ( ) Não }
\end{aligned}
$$

12. Você exerceu alguma atividade remunerada (inclusive bolsa de estudo e estágio) por um periodo maior que um mês nos últimos 6 meses?

\begin{tabular}{|c|c|c|c|c|c|}
\hline & & \multicolumn{2}{|c|}{ a) pai } & \multicolumn{2}{|c|}{ b) mãe } \\
\hline 1 & Não recebeu educação formal & ( & ) & ( & ) \\
\hline 2 & Primeiro grau incompleto & ( & ) & ( & ) \\
\hline 3 & Primeiro grau completo & ( & ) & ( & ) \\
\hline 4 & Segundo grau incompleto & ( & ) & ( & ) \\
\hline 5 & Segundo grau completo & ( & ) & ( & ) \\
\hline 6 & Superior incompleto & ( & ) & ( & ) \\
\hline 7 & Superior completo & ( & ) & ( & ) \\
\hline 8 & Não sei & ( & ) & ( & ) \\
\hline
\end{tabular}
1. ( ) Sim
2. ( ) Não

13. Qual o grau de escolaridade de seus pais?

14. Qual é aproximadamente sua renda familiar ? $(\mathrm{SM}=\mathrm{R} \$ 100,00)$

1. ( ) Até 10 salários mínimos

2. ( ) De 10 a 20 salários mínimos

3. ( ) De 21 a 30 salários mínimos

4. ( ) De 31 a 40 salários mínimos

5. ( ) Mais de 40 salários mínimos

15. Seus pais vivem:

1. ( ) Juntos

2. ( ) Separados

3. ( ) Pai ou mãe falecidos

16. Quando você tem um problema pessoal mais sério, quem você procura em primeiro lugar?
1. ( ) Mãe
2.( ) Pai
3. ( ) Irmão
4. ( ) Amigos
5. ( ) Namorado(a)/ companheiro(a)
6. ( ) Terapeuta
7. ( ) Ninguém
8. ( ) Outros 
17. Atualmente, de quantas horas livres você dispõe em média a cada dia da semana? (Excluir período de sono)
1. ( ) Nenhuma
2. ( ) Até 2 horas
3. ( ) De 2 a 4 horas
4. ( ) De 4 a 6 horas
5. ( ) Mais do que 6 horas

18. Atualmente, de quantas horas livres você dispõe em média por dia, durante o fím de semana? (Excluir período de sono)
1. ( ) De todo meu tempo
2. ( ) De algumas horas por dia
3. ( ) De menos de uma hora por dia
4. ( ) De nenhuma hora

19. O que você costuma fazer nas suas horas livres? (Excluir período de sono e assinalar apenas a mais freqüente)
1. ( ) Ir à igreja
2. ( ) Sair/viajar com amigos/namorado(a)
3. ( ) Praticar esportes
4. ( ) Assistir televisão
5. ( ) Participar de atividades culturais (cinema, teatro, shows, etc.)
6. ( ) Freqüentar bares/festas (boites, danceterias)
7. ( ) Ler livros, revistas não relacionadas com o seu curso
8. ( ) Outros

20. Você pratica estas atividades com a freqüência que gostaria?
1. ( ) Sim
2. ( ) Não

21. O que você faz, em geral, quando falta as aulas ? (assinale apenas a mais freqüente)

1. ( ) Não falto as aulas

2. ( ) Vou ao cinema, clube, etc.

3. ( ) Estudo em casa

4. ( ) Estudo na faculdade

5. ( ) Não faço nada

6. ( ) Só falto quando estou doente

7. ( ) Trabalho

8. ( ) Durmo elou descanso

9. ( ) Fico no Diretório Acadêmico, Centro Acadêmico, CEPEUSP ou Atlética

10. ( ) Outros 
22. Que lugares você costuma freqüentar dentro da universidade, que não os exigidos pela suas atividades acadêmicas? (assinale apenas a mais freqüente)
1. ( ) CA/DA
2. ( ) CEPEUSP e/ou lugares afins
3. ( ) Biblioteca
4. ( ) Lanchonete
5. ( ) Outros

23. Nos últimos 12 meses, você tem sentido dificuldade de fazer novos amigos?
1. ( ) Sim
2. ( ) Não

24. Nos últimos 12 meses, você tem se sentido rejeitado pelo seu grupo de amigos ou outros de sua idade?
1. ( ) Sim
2. ( ) Não

25. Pensando nos últimos 12 meses, você se considera facilmente influenciável pelo seu grupo de amigos?
1. ( ) Sim
2. ( ) Não

26. Você gostaria de ter maiores informações sobre doenças sexualmente transmissiveis (DST's) e vírus da AIDS (HIV)?
1. ( ) Sim
2. ( ) Não

27. Você acha importante o uso de preservativos para a prevenção das DST's/HIV?

1. ( ) Sim

2. ( ) Não

28. Você faz uso de preservativos:

1. ( ) Sempre

2. ( ) Nunca

3. ( ) Às vezes

29. Qual o motivo que o leva a não usar preservativo?

1. ( ) Não gosto

2. ( ) É caro

3. ( ) Esqueço na hora $\mathrm{H}$

4. ( ) Não vou pegar doença nenhuma

5. ( ) Uso sempre 
$\S<30$. Na sua opinião, que estratégias você acha que trariam melhores resultados, numa campanha educativa? (é possível assinalar mais de uma alternativa)
1. ( ) Cartazes
2. ( ) Rádio
3. ( ) Jornal
4. ( ) Cartilhas
5. ( ) Palestras
6. ( ) Cursos
7. ( ) Grupos de discussão
8. ( ) Outros

31. Você está satisfeito com sua escolha profissional ?
1. ( ) Sim
2. ( ) Não

32. Você já pensou em abandonar seu curso ?
1. ( ) Sim
2. ( ) Não
3. ( ) Ainda penso

33. Se você respondeu "sim" a questão anterior, assinale o ano do curso que você pensou em abandoná-lo:
1. ( ) $1 \stackrel{0}{\circ}$. ano
2. ( ) $2^{\underline{a}}$. ano
3. ( ) $3^{\mathrm{o}}$. ano
4. ( ) 40. ano
5. ( ) 5\%. ano
6. ( ) $6^{\mathrm{o}}$. ano

34. Você tem regularmente deixado de fazer seus trabalhos acadêmicos? (responda considerando os últimos 12 meses)
1. ( ) Sim
2. ( ) Não

35. Você considera seu desempenho escolar:

1. ( ) Bom/excelente

2. ( ) Fraco/regular

3. ( ) Insuficiente

36. Quanto às perspectivas de trabalho e financeiras, após a formatura?

1. ( ) Acha que vai se realizar profissional e financeiramente

2. ( ) Acha que vai se realizar profissionalmente e não importa muito quanto a parte financeira

3. ( ) Acha que não vai se realizar profissionalmente mas a perspectiva financeira é boa

4. ( ) Acha que não vai se realizar profissional nem financeiramente 
37. No último semestre e/ou ano você:

1. ( ) Passou direto em tudo

2. ( ) Teve recuperação/exame mas passou em tudo

3. ( ) Ficou de dependência, mas não perdeu o ano/semestre

4. ( ) Repetiu o ano

5. ( ) Outro

38. Se você tivesse alguma dúvida a respeito de álcool e drogas, quem você procuraria em primeiro lugar?

1. ( ) Professores

2. ( ) Amigos/colegas de faculdade

3. ( ) Pais

4. ( ) Profissionais especializados

5. ( ) Lider religioso (padre, rabino, etc...)

6. ( ) Livros e/ou artigos científicos

39. Assinale a alternativa que melhor indica o que você pensa a respeito de uma pessoa experimentar as seguintes substâncias:

\begin{tabular}{|c|l|c|c|}
\hline \multicolumn{2}{|l|}{} & a) aprovo & b) desaprovo \\
\hline 1 & Álcool & $($ ) & $($ ) \\
\hline 2 & Maconha & $($ ) & $($ ) \\
\hline 3 & Cocaína (exceto crack) & $($ ) & $($ ) \\
\hline 4 & Crack & $($ ) & $($ ) \\
\hline 5 & Tranqüilizantes & $($ ) & $($ ) \\
\hline 6 & Anfetaminas & $($ ) & $($ ) \\
\hline 7 & Inalantes & & \\
\hline
\end{tabular}

40. Assinale a alternativa que melhor indica o que você pensa a respeito de uma pessoa usar regularmente as seguintes substâncias (no caso do álcool, no mínimo 3 vezes por semana, o equivalente a 5 chopps ou 5 doses de whisky e no mínimo uma vez por semana no caso das outras drogas):

\begin{tabular}{|c|c|c|c|}
\hline & & a) aprovo & b) desaprovo \\
\hline 1 & Álcool & $(\quad)$ & ( \\
\hline 2 & Maconha & $(\quad)$ & $(\quad)$ \\
\hline 3 & Cocaína (exceto crack) & $(\quad)$ & $(\quad)$ \\
\hline 4 & Crack & $(\quad)$ & $(\quad)$ \\
\hline 5 & Tranquilizantes & $(\quad)$ & $(\quad)$ \\
\hline 6 & Anfetaminas & $(\quad)$ & $(\quad)$ \\
\hline 7 & Inalantes & $(\quad)$ & $(\quad)$ \\
\hline
\end{tabular}

41. Você considera a dependência de álcool e outras drogas como um problema de saúde ?

1. ( ) Sim

2. ( ) Não 
42. Na sua opinião, a maioria dos alcoolistas:

1. ( ) Se curam

2. ( ) Melhoram

3. ( ) Não melhoram

4. ( ) Pioram

43. Na sua opinião, a maioria dos dependentes de drogas (exceto álcool):

1. ( ) Se curam

2. ( ) Melhoram

3. ( ) Não melhoram

4. ( ) Pioram

44. Você gostaria de:

1. ( ) Ter mais informações sobre álcool e outras drogas

2. ( ) Ajudar pessoas com problemas de álcool e outras drogas

3. ( ) As duas opções acima

4. ( ) Nenhuma das opções acima

As questões de números 45 a 58 são a respeito de uso de drogas. Na vida, nos últimos 12 meses, e a freqüencia de uso nos últimos trinta dias. O nome da categoria da droga está descrito no primeiro quadrado e seu nome comercial entre parênteses.

Exemplo: Uma pessoa que toma coca-cola todos os fins de semana:

\begin{tabular}{|c|c|c|}
\hline $\begin{array}{l}\text { PADRÃO DE USO: } \\
\text { Você já experimentou (nome } \\
\text { da droga) sem orientação de } \\
\text { médico ou outro } \\
\text { profissional? }\end{array}$ & $\begin{array}{l}\text { USO RECENTE: } \\
\text { Usou esta droga } \\
\text { nos últimos } 12 \\
\text { meses? }\end{array}$ & $\begin{array}{l}\text { FREQÜENCIA: } \\
\text { Com que freqüencia utilizou está } \\
\text { droga nos últimos } 30 \text { dias? }\end{array}$ \\
\hline $\begin{array}{l}\text { REFRIGERANTE } \\
\text { (coca-cola, guaraná, água } \\
\text { tônica, soda etc.) } \\
\text { 1. (X) Sim } \\
\text { 2. ( ) Não }\end{array}$ & $\begin{array}{l}\text { 1. }(X) S \\
\text { 2. }()\end{array}$ & $\begin{array}{l}\text { 1. ( ) Não usei } \\
\text { 2. ( ) Menos que } 1 \text { vez por semana } \\
\text { 3. (X) } 1 \text { ou mais vezes por semana } \\
\text { 4. ( ) Diariamente } \\
\text { 5. ( ) Duas ou três vezes por dia } \\
\text { 6. ( ) Quatro ou mais vezes por dia }\end{array}$ \\
\hline
\end{tabular}




\begin{tabular}{|c|c|c|}
\hline $\begin{array}{l}\text { PADRÃO DE USO: } \\
\text { Você já experimentou } \\
\text { (nome da droga) sem } \\
\text { orientação de médico ou } \\
\text { outro profissional? }\end{array}$ & $\begin{array}{l}\text { USO RECENTE: } \\
\text { Usou esta droga } \\
\text { nos últimos } 12 \\
\text { meses? }\end{array}$ & $\begin{array}{l}\text { FREQÜENCIA: } \\
\text { Com que freqüencia utilizou está } \\
\text { droga nos últimos } 30 \text { dias ? }\end{array}$ \\
\hline $\begin{array}{l}\text { 45. ÁLCOOL } \\
\text { 1. ( ) Sim } \\
\text { 2. ( ) Não }\end{array}$ & $\begin{array}{l}\text { 1.( ) Sim } \\
\text { 2. ( ) Não }\end{array}$ & $\begin{array}{l}\text { 1. ( ) Não usei } \\
\text { 2.( ) Menos que } 1 \text { vez por semana } \\
\text { 3. ( ) } 1 \text { ou mais vezes por semana } \\
\text { 4. ( ) Diariamente } \\
\text { 5. ( ) Duas ou três vezes por dia } \\
\text { 6. ( ) Quatro ou mais vezes por dia }\end{array}$ \\
\hline $\begin{array}{l}\text { 46. TABACO } \\
\text { 1. ( ) Sim } \\
\text { 2. ( ) Não }\end{array}$ & $\begin{array}{l}\text { 1.( ) Sim } \\
\text { 2. ( ) Não }\end{array}$ & $\begin{array}{l}\text { 1. ( ) Não usei } \\
\text { 2.( ) Menos que } 1 \text { vez por semana } \\
\text { 3. ( ) } 1 \text { ou mais vezes por semana } \\
\text { 4. ( ) Diariamente } \\
\text { 5. ( ) Duas ou três vezes por dia } \\
\text { 6. ( ) Quatro ou mais vezes por dia }\end{array}$ \\
\hline $\begin{array}{l}\text { 47. MACONHA / HAXIXE } \\
\text { 1. ( ) Sim } \\
\text { 2. ( ) Não }\end{array}$ & $\begin{array}{l}\text { 1. ( ) Sim } \\
\text { 2. ( ) Não }\end{array}$ & $\begin{array}{l}\text { ( ) Não usei } \\
\text { 2. ( ) Menos que } 1 \text { vez por semana } \\
\text { 3. ( ) } 1 \text { ou mais vezes por semana } \\
\text { 4. ( ) Diariamente } \\
\text { 5. ( ) Duas ou três vezes por dia } \\
\text { 6. ( ) Quatro ou mais vezes por dia }\end{array}$ \\
\hline $\begin{array}{l}\text { 48. ALUCINÓGENOS } \\
\text { (LSD, chá de cogumelo, } \\
\text { mescalina, chá de lírio.) } \\
\text { 1. ( ) Sim } \\
\text { 2. ( ) Não }\end{array}$ & $\begin{array}{l}\text { 1. ( ) Sim } \\
\text { 2. ( ) Não }\end{array}$ & $\begin{array}{l}\text { 1. ( ) Não usei } \\
\text { 2.( ) Menos que } 1 \text { vez por semana } \\
\text { 3. ( ) } 1 \text { ou mais vezes por semana } \\
\text { 4. ( ) Diariamente } \\
\text { 5. ( ) Duas ou três vezes por dia } \\
\text { 6. ( ) Quatro ou mais vezes por dia }\end{array}$ \\
\hline $\begin{array}{l}\text { 49. COCAÍNA } \\
\text { (exceto crack) } \\
\text { 1. ( ) Sim } \\
\text { 2. ( ) Não }\end{array}$ & $\begin{array}{l}\text { 1. () Sim } \\
\text { 2. ( ) Não }\end{array}$ & $\begin{array}{l}\text { 1. ( ) Não usei } \\
\text { 2.( ) Menos que } 1 \text { vez por semana } \\
\text { 3. ( ) } 1 \text { ou mais vezes por semana } \\
\text { 4. ( ) Diariamente } \\
\text { 5. ( ) Duas ou três vezes por dia } \\
\text { 6. ( ) Quatro ou mais vezes por dia }\end{array}$ \\
\hline $\begin{array}{l}\text { 50. CRACK } \\
\text { 1. ( ) Sim } \\
\text { 2. ( ) Não }\end{array}$ & $\begin{array}{l}\text { 1. ( ) Sim } \\
\text { 2.( ) Não }\end{array}$ & $\begin{array}{l}\text { 1. ( ) Não usei } \\
\text { 2. ( ) Menos que } 1 \text { vez por semana } \\
\text { 3. ( ) } 1 \text { ou mais vezes por semana } \\
\text { 4. ( ) Diariamente } \\
\text { 5. ( ) Duas ou três vezes por dia } \\
\text { 6. ( ) Quatro ou mais vezes por dia }\end{array}$ \\
\hline
\end{tabular}




\begin{tabular}{|c|c|c|}
\hline $\begin{array}{l}\text { PADRÃO DE USO: } \\
\text { Você já experimentou } \\
\text { (nome da droga) sem } \\
\text { orientação de médico ou } \\
\text { outro profissional? }\end{array}$ & $\begin{array}{l}\text { USO RECENTE: } \\
\text { Usou esta droga } \\
\text { nos últimos } 12 \\
\text { meses? }\end{array}$ & $\begin{array}{l}\text { FREQÜENCIA: } \\
\text { Com que freqüencia utilizou está } \\
\text { droga nos últimos } 30 \text { dias ? }\end{array}$ \\
\hline $\begin{array}{l}\text { 51. ANFETAMINAS } \\
\text { (Hipofagin, Moderex, } \\
\text { Dualid, Inibex, Desobesi, } \\
\text { Reactivan, Pervetin, } \\
\text { Preludin,fórmulas para } \\
\text { emagrecer) } \\
\text { 1. ( ) Sim } \\
\text { 2. ( ) Não }\end{array}$ & $\begin{array}{l}\text { 1. ( ) Sim } \\
\text { 2.( ) Não }\end{array}$ & $\begin{array}{l}\text { 1. ( ) Não usei } \\
\text { 2.( ) Menos que } 1 \text { vez por semana } \\
\text { 3. ( ) } 1 \text { ou mais vezes por semana } \\
\text { 4. ( ) Diariamente } \\
\text { 5. ( ) Duas ou três vezes por dia } \\
\text { 6.( ) Quatro ou mais vezes por dia }\end{array}$ \\
\hline $\begin{array}{l}\text { 52. ANTI-COLINÉRGICO } \\
\text { (Artane, Akineton, } \\
\text { Asmosterona, Chá de Lírio, } \\
\text { Saia Branca, Véu de Noiva, } \\
\text { Trombeteira, Zabumba, } \\
\text { Cartucho) } \\
\text { 1. ( ) Sim } \\
\text { 2. ( ) Não }\end{array}$ & $\begin{array}{l}\text { 1. ( ) Sim } \\
\text { 2.( ) Não }\end{array}$ & $\begin{array}{l}\text { 1. ( ) Não usei } \\
\text { 2.( ) Menos que } 1 \text { vez por semana } \\
\text { 3. ( ) } 1 \text { ou mais vezes por semana } \\
\text { 4.( ) Diariamente } \\
\text { 5. ( ) Duas ou três vezes por dia } \\
\text { 6.( ) Quatro ou mais vezes por dia }\end{array}$ \\
\hline $\begin{array}{l}\text { 53. SOLVENTES } \\
\text { ORGÂNICOS } \\
\text { (Lança-perfume, loló, cola, } \\
\text { gasolina, benzina, acetona, } \\
\text { thinner, aguarrás, éter, } \\
\text { esmalte, tinta) } \\
\text { 1. ( ) Sim } \\
\text { 2. ( ) Não }\end{array}$ & $\begin{array}{l}\text { 1. () Sim } \\
\text { 2.( ) Não }\end{array}$ & $\begin{array}{l}\text { 1. ( ) Não usei } \\
\text { 2.( ) Menos que } 1 \text { vez por semana } \\
\text { 3. ( ) } 1 \text { ou mais vezes por semana } \\
\text { 4. ( ) Diariamente } \\
\text { 5. ( ) Duas ou três vezes por dia } \\
\text { 6.( ) Quatro ou mais vezes por dia }\end{array}$ \\
\hline $\begin{array}{l}\text { 54. TRANQUILIZANTES, } \\
\text { ANSIOLITICOS E } \\
\text { ANTIDISTÔNICOS } \\
\text { (Diazepan, Diempax, } \\
\text { Valium, Librium, Lorax, } \\
\text { Rohypnol, Somalium, } \\
\text { Lexotan, Dormonid, } \\
\text { Rivotril, Frontal) } \\
\text { 1. ( ) Sim } \\
\text { 2. ( ) Não }\end{array}$ & $\begin{array}{l}\text { 1. ( ) Sim } \\
\text { 2.( ) Não }\end{array}$ & $\begin{array}{l}\text { 1. ( ) Não usei } \\
\text { 2.( ) Menos que } 1 \text { vez por semana } \\
\text { 3. ( ) } 1 \text { ou mais vezes por semana } \\
\text { 4. ( ) Diariamente } \\
\text { 5. ( ) Duas ou três vezes por dia } \\
\text { 6. ( ) Quatro ou mais vezes por dia }\end{array}$ \\
\hline
\end{tabular}




\begin{tabular}{|c|c|c|}
\hline $\begin{array}{l}\text { PADRÃO DE USO: } \\
\text { Você já experimentou } \\
\text { (nome da droga) sem } \\
\text { orientação de médico ou } \\
\text { outro profissional? }\end{array}$ & $\begin{array}{l}\text { USO RECENTE: } \\
\text { Usou esta droga } \\
\text { nos últimos } 12 \\
\text { meses? }\end{array}$ & $\begin{array}{l}\text { FREQÜENCIA: } \\
\text { Com que freqüencia utilizou está } \\
\text { droga nos últimos } 30 \text { dias } ?\end{array}$ \\
\hline $\begin{array}{l}\text { 55. OPIÁCEOS } \\
\text { (Dolatina, Meperioidina, } \\
\text { Demerol, Alfagan, Heroína, } \\
\text { Morfina, Ópio ou } \\
\text { Medicamentos a base de } \\
\text { codeína) } \\
\text { 1. ( ) Sim } \\
\text { 2. ( ) Não }\end{array}$ & $\begin{array}{l}\text { 1. () Sim } \\
\text { 2.( ) Não }\end{array}$ & $\begin{array}{l}\text { 1. ( ) Não usei } \\
\text { 2.( ) Menos que } 1 \text { vez por semana } \\
\text { 3. ( ) } 1 \text { ou mais vezes por semana } \\
\text { 4. ( ) Diariamente } \\
\text { 5. ( ) Duas ou três vezes por dia } \\
\text { 6.( ) Quatro ou mais vezes por dia }\end{array}$ \\
\hline 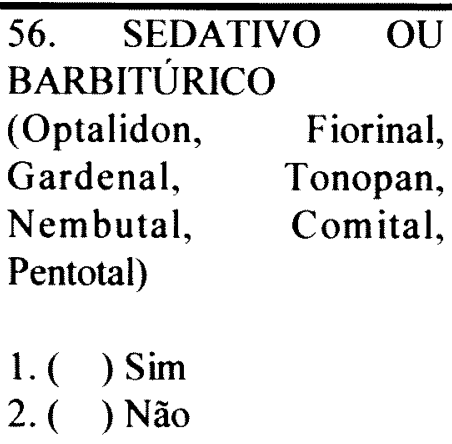 & $\begin{array}{l}\text { 1. ( ) Sim } \\
\text { 2. ( ) Não }\end{array}$ & $\begin{array}{l}\text { 1. ( ) Não usei } \\
\text { 2.( ) Menos que } 1 \text { vez por semana } \\
\text { 3. ( ) } 1 \text { ou mais vezes por semana } \\
\text { 4. ( ) Diariamente } \\
\text { 5. ( ) Duas ou três vezes por dia } \\
\text { 6. ( ) Quatro ou mais vezes por dia }\end{array}$ \\
\hline $\begin{array}{l}\text { 57. ANABOLIZANTES } \\
\text { OU ESTERÓIDES } \\
\text { (Cobactin, Deca-Durabolin, } \\
\text { Zinabol, Enzivital) } \\
\text { 1. ( ) Sim } \\
\text { 2. ( ) Não }\end{array}$ & $\begin{array}{l}\text { 1. () Sim } \\
\text { 2. ( ) Não }\end{array}$ & $\begin{array}{l}\text { 1. ( ) Não usei } \\
\text { 2. ( ) Menos que } 1 \text { vez por semana } \\
\text { 3. ( ) } 1 \text { ou mais vezes por semana } \\
\text { 4. ( ) Diariamente } \\
\text { 5. ( ) Duas ou três vezes por dia } \\
\text { 6. ( ) Quatro ou mais vezes por dia }\end{array}$ \\
\hline $\begin{array}{l}\text { 58. OUTRAS DROGAS } \\
\text { (Periatim, Periavita, } \\
\text { Cobavital, Buclina, } \\
\text { Vibazina, Apetivit, Profol, } \\
\text { Nutrimaiz, Holoten, } \\
\text { Carpinol, Medavane) } \\
\text { 1. ( ) Sim } \\
\text { 2. ( ) Não }\end{array}$ & $\begin{array}{l}\text { 1. ( ) Sim } \\
\text { 2. ( ) Não }\end{array}$ & $\begin{array}{l}\text { 1. ( ) Não usei } \\
\text { 2.( ) Menos que } 1 \text { vez por semana } \\
\text { 3. ( ) } 1 \text { ou mais vezes por semana } \\
\text { 4. ( ) Diariamente } \\
\text { 5. ( ) Duas ou três vezes por dia } \\
\text { 6. ( ) Quatro ou mais vezes por dia }\end{array}$ \\
\hline
\end{tabular}


\&<59. Qual foi o principal motivo que o levou a fazer uso de drogas (exceto álcool e tabaco) pela primeira vez?
1. ( ) Não usei
2. ( ) Prática religiosa
3. ( ) Para me relacionar melhor com outras pessoas
4. ( ) Diversão ou prazer
5. ( ) Porque meus amigos/namorada(o) usam
6. ( ) Para aumentar o desempenho sexual
7. ( ) Por curiosidade
8. ( ) Alívio de tensão psicológica
9. ( ) Alívio de cansaço, fome, frio, dor
10. ( ) Aumentar o desempenho no estudo
11. ( ) Outra

$\$<60$. Quem introduziu você neste uso de drogas (exceto álcool e tabaco)?
1. ( ) Não fiz uso
2. ( ) Família
3. ( ) Colegas de faculdade/amigos
4. ( ) Conhecidos
5. ( ) Amigos
6. ( ) Namorado(a)/companheiro
7. ( ) Profissionais de saúde
9. ( ) Outra

61. Você experimentou drogas (exceto álcool e tabaco) antes de entrar na universidade ?

1.( ) $\mathrm{Sim}$

2. ( ) Não

$\$<62$. Se você respondeu sim à questão anterior, assinale as substâncias que você experimentou antes de entrar na universidade (é possível assinalar mais de uma alternativa)

1. ( ) Maconha

2. ( ) Alucinógenos ( LSD, mescalina, etc.)

3. ( ) Cocaína (exceto crack)

4. ( ) Crack

5. ( ) Anfetamina (Hipofagin, Moderex, Preludin, etc.)

6. ( ) Anti-colinérgico (Artane, chá de lírio, etc.)

7. ( ) Solventes (Lança-perfume, cola, etc.)

8. ( ) Tranquilizantes (Diazepan, Valium, etc.)

9. ( ) Opiáceos (Heroína, morfina)

10. ( ) Sedativo ou barbitúrico (Optalidon, Gardenal, etc.)

11. ( ) Outras 
$3<63$. Se você faz uso freqüente de drogas, exceto tabaco (no caso do álcool, no mínimo 3 vezes por semana, o equivalente a 5 chopps ou 5 doses de whisky e no mínimo uma vez por semana no caso das outras drogas), qual o motivo deste uso?

1. ( ) Não faço

2. ( ) Para participar do grupo de amigos, colegas da faculdade

3. ( ) Para quebrar a rotina

4. ( ) Para curtir os efeitos da droga

5. ( ) Para diminuir ansiedade/nervosismo ou aliviar o estresse

6. ( ) Para aliviar ou evitar sintomas de abstinência

7. ( ) Para cortar os efeitos de outras drogas

$8<64$. Se você faz uso freqüente de drogas, exceto tabaco (no caso do álcool, no mínimo 3 vezes por semana, o equivalente a 5 chopps ou 5 doses de whisky e no mínimo uma vez por semana no caso das outras drogas), com quem faz este uso?

1. ( ) Sozinho

2. ( ) Com amigos/colegas de faculdade

3. ( ) Com irmãos, primos, outros familiares

4. ( ) Com estranhos

5. ( ) Outros

$8<65$. Se você faz uso freqüente de drogas, exceto tabaco (no caso do álcool, no mínimo 3 vezes por semana, o equivalente a 5 chopps ou 5 doses de whisky e no mínimo uma vez por semana no caso das outras drogas), você acha que este uso interfere: (é possivel assinalar mais de uma alternativa)

1. ( ) Na alimentação

2. ( ) No sono

3. ( ) No estudo

4. ( ) No desempenho sexual

5. ( ) No trabalho

6. ( ) Nas relações sociais/afetivas

7. ( ) Outros

8. ( ) Não interfere

66. Nos últimos 12 anos você esteve envolvido em um acidente de carro, depois de ter usado qualquer quantidade de álcool ou drogas?

1. ( ) Sim

2. ( ) Não

67. Considerando os últimos 12 meses, algum membro de sua família bebeu ao ponto de causar problemas em casa, no trabalho ou com amigos?

1. ( ) Sim

2. ( ) Não 
68. Assinale quais dessas pessoas fazem uso não médico e freqüente (no caso do álcool, no mínimo 3 vezes por semana, o equivalente a 5 chopps ou 5 doses de whisky e no mínimo uma vez por semana no caso das outras drogas) das substâncias abaixo relacionadas (é possível assinalar mais de uma alternativa):

\begin{tabular}{|c|c|c|c|c|c|c|}
\hline & & a)pai & b)mãe & c)irmãos & d)amigos & e)nenhum deles \\
\hline 1 & $\overline{A ́ L C O O L}$ & & () & $(\quad)$ & $(\quad)$ & $(\quad)$ \\
\hline 2 & ANFETAMINA & $(5)$ & $(\mathrm{C})$ & $(\mathrm{C})$ & $(\mathrm{C})$ & $(\mathrm{C})$ \\
\hline 3 & COCAÍNA & & () & () & $(\quad)$ & () \\
\hline 4 & CRACK & & () & $(\quad)$ & $(\quad)$ & () \\
\hline 5 & INALANTE & () & () & () & $(1)$ & () \\
\hline 6 & MACONHA & () & () & () & () & () \\
\hline 7 & TRANQUILIZANTE & () & () & () & () & () \\
\hline
\end{tabular}

$8<69$. Você recebeu carta convite para participar da pesquisa através do(a):

1. ( ) Correio

2. ( ) Secretaria

3. ( ) Ambos

$\$<70$. Indique se você teve acesso a algum material informativo sobre a pesquisa, antes de receber a carta convite:

1. ( ) Não

2. ( ) Sim. Quais: ( ) Cartaz

( ) Faixa

( ) Folder

( ) Rádio USP

( ) Jornal USP

$\& 71$. Se você teve acesso a algum material informativo, este fez com que você pensasse sobre o tema drogas?

1. ( ) Sim

2. ( ) Não 


\begin{tabular}{|c|c|c|}
\hline ÁREA & UNIDADE & $\begin{array}{c}\text { SIGL } \\
\text { A }\end{array}$ \\
\hline \multirow{6}{*}{ HUMANAS } & Escola de Comunicações e Artes & $\mathrm{ECA}$ \\
\hline & Faculdade de Arquitetura e Urbanismo & FAU \\
\hline & Faculdade de Direito & FD \\
\hline & Faculdade de Economia, Administração e Contabilidade & FEA \\
\hline & Faculdade de Educação & $\mathrm{FE}$ \\
\hline & Faculdade de Filosofia, Letras e Ciências Humanas & $\begin{array}{c}\text { FFLC } \\
\mathrm{H}\end{array}$ \\
\hline \multirow{6}{*}{ EXATAS } & Escola Politécnica & EP \\
\hline & Instituto Agronômico e Geofísico & IAG \\
\hline & Instituto de Física & IF \\
\hline & Instituto de Geociências & IGc \\
\hline & Instituto de Matemática e Estatística & IME \\
\hline & Instituto de Química & IQ \\
\hline \multirow{9}{*}{ BIOLÓGICAS } & Escola de Educação Física e Esporte & EEF \\
\hline & Escola de Enfermagem & $\mathrm{EF}$ \\
\hline & Faculdade de Ciências Farmacêuticas & FCF \\
\hline & Faculdade de Medicina & FM \\
\hline & Faculdade de Medicina Veterinária e Zootecnia & $\begin{array}{c}\text { FMV } \\
\text { Z }\end{array}$ \\
\hline & Faculdade de Odontologia & FO \\
\hline & Faculdade de Saúde Pública & FSP \\
\hline & Instituto de Biociências & IB \\
\hline & Instituto de Psicologia & IP \\
\hline
\end{tabular}


ANEXO 4 


\section{USO DE ÁLCOOL E DROGAS EM ALUNOS DE GRADUAÇÃO DA UNIVERSIDADE DE SÃO PAULO (1996) '}

Arthur Guerra de Andrade ${ }^{2}$, Sueli de Queiroz ${ }^{2}$, Roberto C. M. Villaboim ${ }^{2}$, Chester L. G. Cesar ${ }^{3}$, Maria Cecilia G. P. Alves ${ }^{4}$, Ana Z. Bassit ${ }^{2}$, Valentim Gentil ${ }^{5}$,Arnaldo A. F. Siqueira ${ }^{3}$, Erasmo M. C. Tolosa ${ }^{6}$.

\section{RESUMO}

Este trabalho apresenta dados sobre o uso de álcool e drogas entre alunos de graduação da Universidade de São Paulo (USP), quanto ao uso na vida, nos últimos 12 meses e últimos 30 dias. A pesquisa foi realizada de janeiro a dezembro de 1996, por meio de amostragem probabilística, tendo sido pesquisados 2.564 alunos. Foi utilizado para coleta de dados questionário anônimo de auto-preenchimento. Foram estimadas prevalências de uso de álcool e drogas nas áreas de ciências Humanas, Biológicas e Exatas, segundo sexo, período de freqüência ao curso, ano de ingresso na universidade e moradia.

Constatou-se que a droga mais usada alguma vez na vida foi o álcool $(90,1 \%)$ seguido de tabaco $(43,3 \%)$, maconha $(30,6 \%)$, solventes $(18,2 \%)$ e cocaína $(7,1 \%)$.

O sexo masculino foi predominante no uso de drogas em relação ao feminino, assim como o fato de morar sem a familia; o período noturno apresentou maior uso de drogas que o diurno.

\section{USE OF ALCOHOL AND DRUG IN UNDERGRADUATE STUDENTS OF THE UNIVERSITY OF SÃO PAULO (1996).}

\section{SUMMARY}

This paper presents data about drug and alcohol use in undergraduate students of the University of São Paulo, Brazil. Data was analysed on lifetime, last 12-month and last 30-days use. The study was carried out from January to December, 1996, through a random sample. The overall response rate was $80 \%$ ( $n=$ $2,564)$. The instrument used was an anonymous self-completed questionnaire. The sample was stratified in three areas: Human Sciences, Biological Sciences and Exact Sciences. The areas were analysed by gender, period of class frequency, entrance year at the university and conditions of living.

The lifetime prevalence rate was: alcohol $(90.1 \%)$, tobacco $(43.3 \%)$, marijuana $(30.6 \%)$, inhalants $(18.2 \%)$ and cocaine $(7.1 \%)$. Males were more likely to use drugs than females. It was also found out that living without family and to study at night have a positive association with drug use.

Palavras-chaves: Prevenção de drogas; Uso de drogas; Estudantes universitários

Key-words: Drug Prevention; Drug use; University students

1. Trabalho realizado pelo GREA - Grupo Interdisciplinar de Estudos de Álcool e Drogas, Instituto de Psiquiatria do Hospital das Clínicas, Faculdade de Medicina da Universidade de São Paulo (FAPESP 95/3310-0).

2. GREA

3. Faculdade de Saúde Pública - USP

4. Secretaria de Saúde do Estado de São Paulo

5. Departamento de Psiquiatria - FMUSP

6. Hospital Universitário - USP 
INTRODUÇÃO

A prevalência do uso de drogas tem sido crescente em todos os lugares do mundo (KESSLER e col., 1994). Problemas derivados deste uso vão desde a criminalidade associada ao tráfico e uso de substâncias ilícitas, passando pelo abuso (uso inadequado) de psicofármacos - que podem resultar até em quadros de dependência - e terminando com o abuso e dependência de substâncias lícitas e de fácil acesso para consumo, como, por exemplo, o álcool e o tabaco.

A abordagem científica deste problema contempla: 1) estudos epidemiológicos entre estudantes e na população geral; 2) sistemas de coleta de informações sobre populações que procuram estabelecimentos de saúde com problemas relacionados ao abuso de drogas; 3 ) índices de morbidade e mortalidade diretamente relacionados ao consumo de drogas (CARLINI-COTRIM e BARBOSA, 1993). É a partir destes dados coletados de forma sistemática que se pode ter uma visão mais clara do problema, possibilitando intervenções mais racionais e eficientes. Os diferentes aspectos, como interesses econômicos, políticos, jurídicos e sociais impedem conclusões simplistas.

No Brasil, nos últimos anos, foram realizados estudos epidemiológicos sobre o assunto, principalmente na população estudantil (CARLINI-COTRIM e col., 1989; CARLINI e col., 1990; GALDURÓZ e col., 1994).

A importância da iniciativa de se realizar pesquisa com jovens se dá pela observação, através de estudos do consumo de drogas nas diversas faixas etárias, de que a juventude é a parcela da população que está mais vulnerável ao uso de drogas, principalmente pelas características próprias da idade (PIMONT e BARRERA, 1982). Estudos demonstram que, nesta faixa etária, ocorrem um maior número de alterações comportamentais e problemas psicológicos, quando do uso de drogas (KANDEL e col., 1992). Além do que, quanto mais cedo as pessoas com problemas de drogas são assistidas, menor é o custo social e maior é a possibilidade de que esta intervenção seja eficaz (HOLDER e BLOSE, 1986).

Seguindo modelo de estudos epidemiológicos nacionais sobre drogas em jovens brasileiros, ANDRADE e col. $(1995 ; 1996)$ realizaram atividades de pesquisa nesta área com estudantes de medicina tanto da Universidade de São Paulo como de outras 8 escolas médicas do Estado de São Paulo, de 1991 a 
1995. O objetivo destas pesquisas foi contribuir para um melhor entendimento do problema de drogas nesta população, inclusive do uso não médico de substâncias psicoativas, com o fim de elaborar um programa de prevenção ao uso e abuso de drogas. Esta atividade inicial, diagnóstica, seria segundo BUCHER (1992) a melhor estratégia para desenvolver programas de prevenção de drogas e, desta forma, diminuir o uso de drogas em uma dada população.

Os resultados encontrados nestas pesquisas indicam alta prevalência do uso esporádico de drogas, confirmando os resultados encontrados por CARLINI e col. (1990), com estudantes de 1o. e 20. graus e MAGALHÃES e col. (1991) com estudantes universitários da cidade de São Paulo. Revelando também que o uso de álcool, maconha, inalantes e tranqüilizantes é maior nos estudantes que cursam os últimos anos do curso médico, e sugerindo que algumas caracteristicas do curso podem estar favorecendo o maior uso de drogas.

Neste sentido, o objetivo desta pesquisa é diagnosticar o padrão de uso de drogas dos alunos de graduação da USP para elaborar um programa de prevenção de drogas dirigido a estes alunos.

Após a consolidação de um programa com estas caracteristicas, pretende-se, caso a avaliação seja positiva, estender e adaptar programa semelhante para outras populações pertencentes à USP: funcionários, professores e alunos de outros campi.

\section{MATERIAL E MÉTODOS}

A pesquisa teve como população alvo todos os alunos de graduação da USP, matriculados na cidade de São Paulo, no ano de 1996.

Foi inicialmente realizado um Estudo Piloto por 3 meses (janeiro a março de 1996), com os seguintes objetivos:

1) Avaliar o instrumento de pesquisa (questionário de auto-preenchimento).

2) Ajustar o desenho geral do projeto de pesquisa para as peculiaridades do local específico, Universidade de São Paulo. Neste sentido, precauções tais como local e horários viáveis de preenchimento dos 
questionários, forma de abordagem dos alunos, padronização de informaç̃es e esclarecimentos, dentre outros, foram redimensionados.

O instrumento usado foi um questionário anônimo e de auto-preenchimento, elaborado com base no proposto pela OMS (SMART,1980), com o objetivo de diagnosticar o padrão de uso na vida, nos últimos 12 meses e nos últimos 30 dias $^{8}$ das seguintes substâncias: álcool, tabaco, maconha, alucinógenos, cocaína, anfetaminas, anticolinérgicos, tranqüilizantes, ansiolíticos, antidistônicos, opiáceos, sedativos, barbitúricos e anabolizantes. Para se obter um maior controle sobre a veracidade das respostas, foi também incluída uma questão com nomes falsos de drogas, que quando respondida afirmativamente, anulava todo o questionário. O questionário teve por objetivo medir o uso de drogas, mas não diagnosticar quadros clínicos, tais como abuso ou dependência de álcool e/ou drogas. Além das questões referentes ao uso de drogas, o questionário também contemplou questões sobre atitudes frente ao uso experimental e regular de substâncias psicoativas, objeto de outra investigação no mesmo projeto. Considerando-se a natureza do assunto, especialmente no que se refere ao uso de drogas, foi de grande importância a garantia de anonimato dos participantes, fato que solicitou auxiliares de pesquisa treinados e habilitados para eventuais esclarecimentos e procedimentos que estimulassem a confiança dos alunos.

Os alunos foram sorteados utilizando amostragem estratificada, com partilha igual. As áreas de estudos em que a USP é dividida, a nível de ensino (Humanas, Exatas e Biológicas) constituíram domínios de estudo, uma vez que se considerou necessário estimar as proporções de interesse em cada uma delas, separadamente. Os alunos foram, ainda, divididos em sub-classes segundo as variáveis: sexo (masculino e feminino), moradia (com família e sem família), período do curso (diurno e noturno) e ano de ingresso na universidade (até 1990; 1991 a 1993 e 1994 a 1996).

Considerando-se o erro de amostragem tolerado (5\%), o nível de confiança fixado (95\%), a proporção a ser obtida (50\%), a divisão da população em sub-classes (37\%, a menor delas) e a ausência de resposta esperada (20\%), estimou-se em 3.539 o número de alunos a serem entrevistados. O número total de alunos de graduação da USP na cidade de São Paulo em 1996 foi de 29.305. Os alunos,

${ }^{8}$ Metodologia habitual nos atuais estudos quantitativos sobre uso de drogas. 
ordenados por unidade, foram selecionados por sorteio sistemático, obtendo-se os números descritos na tabela 1. Desses sorteados, 336 foram excluídos como não pertencentes à amostra (alunos jả formados ou não matriculados), reduzindo a amostra a 3.203 alunos.

A coleta de dados foi realizada de abril a outubro de 1996. Os alunos sorteados foram convidados a responder o questionário, através de carta-convite informando sobre os diferentes dias, horários e locais disponiveis dentro da USP, para o preenchimento do questionário. O tempo médio de auto-preenchimento foi de 20 minutos e, após o término, os questionários foram depositados, pelos próprios alunos, em urnas fechadas. O comparecimento espontâneo após o primeiro convite foi de $22 \%$ do total da amostra. Para que esse percentual atingisse $80 \%$ - fixado como limite mínimo aceitável para o estudo - houve necessidade de outros convites e de outras formas de aproximação com os alunos, ficando evidente a dificuldade em lidar com assuntos delicados como uso de álcool e drogas em pesquisa epidemiológica.

Com a intenção de condensar os dados, as substâncias pesquisadas foram divididas em quatro categorias: álcool, tabaco, “drogas" (incluíndo todas as substâncias psicoativas investigadas no questionário, exceto álcool e tabaco) e cocaína. A opção de estudar cocaína como uma substância psicoativa à parte das "drogas" refere-se à suposição de um aumento da oferta de cocaína em São Paulo, tanto na forma de cocaína pura como na de "crack".

Foi feita análise de variância para testar igualdade entre as proporções estimadas e as diferenças foram identificadas pelo teste de Tuckey. Diferenças entre proporções que envolviam somente dois grupos foram verificadas pelo teste de Chi-quadrado. Os intervalos de confiança foram estimados ao nível de $95 \%$, considerando no cálculo das proporções e suas variâncias, ponderações que diminuíssem o efeito da ausência de resposta, além daquelas referentes à estratificação. 
RESULTADOS

Os resultados foram obtidos a partir dos 2.564 questionários respondidos, total que corresponde a $80 \%$ da amostra $(n=3.203)$. Deste total foram anulados 58 questionários $(18 \%)$ sendo 24 questionários respondidos por alunos que não faziam parte da amostra e 34 por responderem sim à questão com nomes falsos de drogas (vide material e métodos).

Encontrou-se um perfil de alunos que corresponde a idade entre 20 e 24 anos $(60 \%)$, solteiro (91\%), morando com a familia $(81 \%)$, com religião $(72 \%)$, porém não praticante $(61 \%)$.

O álcool é a droga mais usada pelos alunos da USP, sendo que quase todos os alunos $(90,1 \%)$ o experimentaram na vida, 80,9\% nos últimos 12 meses e 74,1\% nos últimos 30 dias (tabela 2).

Segue, por ordem de freqüência, o tabaco, que foi utilizado na vida por quase metade dos alunos $(43,3 \%)$ e por $23,5 \%$ nos últimos 30 dias.

A utilização na vida de "drogas", categoria que engloba todas as substâncias psicoativas investigadas no questionário, com exceção de álcool e tabaco, foi citada por $38,1 \%$ dos alunos pesquisados. Esse percentual diminue para $23,6 \%$ nos últimos 12 meses e $18,9 \%$ nos últimos 30 dias.

Cocaína, embora incluída no grupo "drogas", foi também avaliada em separado apresentando percentuais de 7,1; 3,2 e 1,7 de uso na vida, nos últimos 12 meses e últimos 30 dias, respectivamente.

A prevalência do uso de drogas e álcool não ocorre sempre de forma homogênea entre as áreas de Humanas, Biológicas e Exatas (tabela 2), o que determinou que os dados fossem apresentados separadamente para as três áreas. A presença do asterisco no total da tabela 2 , indica a existência de diferenças estatisticamente significantes entre as proporções.

$\mathrm{Na}$ área de Exatas, menor proporção de alunos refere uso de "drogas" em qualquer das modalidades (na vida, últimos 12 meses, últimos 30 dias); para tabaco o uso é maior na área de Biológicas. Para álcool, os percentuais são mais próximos, tendo sido identificada somente diferenças no uso na vida, com menor porcentagem na área de Humanas. Quanto ao uso de cocaína, não puderam ser identificadas diferenças entre as áreas de estudo.

Quando comparado o uso de substâncias psicoativas nos dois períodos de freqüência ao curso, diurno (que engloba os períodos matutino, vespertino e integral) e noturno (tabela 3), observa-se que há 
menos uso na vida de "drogas" no primeiro deles, e essa diferença é percebida também no uso de cocaína. No entanto, o uso mais frequênte (últimos 12 meses e últimos 30 dias) não difere nos dois grupos, o mesmo ocorrendo para o uso de tabaco e álcool.

Observa-se, tanto em relação à variável período do curso, como nas outras variáveis, que as diferenças constatadas no total, nem sempre estão presentes em todas as áreas de estudo. Como exemplo, o uso de "drogas" nos últimos 12 meses difere, em relação ao período do curso, nas áreas de Humanas e Exatas e não na área de Biológicas.

Em relação à variável sexo (tabela 4), observa-se que referências ao uso são sempre mais freqüentes entre alunos do sexo masculino. Com respostas afirmativas quanto ao uso de "drogas" na vida, nos últimos 12 meses e últimos 30 dias, nessa ordem, foram estimados $42,0 \%, 29,7 \%$ e $20,2 \%$ de alunos do sexo masculino e percentuais menores, $33,7 \%, 22,0 \%$ e $17,7 \%$ de alunas. As diferenças foram maiores para os homens quando se referem ao uso de cocaína e, conseqüentemente, ao de "drogas", em comparação ao uso de tabaco e álcool. Vale salientar que, em relação ao uso de "drogas" e cocaína, diferenças relacionadas ao sexo não foram identificadas na área de Humanas, neste estudo.

O uso na vida e nos últimos 12 meses de tabaco, "drogas" e cocaína é maior para os alunos que moram sem a família (tabela 5). Para o álcool esta diferença ocorre apenas com os alunos que referem uso mais recente (últimos 30 dias). Nota-se um uso significativamente maior de tabaco, "drogas" e cocaina nos alunos que moram sem a família nas áreas de Humanas e Exatas.

Quanto à variável ano de ingresso na universidade (tabela 6) não se observou nenhuma tendência nas três faixas. No geral, para o tabaco aparece uma diferença entre os alunos que entraram na escola nos anos de 1994 a 1996 em relação aos que entraram na escola de 1991 a 1993, com uso maior pelos alunos mais velhos. Isto é observado para o uso na vida, nos últimos 12 meses e nos últimos 30 dias. Os alunos dos primeiros anos da área de Biológicas e Exatas usaram menos álcool no último ano e nos últimos 30 dias.

Dentre os alunos que ingressaram na USP até 1990 - ultrapassando portanto o tempo normal dos cursos - os da área de Biológicas fazem um uso na vida e nos últimos 12 meses de cocaína 
significativamente maior que os outros. Na área de Biológicas, o uso na vida e nos últimos 12 meses de "drogas", aparece com uma tendência de aumento com o tempo de permanência na universidade.

Objetivando identificar a existência de associação entre o uso de maconha e a utilização de outras drogas, foram estimados os percentuais de alunos que utilizaram na vida outras drogas dentre os que já usaram maconha e entre os que não o fizeram (tabela 7). Observou-se que entre os que referem uso na vida, $57,3 \%$ experimentaram também outra droga, sendo que esse percentual diminui para $10,6 \%$ entre os que nunca experimentaram maconha.

\section{DISCUSSÃO}

O uso de drogas entre estudantes universitários da USP é preocupante, especialmente quando os dados obtidos neste sentido são comparados com estudos em universitários de outras escolas e mesmo em estudantes de 10. e 2o. graus. Estudantes universitários são considerados grupo especial de investimento científico no país, particularmente devido às funções que deverão exercer na sociedade, em futuro próximo.

Desta forma, quando comparamos uso de drogas na vida, nos últimos 12 meses e últimos 30 dias entre estudantes da USP e estudantes de medicina de 9 escolas do Estado de São Paulo (ANDRADE, 1996), usando a mesma metodologia, temos que (tabela 8) em relação ao uso mais freqüente de álcool (últimos 30 dias) os alunos da USP (inclusive medicina) fazem um uso 1,5 vezes maior que os estudantes das escolas médicas. Uma das possibilidades para se entender esta complexa questão seria a facilidade de acesso ao álcool pelos estudantes da USP, visto que a oferta de bebidas alcoólicas em ambientes universitários de outras áreas que não da saúde é maior que, por exemplo em ambientes hospitalares. $\mathrm{O}$ uso de tabaco nos últimos 30 dias pelos estudantes da USP é mais de 2 vezes maior que nos estudantes das escolas médicas. Quanto à maconha, é muito menor o número de alunos USP que no mínimo já experimentaram a droga, mas a diferença de uso de maconha entre os alunos da USP e estudantes de Medicina de 9 escolas é maior quando o uso desta substância é mais freqüente (últimos 12 meses e últimos 30 dias). 
É válido lembrar que a descrição quantitativa do uso de drogas em uma população específica, como apresentado e discutido neste artigo, não reflete, per se, o comportamento geral do grupo estudado. Complementar e tão importante quanto a mensuração do uso de drogas é o estudo qualitativo onde são estudadas variáveis como atitudes, crenças e conhecimento sobre o tema. Como já pontuado anteriormente, este será objeto de estudo/publicação seqüencial a este artigo.

Por ser o problema de uso de drogas complexo, sujeito a modificações rápidas e multifacetado, com abordagens ligadas ao campo da saúde, da justiça, da educação, da economia, dentre outras, é importante que se leve em conta as limitações dos resultados encontrados. No campo de uso de drogas ilícitas a informação obtida deve ser filtrada e criticada.

O ponto mais importante deste artigo, entretanto, é a identificação de sub-grupos com maior uso de drogas, pelas variáveis áreas de estudo, sexo, moradia, periodo do curso e ano de ingresso, além do tipo de droga, visando a adequação de mensagens específicas, no que se refere à elaboração de um programa de prevenção de drogas para os alunos.

Desta forma, respeitando-se a limitação de recursos existentes, poderíamos inicialmente concentrar os esforços de um programa de prevenção de drogas para os alunos da USP para uma população que especialmente possua o seguinte perfil:

- Alunos de Humanas, usando álcool, outras drogas, inclusive cocaína, sexo masculino, estudando no periodo noturno e morando sem a família.

- Alunos de Biológicas, usando tabaco, sexo masculino, período noturno, morando sem a família.

- Alunos de Exatas, sem uso de alguma droga em especial, sexo masculino, período diurno, morando sem a familia.

Evidentemente que esta sugestão de abordagem se refere aos alunos que já estão usando drogas. Também seria válido a hipótese de que um programa de prevenção de drogas poderia ser oferecido para aqueles que não fazem uso de drogas ou o fazem em pequenas quantidades no momento e que talvez possam vir a modificar esse uso, para maior uso no futuro, como, por exemplo, alunas (sexo feminino), que moram com a família, estudando no período diurno. 
Os dados obtidos nesta investigação referem-se, obviamente, aos alunos que responderam o questionário; 639 alunos (20\% da amostra selecionada), por algum motivo não responderam o questionário ("non-respondents"). É possivel que essa sub-amostra tenha comprometimento diferente com o uso de drogas. Este tipo de informação seria essencial para um eficaz programa de prevenção de drogas entre os alunos da USP. A metodologia usada para acessar os $80 \%$ da amostra que respondeu o questionário não é adequada para acessar os "non-respondents". 


\section{REFERÊNCIAS BIBLIOGRÁFICAS}

1. ANDRADE, A.G.; BASSIT, A.Z.; MESQUITA, A.M. e col. (1995). "Prevalência do uso de drogas entre alunos da Faculdade de Medicina da Universidade de São Paulo". Revista ABP-APAL 17(2): 41-46.

2. ANDRADE, A.G.; BASSIT, A.Z.; KERR-CORRÊA, F. e col. (1996). "Fatores de risco associados ao uso de álcool e drogas na vida, entre estudantes de medicina do Estado de São Paulo". Revista ABPAPAL. Submetido à apreciação.

3. BUCHER, R. (1992). "Drogas e Drogadição no Brasil". Artes Médicas, Porto Alegre.

4. CARLINI-COTRIM, B.; SILVA-FILHO, A.R.; BARBOSA, M.T.S. e col. (1989). "O abuso de drogas por estudantes de 1o. e 2o. graus da rede estadual em dez capitais, em 1987. Em: Consumo de drogas psicotrópicas no Brasil em 1987. Ministério da Saúde e Ministério da Justiça, Brasília.

5. CARLINI-COTRIM, B. e BARBOSA, M.T.S. (1993). "Pesquisas epidemiológicas sobre o uso de drogas entre estudantes: um manual de orientações gerais". Centro Brasileiro de Informações sobre Drogas Psicotrópicas (CEBRID). Departamento de Psicobiologia da Escola Paulista de Medicina.

6. CARLINI, E.A.; CARLINI-COTRIN, B.; SILVA-FILHO, A.R. e col. (1990). "II Levantamento nacional sobre o uso de psicotrópicos em estudantes de 1o. e 2o. graus, 1989". Centro Brasileiro de Informações sobre Drogas Psicotrópicas (CEBRID). Departamento de Psicobiologia da Escola Paulista de Medicina.

7. GALDURÓZ, J.C.F.; D'ALMEIDA, V.; CARVALHO, V. e col. (1994). "III Levantamento sobre uso de drogas entre estudantes de 1o. e 20. graus em dez capitais brasileiras - 1993", Centro Brasileiro de Informações sobre Drogas Psicotrópicas (CEBRID). Departamento de Psicobiologia da Escola Paulista de Medicina.

8. HOLDER, H.D. e BLOSE, J.O. (1986). Alcoholism treatment and total health care utilization and costs. Journal of the American Medical Association, 256:1456-1460.

9. KANDEL, D.B.; YAMAGUCHI, K.; CHEN, K. (1992). "Stages of progression in drug involvement from adolescent to adulthood: further evidence for the gateway theory. Journal of Studies on Alcohol, $53: 447-457$.

10. KESSLER, R.C.; Mc GONAGLE, K.A.; ZHAO, S. e col. (1994). "Lifetime and 12-month prevalence of DSM-III-R Psychiatric Disorders in the United States". Arch Gen Psychiatry, 51:8-19.

11. MAGALHÃES, M.P.; BARROS, R.S.; SILVA, M.T.A. (1991). "Uso de drogas entre universitários: a experiência com maconha como fator delimitante". Revista ABP-APAL 13(3):97-104.

12. PIMONT, R.P; BARRERA, L. (1982). “O universitário brasileiro frente ao problema dos tóxicos". Ciência e Cultura, 14(10): 1279-1285.

13. SMART, R.G.; HUGLES, P.H.; JOHNSTORN, L.D. e col. (1980). "A methodology for student drug-use surverys". WHO Offset Publication, Genebra. 
TABELA 1 - Distribuição do número de alunos sorteados por área/unidade USP, 1996

ÁREA UNIDADE

HUMANAS

Escola de Comunicação e Arte (ECA)

Faculdade de Arquitetura e Urbanismo (FAU)

Faculdade de Direito (FD)

Faculdade de Economia, Administração e Contabilidade (FEA)

Faculdade de Educação (FE)

Faculdade de Filosofia, Letras e Ciências Humanas (FFLCH)

Sub-total

Escola Politécnica (EP)

Instituto Agronômico e Geofísico (IAG)

Instituto de Física (IF)

Instituto de Geociência (IGc)

Instituto de Matemática e Estatística (IME)

Instituto de Química (IQ)

Sub-total

Escola de Educação Física (EEF)

Escola de Enfermagem (EE)

Faculdade de Ciência Farmacêutica (FCF)

Faculdade de Medicina (FM)

Faculdade de Medicina e Veterinária e Zootecnia (FMVZ)

Faculdade de Odontologia (FO)

Faculdade de Saúde Pública (FSP)

Instituto de Biologia (IB)

Instituto de Psicologia (IP)

Sub-total

Total
NÚMERO DE

ALUNOS

SORTEADOS

97

170

224

184

495

1241

603

22

197

38

185

55

1198

105

79

179

317

94

168

30

145

81

1100

3539 
TABELA 2 - Uso de substâncias psicoativas em estudantes da USP, em relação às áreas de estudo, em 1996.

Dados em porcentagem, com intervalo de confiança de $95 \%(n=2.506)$.

\begin{tabular}{|c|c|c|c|c|c|c|c|}
\hline \multirow[t]{2}{*}{ Substância } & \multirow[t]{2}{*}{ Área } & \multicolumn{2}{|c|}{ Na vida } & \multicolumn{2}{|c|}{ Últimos 12 meses } & \multicolumn{2}{|c|}{ Últimos 30 dias } \\
\hline & & $\%$ & $\mathrm{IC}_{95 \%}$ & $\%$ & IC $_{95 \%}$ & $\%$ & IC $_{95 \%}$ \\
\hline \multirow[t]{4}{*}{ ÁlCOOL } & Humanas & 88.6 & {$[85,5 ; 91,7]$} & 80.4 & {$[76,7 ; 84,0]$} & 73.9 & {$[69,8 ; 77,9]$} \\
\hline & Biológicas & 93.3 & {$[91,8 ; 94,9]$} & 82.3 & {$[79,9 ; 84,7]$} & 75.2 & {$[72,5 ; 77,9]$} \\
\hline & Exatas & 92.6 & {$[90,8 ; 94,4]$} & 81.5 & {$[78,9 ; 84,2]$} & 74.3 & {$[71,3 ; 77,3]$} \\
\hline & Total & $90,1^{*}$ & {$[88,0 ; 92,1]$} & 80.9 & {$[78,4 ; 83,4]$} & 74.1 & {$[71,4 ; 76,9]$} \\
\hline \multirow[t]{4}{*}{ TABACO } & Humanas & 44 & {$[39,6 ; 48,4]$} & 25.2 & {$[21,2 ; 29,2]$} & 23.2 & {$[19,2 ; 27,2]$} \\
\hline & Biológicas & 45.3 & {$[42,2 ; 48,4]$} & 29.6 & {$[26,7 ; 32,5]$} & 26.9 & {$[24,0 ; 29,9]$} \\
\hline & Exatas & 40 & {$[36,6 ; 43,3]$} & 24.2 & {$[21,1 ; 27,2]$} & 22 & {$[19,0 ; 25,1]$} \\
\hline & Total & 43.3 & {$[40,3 ; 46,3]$} & $25,6^{*}$ & {$[22,9 ; 28,3]$} & $23,5^{*}$ & {$[20,8 ; 26,2]$} \\
\hline \multirow[t]{4}{*}{ 'DROGAS } & Humanas & 39.2 & {$[35,0 ; 43,5]$} & 27.1 & {$[23,1 ; 31,0]$} & 19.1 & {$[15,6 ; 22,6]$} \\
\hline & Biológicas & 41 & {$[38,0 ; 44,0]$} & 30.6 & {$[27,7 ; 33,4]$} & 22.6 & {$[20,0 ; 25,1]$} \\
\hline & Exatas & 32.8 & {$[29,7 ; 36,0]$} & 21 & {$[18,3 ; 23,8]$} & 15.8 & {$[13,4 ; 18,2]$} \\
\hline & Total & $38,1^{*}$ & {$[35,3 ; 41,0]$} & $26,3^{*}$ & {$[23,6 ; 28,9]$} & $18,9^{*}$ & {$[16,5 ; 21,3]$} \\
\hline \multirow[t]{4}{*}{ COCAÍNA } & Humanas & 7.8 & {$[5,3 ; 10,2]$} & 3.4 & {$[2,1 ; 4,8]$} & 1.7 & {$[0,7 ; 2,7]$} \\
\hline & Biológicas & 6.4 & {$[5,0 ; 8,0]$} & 3.2 & {$[2,1 ; 4,3]$} & 1.9 & {$[1,1 ; 2,8]$} \\
\hline & Exatas & 5.2 & {$[3,7 ; 6,6]$} & 2.7 & {$[1,7 ; 3,8]$} & 1.5 & {$[0,7 ; 2,3]$} \\
\hline & Total & 7.1 & {$[5,4 ; 8,7]$} & 3.2 & {$[2,3 ; 4,2]$} & 1.7 & {$[1,0 ; 2,4]$} \\
\hline
\end{tabular}

* Diferença significativa $(p<0,05)$

Andrade, A.G. 
TABELA 3 - Uso de substâncias psicoativas em alunos da USP nas áreas, em relação ao periodo do curso. Dados em porcentagem $(n=2.506)$.

\begin{tabular}{|c|c|c|c|c|c|}
\hline \multirow[b]{2}{*}{ Substância } & \multirow[b]{2}{*}{ Área } & \multirow[b]{2}{*}{ Período } & \multicolumn{3}{|c|}{ Período de uso } \\
\hline & & & $\begin{array}{c}\text { Na vida } \\
\%\end{array}$ & $\begin{array}{c}\text { Últimos } \\
12 \text { meses } \\
\%\end{array}$ & $\begin{array}{c}\text { Últimos } \\
30 \text { dias } \\
\%\end{array}$ \\
\hline \multirow[t]{8}{*}{ ÁLCOOL } & Humanas & Diurno & 87,9 & 78,1 & 72,4 \\
\hline & & Noturno & 90,7 & $84,0^{*}$ & $77,5^{*}$ \\
\hline & Biológicas & Diurno & 93,1 & 81,9 & 74,8 \\
\hline & & Noturno & 94,2 & 84,1 & 76,4 \\
\hline & Exatas & Diurno & $93,3^{*}$ & $82,4^{*}$ & $75,7^{*}$ \\
\hline & & Noturno & 88,9 & 76,0 & 67,0 \\
\hline & Total & Diurno & 90,3 & 80,0 & 73,7 \\
\hline & & Noturno & 90,8 & 83,3 & 76,5 \\
\hline \multirow[t]{8}{*}{ TABACO } & Humanas & Diurno & 45,5 & 26,2 & 23,8 \\
\hline & & Noturno & 42,3 & 23,1 & 22,7 \\
\hline & Biológicas & Diurno & 44,5 & 28,8 & 26,5 \\
\hline & & Noturno & 48,9 & 32,8 & 28,2 \\
\hline & Exatas & Diurno & 41,0 & 25,1 & 22,6 \\
\hline & & Noturno & 32,8 & 19,3 & 19,1 \\
\hline & Total & Diurno & 44,1 & 26,3 & 23,9 \\
\hline & & Noturno & 42,0 & 23,5 & 22,8 \\
\hline \multirow[t]{8}{*}{ “DROGAS" } & Humanas & Diurno & 35,9 & 24,4 & 17,7 \\
\hline & & Noturno & $43,3^{*}$ & $29,5^{*}$ & 21,3 \\
\hline & Biológicas & Diurno & 38,6 & 29,6 & 21,4 \\
\hline & & Noturno & $49,1^{*}$ & 33,1 & 25,7 \\
\hline & Exatas & Diurno & $35,2^{*}$ & $22,5^{*}$ & 16,7 \\
\hline & & Noturno & 21,0 & 13,4 & 10,9 \\
\hline & Total & Diurno & 36,2 & 24,8 & 18,1 \\
\hline & & Noturno & $41,7^{*}$ & 28,3 & 20,7 \\
\hline \multirow[t]{8}{*}{ COCAIINA } & Humanas & Diurno & 5,7 & 2,9 & 1,5 \\
\hline & & Noturno & $10,2^{*}$ & 3,8 & 1,8 \\
\hline & Biológicas & Diurno & 6,0 & 3,3 & 2,2 \\
\hline & & Noturno & 8,2 & 2,6 & 1,1 \\
\hline & Exatas & Diurno & 5,3 & 3,0 & 1,5 \\
\hline & & Noturno & 5,1 & 1,7 & 1,7 \\
\hline & Total & Diurno & 5,6 & 3,0 & 1,6 \\
\hline & & Noturno & $9,6^{*}$ & 3,6 & 1,8 \\
\hline
\end{tabular}


TABELA 4 - Uso de substâncias psicoativas em alunos da USP nas áreas, em relação ao sexo. Dados em porcentagem $(n=2.506)$.

$\mathbf{M}=$ masculino $\quad F=$ feminino

\begin{tabular}{|c|c|c|c|c|c|}
\hline \multirow[b]{2}{*}{ Substância } & \multirow[b]{2}{*}{ Área } & \multirow[b]{2}{*}{ Sexo } & \multicolumn{3}{|c|}{ Período de uso } \\
\hline & & & $\begin{array}{c}\text { Na vida } \\
\%\end{array}$ & $\begin{array}{c}\text { Últimos } \\
12 \text { meses } \\
\%\end{array}$ & $\begin{array}{c}\text { Últimos } \\
\mathbf{3 0} \text { dias } \\
\%\end{array}$ \\
\hline \multirow[t]{4}{*}{ ÁLCOOL } & Humanas & $\begin{array}{l}M \\
F\end{array}$ & $\begin{array}{l}94,0^{*} \\
84,0\end{array}$ & $\begin{array}{c}86,5^{*} \\
74,8\end{array}$ & $\begin{array}{c}79,8^{*} \\
69,5\end{array}$ \\
\hline & Biológicas & $\begin{array}{l}M \\
F\end{array}$ & $\begin{array}{l}94,6 \\
92,4\end{array}$ & $\begin{array}{l}85,6^{*} \\
79,8\end{array}$ & $\begin{array}{l}81,0 * \\
70,9\end{array}$ \\
\hline & Exatas & $\begin{array}{l}M \\
F\end{array}$ & $\begin{array}{l}93,3 \\
89,8\end{array}$ & $\begin{array}{l}84,3^{*} \\
70,3\end{array}$ & $\begin{array}{l}76,0^{*} \\
66,7\end{array}$ \\
\hline & Total & $\begin{array}{l}M \\
F\end{array}$ & $\begin{array}{l}93,8^{*} \\
85,8\end{array}$ & $\begin{array}{l}85,7^{*} \\
75,2\end{array}$ & $\begin{array}{l}78,7^{*} \\
69,5\end{array}$ \\
\hline \multirow[t]{4}{*}{ TABACO } & Humanas & $\begin{array}{l}\mathrm{M} \\
\mathrm{F}\end{array}$ & $\begin{array}{l}48,6^{*} \\
39,8\end{array}$ & $\begin{array}{l}27,4 \\
22,7\end{array}$ & $\begin{array}{l}26,8 * \\
20,5\end{array}$ \\
\hline & Biológicas & $\begin{array}{l}M \\
F\end{array}$ & $\begin{array}{l}45,9 \\
44,9\end{array}$ & $\begin{array}{l}29,7 \\
29,5\end{array}$ & $\begin{array}{l}25,0 \\
28,2\end{array}$ \\
\hline & Exatas & $\begin{array}{l}M \\
F\end{array}$ & $\begin{array}{l}41,3^{*} \\
33,4\end{array}$ & $\begin{array}{l}25,5^{*} \\
18,6\end{array}$ & $\begin{array}{l}23,1 \\
17,7\end{array}$ \\
\hline & Total & $\begin{array}{l}M \\
F\end{array}$ & $\begin{array}{l}45,9^{*} \\
40,1\end{array}$ & $\begin{array}{l}27,0^{*} \\
23,5\end{array}$ & $\begin{array}{l}25,4 \\
21,5\end{array}$ \\
\hline \multirow[t]{4}{*}{ “DROGAS" } & Humanas & $\begin{array}{l}\mathrm{M} \\
\mathrm{F}\end{array}$ & $\begin{array}{l}45,3^{*} \\
34,3\end{array}$ & $\begin{array}{l}32,6^{*} \\
21,9\end{array}$ & $\begin{array}{l}21,1 \\
17,8\end{array}$ \\
\hline & Biológicas & $\begin{array}{l}M \\
F\end{array}$ & $\begin{array}{l}49,9^{*} \\
34,5\end{array}$ & $\begin{array}{l}39,3^{*} \\
24,1\end{array}$ & $\begin{array}{c}27,8^{*} \\
18,6\end{array}$ \\
\hline & Exatas & $\begin{array}{l}M \\
F\end{array}$ & $\begin{array}{l}33,8 \\
28,8\end{array}$ & $\begin{array}{l}21,5 \\
19,1\end{array}$ & $\begin{array}{l}16,0 \\
15,0\end{array}$ \\
\hline & Total & $\begin{array}{l}M \\
F\end{array}$ & $\begin{array}{l}42,0^{*} \\
33,7\end{array}$ & $\begin{array}{l}29,7^{*} \\
22,0\end{array}$ & $\begin{array}{l}20,2 \\
17,7\end{array}$ \\
\hline \multirow[t]{4}{*}{ COCAÍNA } & Humanas & $\begin{array}{c}M \\
F\end{array}$ & $\begin{array}{l}9,5 \\
6,3\end{array}$ & $\begin{array}{l}4,4 \\
2,5\end{array}$ & $\begin{array}{l}2,6^{*} \\
0,8\end{array}$ \\
\hline & Biológicas & $\begin{array}{l}M \\
F\end{array}$ & $\begin{array}{c}10,7^{*} \\
3,4\end{array}$ & $\begin{array}{l}5,6^{*} \\
1,5\end{array}$ & $\begin{array}{l}3,1^{*} \\
1,1\end{array}$ \\
\hline & Exatas & $\begin{array}{l}\mathrm{M} \\
\mathrm{F}\end{array}$ & $\begin{array}{l}5,0 \\
6,2\end{array}$ & $\begin{array}{l}2,5 \\
3,8\end{array}$ & $\begin{array}{l}1,3 \\
2,3\end{array}$ \\
\hline & Total & $\begin{array}{l}M \\
F\end{array}$ & $\begin{array}{l}8,2^{*} \\
5,8\end{array}$ & $\begin{array}{l}3,9^{*} \\
2,4\end{array}$ & $\begin{array}{l}2,2^{*} \\
1,0\end{array}$ \\
\hline * Aumento est & icamente sig & vo $(p<c$ & & & A.G. \\
\hline
\end{tabular}


TABELA 5 - Uso de substâncias psicoativas em alunos da USP nas áreas. em relação à moradia Dados em porcentagem $(n=2.506)$.

\begin{tabular}{|c|c|c|c|c|c|}
\hline \multirow[b]{2}{*}{ Substância } & \multirow[b]{2}{*}{ Área } & \multirow[b]{2}{*}{ Mora } & \multicolumn{3}{|c|}{ Periodo de uso } \\
\hline & & & $\begin{array}{c}\text { Na vida } \\
\%\end{array}$ & $\begin{array}{c}\text { Últimos } \\
12 \text { meses } \\
\%\end{array}$ & $\begin{array}{c}\text { Éltimos } \\
30 \text { dias } \\
\%\end{array}$ \\
\hline \multirow[t]{8}{*}{ Al COOL } & Humanas & rom familia & 87,9 & 79.4 & 73.1 \\
\hline & & Sem familia & 92.2 & 84.8 & $80.0^{*}$ \\
\hline & Biobogras & Com familia & 93.8 & 82.3 & 75.1 \\
\hline & & Sem família & 91.5 & 81.6 & 75.3 \\
\hline & Exatas & Com familia & 92,3 & 80.8 & 72.9 \\
\hline & & Sem familia & 94.0 & 85.8 & $81.3^{*}$ \\
\hline & Tota! & Com familia & 91,7 & 81.0 & 73.8 \\
\hline & & Sem familia & 92.4 & 83,6 & $78.3^{*}$ \\
\hline \multirow[t]{8}{*}{ TABACO } & Humanas & Com familia & 42.3 & 22.4 & 21.1 \\
\hline & & Sem familia & $50.7^{*}$ & $35.4^{*}$ & $32.8^{*}$ \\
\hline & Biolingicas & Com família & 46.2 & 29.9 & 26.9 \\
\hline & & Sem familia & 41.8 & 28.2 & 26.3 \\
\hline & Exalas & Com familia & 37.6 & 21,8 & 20.3 \\
\hline & & Sem família & $52,3^{*}$ & $36.9 *$ & $31.4^{*}$ \\
\hline & Iona & Com familia & 42.2 & 25.1 & 23.1 \\
\hline & & Sem familia & $47.2^{*}$ & $32,7^{*}$ & 29.5 \\
\hline \multirow[t]{8}{*}{ "DROGAS" } & Humanas & Com familia & 36.0 & 24.2 & 18.3 \\
\hline & & Sem familia & $53.9^{*}$ & $38.7^{*}$ & 23.9 \\
\hline & Bioligicas & Com familia & 40,4 & 30.0 & 20.9 \\
\hline & & Sem familia & 42.4 & 32.0 & $28.3^{*}$ \\
\hline & Fxaia: & Com familia & 30.9 & 19.4 & 14.5 \\
\hline & & Sem familia & $44,0^{*}$ & $30.0^{*}$ & $22.5^{*}$ \\
\hline & Tolal & Com família & 36.0 & 24.8 & 18.0 \\
\hline & & Sem familia & $46,0^{*}$ & $33.2^{*}$ & 20.7 \\
\hline \multirow[t]{8}{*}{ COCAÍNA } & Humanas & Com familia & 6.9 & 2.6 & 1.4 \\
\hline & & Sem família & $11.8^{*}$ & $6.8^{*}$ & 2.8 \\
\hline & Bidingicas & Com familia & 5.8 & 2.6 & 1.6 \\
\hline & & Sem familia & 8.2 & 4.9 & 2.9 \\
\hline & Fxalas & Com familia & 4.1 & 2.1 & 0.8 \\
\hline & & Sem família & $10.8^{*}$ & $6.4^{*}$ & $5.1^{*}$ \\
\hline & Tosi & Com familia & 5.5 & 2.4 & 1.3 \\
\hline & & Sem familia & $9,9^{*}$ & $5.8^{*}$ & $3.5^{*}$ \\
\hline
\end{tabular}


TABELA 6 - Uso de substâncias psicoativas em alunos da USP nas áreas, em relação ao ano de ingresso na universidade. Dados em porcentagem ( $n=2.506)$

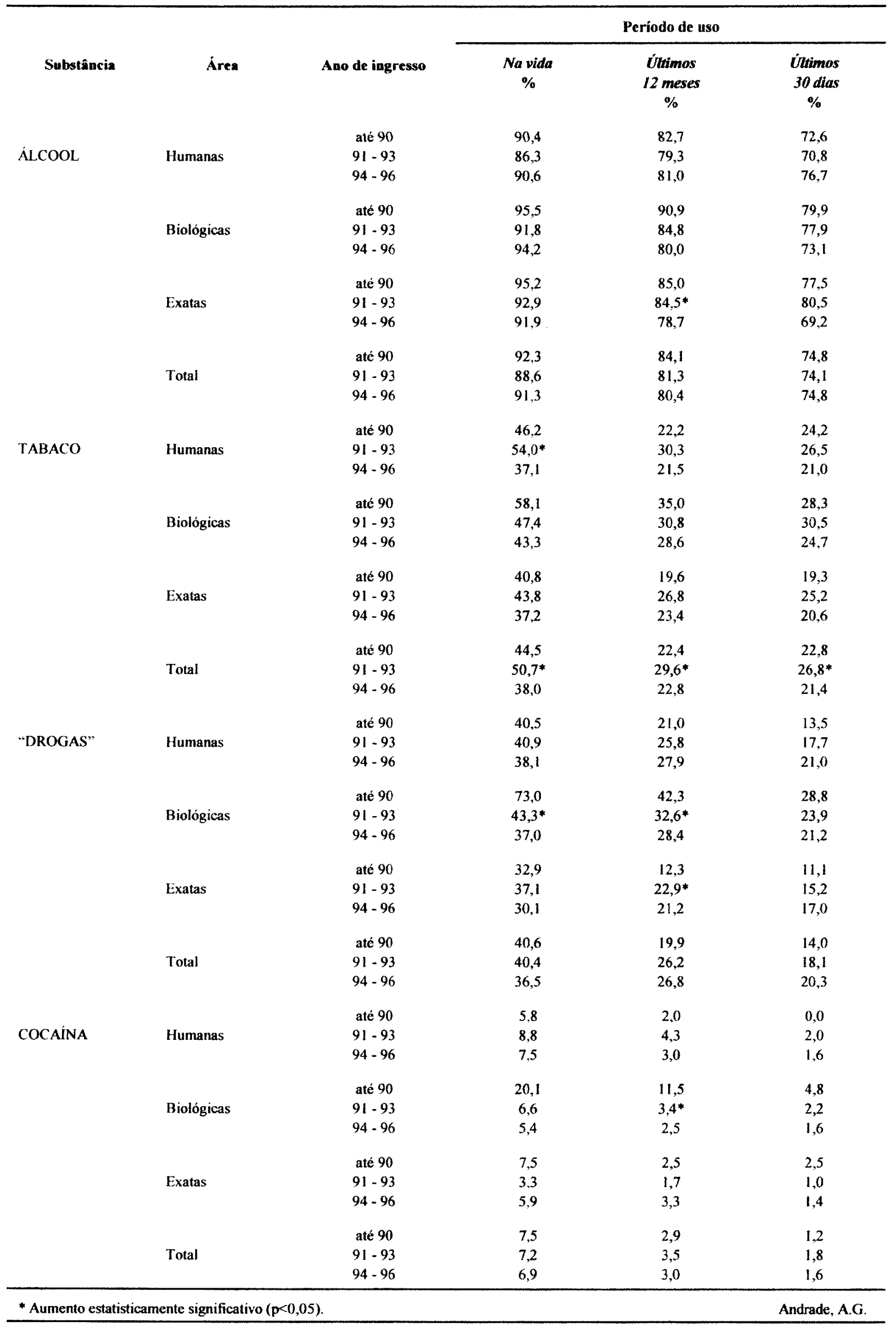


TABELA 7 - Distribuição dos alunos pesquisados, segundo utilização de maconha e de outras drogas (exceto maconha, álcool e tabaco)

\begin{tabular}{|c|c|c|c|c|c|c|}
\hline \multirow{3}{*}{ MACONHA } & \multicolumn{6}{|c|}{ OUTRAS DROGAS } \\
\hline & \multicolumn{2}{|c|}{ SIM } & \multicolumn{2}{|c|}{ NÃO } & \multicolumn{2}{|c|}{ TOTAL } \\
\hline & n & $\%$ & $\mathrm{n}$ & $\%$ & $\mathbf{n}$ & $\%$ \\
\hline SIM & 440 & 57 & 328 & 43 & 768 & 100 \\
\hline NÃO & 184 & 11 & 1554 & 89 & 1738 & 100 \\
\hline TOTAL & 624 & 25 & 1882 & 75 & 2506 & 100 \\
\hline
\end{tabular}

TABELA 8 - Comparação entre estudantes da USP ( $n=2.506)$ e de 9 escolas médicas do Estado de São Paulo (Consórcio de Escolas Médicas, $n=3.725$ ) quanto ao uso de substâncias psicoativas. Dados em porcentagem.

\begin{tabular}{lcccccc}
\hline & \multicolumn{2}{c}{ Uso na vida } & \multicolumn{2}{c}{ Últimos 12 meses } & \multicolumn{2}{c}{ Útimos 30 dias } \\
& USP & Consórcio & USP & Consórcio & USP & Consórcio \\
ÁLCOOL & 90 & 89 & 81 & 83 & 74 & 48 \\
TABACO & 43 & 40 & 26 & 23 & 24 & 10 \\
MACONHA & 31 & 75 & 20 & 16 & 15 & 9 \\
COCAÍNA & 7 & 5 & 3 & 3 & 2 & 1 \\
\hline
\end{tabular}

Correspondência para:

Dr. Arthur Guerra de Andrade

GREA - Grupo Interdisciplinar de Estudos de Álcool e Drogas - IPq - HC - FMUSP

Rua Dr. Ovídio Pires de Campos s/n

Caixa Postal 8091 - CEP 05403-010 - São Paulo - SP

Tel/fax: (011) 3064-4973 
ANEXO 5 
Análise Univariada - variável dependente uso de "drogas" nos últimos 12 meses.

\begin{tabular}{|c|c|c|c|c|}
\hline Variável & Categoria & OR & $\begin{array}{c}\mathbf{p} \\
\text { (categoria) }\end{array}$ & $\begin{array}{c}p \\
\text { (variável) }\end{array}$ \\
\hline \multirow[t]{3}{*}{ Área } & Humanas & 1,35 & 0,0115 & \\
\hline & Biológicas & 1,62 & 0,0000 & $<0,0001$ \\
\hline & Exatas & 1 & - & \\
\hline \multirow[t]{21}{*}{ Unidade } & ECA & 6,28 & 0,0000 & \\
\hline & $\mathrm{EE}$ & 2,75 & 0,0286 & \\
\hline & EEFE & 8,94 & 0,0000 & \\
\hline & $\mathrm{EP}$ & 4,04 & 0,0001 & \\
\hline & FAU & 9,20 & 0,0000 & \\
\hline & FCF & 4,08 & 0,0005 & \\
\hline & FD & 3,95 & 0,0006 & \\
\hline & $\mathrm{FE}$ & 5,15 & 0,0058 & \\
\hline & FEA & 4,05 & 0,0004 & \\
\hline & FFLCH & 4,51 & 0,0001 & $<0,0001$ \\
\hline & FM & 5,06 & 0,0000 & \\
\hline & FMVZ & 5,59 & 0,0001 & \\
\hline & FO & 5,63 & 0,0000 & \\
\hline & FSP & 2,34 & 0,1863 & \\
\hline & IAG & 6,94 & 0,0009 & \\
\hline & IB & 9,33 & 0,0000 & \\
\hline & IF & 2,94 & 0,0083 & \\
\hline & IG & 11,45 & 0,0000 & \\
\hline & IME & 1 & - & \\
\hline & IP & 8,49 & 0,0000 & \\
\hline & IQ & 2,39 & 0,1453 & \\
\hline \multirow[t]{4}{*}{ Ano de Ingresso } & Até 1990 & 1 & - & \\
\hline & $1991-93$ & 1,36 & 0,1318 & \\
\hline & $1994-96$ & 1,21 & 0,3429 & 0,3795 \\
\hline & Ignorado & 1,40 & 0,4025 & \\
\hline \multirow[t]{7}{*}{ Ano do Curso } & $1^{\circ}$ ano & 1 & - & \\
\hline & $2^{\circ}$ ano & 0,95 & 0,7356 & \\
\hline & $3^{\circ}$ ano & 1,06 & 0,6865 & \\
\hline & $4^{\circ}$ ano & 1,03 & 0,8137 & 0,3534 \\
\hline & $5^{\circ}$ ano & 1,19 & 0,2730 & \\
\hline & $6^{\circ}$ ano & 1,51 & 0,0431 & \\
\hline & Ignorado & 0,87 & 0,6883 & \\
\hline \multirow[t]{3}{*}{ Período } & Diurno & 1 & - & \\
\hline & Noturno & 1,01 & 0,9181 & 0,6782 \\
\hline & Ignorado & 1,39 & 0,3788 & \\
\hline
\end{tabular}




\begin{tabular}{|c|c|c|c|c|}
\hline Variável & Categoria & OR & $\begin{array}{c}\mathbf{p} \\
\text { (categoria) }\end{array}$ & $\begin{array}{c}p \\
\text { (variável) }\end{array}$ \\
\hline \multirow[t]{3}{*}{ Sexo } & Masculino & 1,39 & 0,0004 & \multirow{3}{*}{0,0014} \\
\hline & Feminino & 1 & - & \\
\hline & Ignorado & 1,68 & 0,3032 & \\
\hline \multirow[t]{4}{*}{ Faixa Etária } & $15-19$ & 1,22 & 0,1937 & \multirow{4}{*}{0,0008} \\
\hline & $20-24$ & 1,61 & 0,0002 & \\
\hline & 25 ou + & 1 & - & \\
\hline & Ignorado & 1,75 & 0,3079 & \\
\hline \multirow[t]{4}{*}{ Estado Civil } & Solteiro & 1,81 & 0,0026 & \multirow{4}{*}{0,0021} \\
\hline & Casado/vive junto & 1 & - & \\
\hline & Outro & 2,41 & 0,0792 & \\
\hline & Ignorado & 2,19 & 0,1708 & \\
\hline \multirow[t]{5}{*}{ Moradia } & Pais & 1,59 & 0,0196 & \multirow{5}{*}{$<0,0001$} \\
\hline & Cônjuge & 1 & - & \\
\hline & Amigos/só & 2,59 & 0,0000 & \\
\hline & CRUSP/outros & 1,42 & 0,2756 & \\
\hline & Ignorado & 1,97 & 0,1947 & \\
\hline \multirow[t]{3}{*}{ Tem religião } & $\operatorname{Sim}$ & 1 & - & \multirow{3}{*}{$<0,0001$} \\
\hline & Não & 1,59 & 0,0000 & \\
\hline & Ignorado & 1,76 & 0,1552 & \\
\hline \multirow[t]{3}{*}{ Pratica Religião } & $\mathrm{Sim}$ & 1 & - & \multirow{3}{*}{$<0,0001$} \\
\hline & Não & 1,76 & 0,0000 & \\
\hline & Ignorado & 2,28 & 0,0000 & \\
\hline \multirow{3}{*}{$\begin{array}{l}\text { Exerceu atividade remunerada } \\
\text { por período maior que um mês } \\
\text { nos últimos } 6 \text { meses }\end{array}$} & Sim & 1,28 & 0,0071 & \multirow{3}{*}{0,0069} \\
\hline & Não & 1 & - & \\
\hline & Ignorado & 1,33 & 0,5929 & \\
\hline
\end{tabular}


continuação

\begin{tabular}{|c|c|c|c|c|}
\hline Variável & Categoria & $\mathbf{O R}$ & $\stackrel{\mathrm{p}}{\text { (categoria) }}$ & $\begin{array}{c}p \\
\text { (variável) }\end{array}$ \\
\hline \multirow[t]{4}{*}{ Escolaridade Pai } & Primeiro grau & 1 & - & \\
\hline & Segundo grau & 1,79 & 0,0006 & $<0,0001$ \\
\hline & Superior & 2,76 & 0,0000 & \\
\hline & Ignorado & 3,01 & 0,0008 & \\
\hline \multirow[t]{4}{*}{ Escolaridade Mãe } & Primeiro grau & 1 & - & \\
\hline & Segundo grau & 1,73 & 0,0000 & $<0,0001$ \\
\hline & Superior & 2,49 & 0,0000 & \\
\hline & Ignorado & 1,51 & 0,2922 & \\
\hline \multirow[t]{4}{*}{ Renda Familiar } & Até $20 \mathrm{SM}$ & 1 & - & \\
\hline & $20-40 \mathrm{SM}$ & 1,43 & 0,0016 & $<0,0001$ \\
\hline & $+40 \mathrm{SM}$ & 2,07 & 0,0000 & \\
\hline & Ignorado & 1,35 & 0,1441 & \\
\hline \multirow[t]{4}{*}{ Os pais vivem } & Juntos & 1,37 & 0,0533 & \\
\hline & Separados & 2,13 & 0,0001 & 0,0003 \\
\hline & Pai/mãe falecidos & 1 & - & \\
\hline & Ignorado & 0,68 & 0,5541 & \\
\hline \multirow{3}{*}{$\begin{array}{l}\text { Algum membro da família bebeu } \\
\text { ao ponto de causar problemas em } \\
\text { casa, no trabalho ou com amigos }\end{array}$} & $\operatorname{Sim}$ & 1,10 & 0,4818 & \\
\hline & Não & 1 & - & $<0,0001$ \\
\hline & Ignorado & 0,42 & 0,0001 & \\
\hline \multirow[t]{3}{*}{ Pai faz uso freqüente de álcool } & $\operatorname{Sim}$ & 1,33 & 0,0104 & \\
\hline & Não & 1 & - & $<0,0001$ \\
\hline & Ignorado & 0,36 & 0,0001 & \\
\hline \multirow[t]{3}{*}{ Mãe faz uso freqüente de álcool } & $\operatorname{Sim}$ & 3,08 & 0,0000 & \\
\hline & Não & 1 & - & $<0,0001$ \\
\hline & Ignorado & 0,36 & 0,0001 & \\
\hline \multirow[t]{3}{*}{ Irmão faz uso freqüente de álcool } & $\operatorname{Sim}$ & 1 & - & \\
\hline & Não & 2,00 & 0,0000 & $<0,0001$ \\
\hline & Ignorado & 0,37 & 0,0001 & \\
\hline \multirow{3}{*}{$\begin{array}{l}\text { Pai faz uso não médico e } \\
\text { freqüente de outras drogas }\end{array}$} & Sim & 1 & - & \\
\hline & Não & 3,89 & 0,0000 & $<0,0001$ \\
\hline & Ignorado & -- & - & \\
\hline
\end{tabular}


continuação

\begin{tabular}{|c|c|c|c|c|}
\hline Variável & Categoria & $\mathbf{O R}$ & $\begin{array}{c}\mathrm{p} \\
\text { (categoria) }\end{array}$ & $\begin{array}{c}\mathbf{p} \\
\text { (variável) }\end{array}$ \\
\hline $\begin{array}{l}\text { Mãe faz uso não médico e freqüente } \\
\text { de outras drogas }\end{array}$ & $\begin{array}{l}\text { Sim } \\
\text { Não } \\
\text { Ignorado }\end{array}$ & $\begin{array}{c}1 \\
2,63 \\
-\end{array}$ & 0,0000 & $<0,0001$ \\
\hline $\begin{array}{l}\text { Irmão faz uso não médico e } \\
\text { freqüente de outras drogas }\end{array}$ & $\begin{array}{l}\text { Sim } \\
\text { Não } \\
\text { Ignorado }\end{array}$ & $\begin{array}{c}1 \\
4,83 \\
-\end{array}$ & $\begin{array}{c}- \\
0,0000 \\
-\end{array}$ & $<0,0001$ \\
\hline $\begin{array}{l}\text { Quando tem problema pessoal sério } \\
\text { quem procura primeiro }\end{array}$ & $\begin{array}{l}\text { Pais } \\
\text { Irmão } \\
\text { Amigos } \\
\text { Namorados } \\
\text { Terapeuta } \\
\text { Ninguém } \\
\text { Outros } \\
\text { Ignorado }\end{array}$ & $\begin{array}{c}1 \\
1,99 \\
2,89 \\
1,40 \\
3,29 \\
1,48 \\
0,39 \\
1,85\end{array}$ & $\begin{array}{c}- \\
0,0005 \\
0,0000 \\
0,0148 \\
0,0002 \\
0,0128 \\
0,1982 \\
0,0016 \\
\end{array}$ & $<0,0001$ \\
\hline Dificuldades de fazer novos amigos & $\begin{array}{l}\text { Sim } \\
\text { Não } \\
\text { Ignorado }\end{array}$ & $\begin{array}{c}1 \\
1,12 \\
1,08\end{array}$ & $\begin{array}{c}- \\
0,3457 \\
0,7520\end{array}$ & 0,6395 \\
\hline $\begin{array}{l}\text { Tem se sentido rejeitado por amigos } \\
\text { ou por outros da mesma idade }\end{array}$ & $\begin{array}{l}\text { Sim } \\
\text { Não } \\
\text { Ignorado }\end{array}$ & $\begin{array}{c}1,02 \\
1 \\
1,00\end{array}$ & $\begin{array}{c}0,9053 \\
- \\
0,9983\end{array}$ & 0,9929 \\
\hline $\begin{array}{l}\text { Facilmente influenciável pelo grupo } \\
\text { de amigos }\end{array}$ & $\begin{array}{l}\text { Sim } \\
\text { Não } \\
\text { Ignorado }\end{array}$ & $\begin{array}{c}1,50 \\
1 \\
1,09\end{array}$ & $\begin{array}{c}0,0024 \\
- \\
0,7060\end{array}$ & 0,0100 \\
\hline $\begin{array}{l}\text { Amigos fazem uso freqüente de } \\
\text { álcool }\end{array}$ & $\begin{array}{l}\text { Sim } \\
\text { Não } \\
\text { Ignorado }\end{array}$ & $\begin{array}{c}2,61 \\
1 \\
0,55\end{array}$ & $\begin{array}{c}0,0000 \\
- \\
0,0206\end{array}$ & $<0,0001$ \\
\hline $\begin{array}{l}\text { Amigos fazem uso não médico e } \\
\text { freqüente de outras drogas }\end{array}$ & $\begin{array}{l}\text { Sim } \\
\text { Não } \\
\text { Ignorado }\end{array}$ & $\begin{array}{c}5,14 \\
1 \\
-\end{array}$ & $\begin{array}{c}0,0000 \\
- \\
-\end{array}$ & $<0,0001$ \\
\hline
\end{tabular}


continuação

\begin{tabular}{|c|c|c|c|c|}
\hline Variável & Categoria & OR & $\begin{array}{c}p \\
\text { (categoria) }\end{array}$ & $\begin{array}{c}p \\
\text { (variável) }\end{array}$ \\
\hline \multirow{6}{*}{$\begin{array}{l}\text { Horas livres a cada dia útil da } \\
\text { semana }\end{array}$} & Nenhuma & 1 & - & \multirow{6}{*}{0,1068} \\
\hline & Até 2 horas & 1,19 & 0,3013 & \\
\hline & De 2 a 4 horas & 1,39 & 0,0375 & \\
\hline & De 4 a 6 horas & 1,19 & 0,3277 & \\
\hline & Mais do que 6 horas & 1,54 & 0,0362 & \\
\hline & Ignorado & 0,52 & 0,3043 & \\
\hline \multirow{4}{*}{$\begin{array}{l}\text { Horas livres durante o fim de } \\
\text { semana }\end{array}$} & Todo o tempo & 3,30 & 0,0019 & \multirow{4}{*}{$<0,0001$} \\
\hline & Algumas horas/dia & 2,17 & 0,0424 & \\
\hline & Menos de uma hora/dia & 1 & - & \\
\hline & Ignorado & 1,10 & 0,8911 & \\
\hline \multirow[t]{8}{*}{ O que faz nas horas livres } & Igreja & 1 & - & \multirow{8}{*}{$<0,0001$} \\
\hline & Sai/viaja & 5,27 & 0,0054 & \\
\hline & Esportes & 5,46 & 0,0052 & \\
\hline & Leitura / TV & 2,68 & 0,1029 & \\
\hline & Atividades culturais & 6,23 & 0,0025 & \\
\hline & Bares/festas & 14,04 & 0,0000 & \\
\hline & Outros & 2,81 & 0,0989 & \\
\hline & Ignorado & 5,49 & 0,0045 & \\
\hline \multirow{3}{*}{$\begin{array}{l}\text { Pratica as atividades com a } \\
\text { freqüência que gostaria }\end{array}$} & Sim & 1,33 & 0,0017 & \multirow{3}{*}{0,0022} \\
\hline & Não & 1 & - & \\
\hline & Ignorado & 0,53 & 0,1947 & \\
\hline \multirow{8}{*}{$\begin{array}{l}\text { O que faz quando falta às } \\
\text { aulas }\end{array}$} & Não falta & 1,42 & 0,2120 & \multirow{8}{*}{$<0,0001$} \\
\hline & Cinema/clube & 3,35 & 0,0004 & \\
\hline & Estuda em casa & 2,02 & 0,0162 & \\
\hline & Estuda na faculdade & 1 & - & \\
\hline & Dorme / faz nada & 4,05 & 0,0000 & \\
\hline & Trabalha & 2,62 & 0,0010 & \\
\hline & $\mathrm{CA} / \mathrm{DA} /$ Atlética & 6,53 & 0,0000 & \\
\hline & Outros / Ignorado & 3,03 & 0,0001 & \\
\hline
\end{tabular}

continua 


\begin{tabular}{|c|c|c|c|c|}
\hline Variável & Categoria & OR & $\stackrel{p}{\text { (categoria) }}$ & $\frac{p}{\text { (variável) }}$ \\
\hline \multirow{5}{*}{$\begin{array}{l}\text { Lugares que freqüenta na } \\
\text { universidade }\end{array}$} & $\mathrm{CA} / \mathrm{DA}$ & 5,60 & 0,0000 & \multirow{5}{*}{$<0,0001$} \\
\hline & CEPEUSP & 2,71 & 0,0000 & \\
\hline & Biblioteca & 1 & - & \\
\hline & Lanchonete & 2,36 & 0,0000 & \\
\hline & Outros / ignorado & 2,41 & 0,0000 & \\
\hline \multirow{3}{*}{$\begin{array}{l}\text { Está satisfeito com escolha } \\
\text { profissional }\end{array}$} & Sim & 1 & - & \multirow{3}{*}{0,1060} \\
\hline & Não & 1,31 & 0,0395 & \\
\hline & Ignorado & 1,15 & 0,4904 & \\
\hline \multirow{4}{*}{$\begin{array}{l}\text { Pensou seriamente em abandonar o } \\
\text { curso }\end{array}$} & Sim & 1,30 & 0,0090 & \multirow{4}{*}{0,0397} \\
\hline & Não & 1 & - & \\
\hline & Ainda pensa & 1,26 & 0,2609 & \\
\hline & Ignorado & 1,36 & 0,1576 & \\
\hline \multirow{7}{*}{$\begin{array}{l}\text { Em qual ano pensou em abandonar } \\
\text { o curso }\end{array}$} & $1^{\circ}$ ano & 1,52 & 0,6030 & \multirow{7}{*}{0,2987} \\
\hline & $2^{\circ}$ ano & 1,29 & 0,7573 & \\
\hline & $3^{\circ}$ ano & 1,83 & 0,4620 & \\
\hline & $4^{\circ}$ ano & 1,17 & 0,8613 & \\
\hline & $5^{\circ}$ ano & 1 & - & \\
\hline & $6^{\circ}$ ano & 1,17 & 0,9127 & \\
\hline & Ignorado & 1,20 & 0,8213 & \\
\hline \multirow{3}{*}{$\begin{array}{l}\text { Tem deixado de fazer trabalhos } \\
\text { acadêmicos }\end{array}$} & Sim & 1,91 & 0,0000 & \multirow{3}{*}{$<0,0001$} \\
\hline & Não & 1 & - & \\
\hline & Ignorado & 0,62 & 0,3348 & \\
\hline \multirow[t]{3}{*}{ Desempenho escolar } & Bom/excelente & 1 & - & \multirow{3}{*}{0,0006} \\
\hline & Fraco/regular & 1,42 & 0,0001 & \\
\hline & Ignorado & 0,89 & 0,8233 & \\
\hline
\end{tabular}


continuação

\begin{tabular}{|c|c|c|c|c|}
\hline Variável & Categoria & $\mathbf{O R}$ & $\begin{array}{c}\mathbf{p} \\
\text { (categoria) }\end{array}$ & $\begin{array}{c}\mathbf{p} \\
\text { (variável) }\end{array}$ \\
\hline \multirow{5}{*}{$\begin{array}{l}\text { Perspectivas de } \\
\text { trabalho e } \\
\text { financeiras, após } \\
\text { formatura }\end{array}$} & Realização prof. e financeira & 1,05 & 0,7671 & \multirow{5}{*}{0,7271} \\
\hline & Realização prof. e não financeira & 1,14 & 0,4687 & \\
\hline & Realização financeira e não prof. & 1 & - & \\
\hline & Sem realização prof. e financeira & 1,30 & 0,2532 & \\
\hline & Ignorado & 1,04 & 0,8814 & \\
\hline \multirow{6}{*}{$\begin{array}{l}\text { Desempenho no } \\
\text { último semestre }\end{array}$} & Passou direto & 1 & - & \multirow{6}{*}{0,0003} \\
\hline & Passou c/ recuperação & 1,58 & 0,0009 & \\
\hline & Passou com dependência & 1,42 & 0,0020 & \\
\hline & Repetiu de ano & 1,11 & 0,6338 & \\
\hline & Outro & 0,67 & 0,0715 & \\
\hline & Ignorado & 1,06 & 0,8528 & \\
\hline \multirow{3}{*}{$\begin{array}{l}\text { Gostaria de ter mais } \\
\text { informações sobre } \\
\text { DST's e AIDS }\end{array}$} & Sim & 1 & - & \multirow{3}{*}{0,1228} \\
\hline & Não & 1,20 & 0,0506 & \\
\hline & Ignorado & 0,92 & 0,7498 & \\
\hline \multirow{3}{*}{$\begin{array}{l}\text { Acha importante o } \\
\text { uso de preservativo }\end{array}$} & Sim & 2,18 & 0,1508 & \multirow{3}{*}{0,2913} \\
\hline & Não & 1 & - & \\
\hline & Ignorado & 2,51 & 0,1163 & \\
\hline \multirow{4}{*}{$\begin{array}{l}\text { Faz uso de } \\
\text { preservativo }\end{array}$} & Sempre & 2,01 & 0,0000 & \multirow{4}{*}{$<0,0001$} \\
\hline & Nunca & 1 & - & \\
\hline & Às vezes & 2,54 & 0,0000 & \\
\hline & Ignorado & 1,18 & 0,4547 & \\
\hline \multirow{5}{*}{$\begin{array}{l}\text { Motivo para não usar } \\
\text { preservativo }\end{array}$} & Usa sempre & 3,65 & 0,0000 & \multirow{5}{*}{$<0,0001$} \\
\hline & Tem parceiro fixo & 3,87 & 0,0000 & \\
\hline & Não mantém relações sexuais & 1 & - & \\
\hline & Outros motivos & 8,67 & 0,0000 & \\
\hline & Ignorado & 3,37 & 0,0000 & \\
\hline \multirow{7}{*}{$\begin{array}{l}\text { Se tivesse dúvidas } \\
\text { sobre álcool e drogas } \\
\text { quem procuraria } \\
\text { primeiro }\end{array}$} & Professores & 2,34 & 0,0021 & \multirow{7}{*}{$<0,0001$} \\
\hline & Amigos/colegas de faculdade & 3,36 & 0,0000 & \\
\hline & Pais & 1 & - & \\
\hline & Profissionais especializados & 2,10 & 0,0001 & \\
\hline & Lider religioso & 1,48 & 0,4536 & \\
\hline & Livros e/ou artigos científicos & 1,82 & 0,0004 & \\
\hline & Ignorado & 1,97 & 0,0067 & \\
\hline
\end{tabular}


continuação

\begin{tabular}{|c|c|c|c|c|}
\hline Variável & Categoria & $\mathbf{O R}$ & $\begin{array}{c}\mathbf{p} \\
\text { (categoria) }\end{array}$ & $\begin{array}{c}P \\
\text { (variável) }\end{array}$ \\
\hline \multirow[t]{3}{*}{ Experimentar álcool } & Aprova & 5,25 & 0,0000 & \\
\hline & Desaprova & 1 & - & $<0,0001$ \\
\hline & Ignorado & 3,35 & 0,0010 & \\
\hline \multirow[t]{3}{*}{ Experimentar maconha } & Aprova & 10,27 & 0,0000 & \\
\hline & Desaprova & 1 & - & $<0,0001$ \\
\hline & Ignorado & 5,13 & 0,0000 & \\
\hline \multirow[t]{3}{*}{ Experimentar cocaína } & Aprova & 5,84 & 0,0000 & \\
\hline & Desaprova & 1 & - & $<0,0001$ \\
\hline & Ignorado & 1,38 & 0,2340 & \\
\hline \multirow[t]{3}{*}{ Experimentar crack } & Aprova & 3,32 & 0,0000 & \\
\hline & Desaprova & 1 & - & $<0,0001$ \\
\hline & Ignorado & 1,16 & 0,5707 & \\
\hline \multirow[t]{3}{*}{ Experimentar tranqüilizantes } & Aprova & 2,30 & 0,0000 & \\
\hline & Desaprova & 1 & - & $<0,0001$ \\
\hline & Ignorado & 1,48 & 0,0979 & \\
\hline \multirow[t]{3}{*}{ Experimentar anfetaminas } & Aprova & 3,86 & 0,0000 & \\
\hline & Desaprova & 1 & - & $<0,0001$ \\
\hline & Ignorado & 1,17 & 0,4958 & \\
\hline \multirow[t]{3}{*}{ Experimentar inalantes } & Aprova & 5,69 & 0,0000 & \\
\hline & Desaprova & 1 & - & $<0,0001$ \\
\hline & Ignorado & 1,60 & 0,0439 & \\
\hline \multirow[t]{3}{*}{ Usar regularmente álcool } & Aprova & 2,46 & 0,0000 & \\
\hline & Desaprova & 1 & - & $<0,0001$ \\
\hline & Ignorado & 1,15 & 0,6220 & \\
\hline \multirow[t]{3}{*}{ Usar regularmente maconha } & Aprova & 11,43 & 0,0000 & \\
\hline & Desaprova & 1 & - & $<0,0001$ \\
\hline & Ignorado & 2,07 & 0,0054 & \\
\hline
\end{tabular}




\begin{tabular}{|c|c|c|c|c|}
\hline Variável & Categoria & OR & $\stackrel{\mathbf{p}}{\text { (categoria) }}$ & $\begin{array}{c}p \\
\text { (variável) }\end{array}$ \\
\hline \multirow{3}{*}{ Usar regularmente cocaína } & Aprova & 4,45 & 0,0000 & \\
\hline & Desaprova & 1 & - & $<0,0001$ \\
\hline & Ignorado & 1,17 & 0,5634 & \\
\hline \multirow[t]{3}{*}{ Usar regularmente crack } & Aprova & 2,37 & 0,0367 & \\
\hline & Desaprova & 1 & - & 0,0959 \\
\hline & Ignorado & 1,17 & 0,5422 & \\
\hline \multirow[t]{3}{*}{ Usar regularmente tranqüilizantes } & Aprova & 2,00 & 0,0006 & \\
\hline & Desaprova & 1 & - & 0,0025 \\
\hline & Ignorado & 1,16 & 0,5643 & \\
\hline \multirow[t]{3}{*}{ Usar regularmente anfetaminas } & Aprova & 2,85 & 0,0000 & \\
\hline & Desaprova & 1 & - & 0,0001 \\
\hline & Ignorado & 0,96 & 0,8835 & \\
\hline \multirow[t]{3}{*}{ Usar regularmente inalantes } & Aprova & 3,28 & 0,0000 & \\
\hline & Desaprova & 1 & - & 0,0001 \\
\hline & Ignorado & 0,98 & 0,9282 & \\
\hline \multirow{3}{*}{$\begin{array}{l}\text { Acha que a dependência de álcool é } \\
\text { outras drogas é um problema de } \\
\text { saúde }\end{array}$} & Sim & 1 & - & \\
\hline & Não & 1,08 & 0,5610 & 0,8158 \\
\hline & Ignorado & 1,11 & 0,7714 & \\
\hline \multirow{5}{*}{$\begin{array}{l}\text { Opinião sobre a maioria dos } \\
\text { alcoolistas }\end{array}$} & Se curam & 1,22 & 0,3770 & \\
\hline & Melhoram & 1,05 & 0,7400 & \\
\hline & Não melhoram & 1,15 & 0,2701 & 0,0392 \\
\hline & Pioram & 1 & - & \\
\hline & Ignorado & 2,13 & 0,0026 & \\
\hline \multirow{5}{*}{$\begin{array}{l}\text { Opinião sobre a maioria dos } \\
\text { dependentes de drogas }\end{array}$} & Se curam & 2,50 & 0,0001 & \\
\hline & Melhoram & 2,05 & 0,0000 & \\
\hline & Não melhoram & 1,52 & 0,0002 & $<0,0001$ \\
\hline & Pioram & 1 & - & \\
\hline & Ignorado & 2,92 & 0,0000 & \\
\hline
\end{tabular}


continuação

\begin{tabular}{|c|c|c|c|c|}
\hline Variável & Categoria & OR & $\begin{array}{c}\mathbf{p} \\
\text { (categoria) }\end{array}$ & $\stackrel{p}{\text { (variável) }}$ \\
\hline \multirow{5}{*}{$\begin{array}{l}\text { O que gostaria em relação a } \\
\text { álcool e drogas }\end{array}$} & Ter mais informações & 1,51 & 0,0012 & \multirow{5}{*}{0,0001} \\
\hline & Ajudar pessoas & 1,63 & 0,0020 & \\
\hline & Ambas & 1 & - & \\
\hline & Nenhuma delas & 1,77 & 0,0000 & \\
\hline & Ignorado & 1,67 & 0,1122 & \\
\hline \multirow{3}{*}{$\begin{array}{l}\text { Usou álcool nos últimos } 12 \\
\text { meses }\end{array}$} & $\operatorname{Sim}$ & 1 & - & \multirow{3}{*}{$<0,0001$} \\
\hline & Não & 6,10 & 0,0000 & \\
\hline & Ignorado & 0,39 & 0,2041 & \\
\hline \multirow{3}{*}{$\begin{array}{l}\text { Usou tabaco nos últimos } 12 \\
\text { meses }\end{array}$} & $\operatorname{Sim}$ & 6,75 & 0,0000 & \multirow{3}{*}{$<0,0001$} \\
\hline & Não & 1 & - & \\
\hline & Ignorado & 0,78 & 0,2743 & \\
\hline \multirow{3}{*}{$\begin{array}{l}\text { Experimentou drogas sem } \\
\text { prescrição antes de entrar na } \\
\text { universidade }\end{array}$} & Sim & 10,69 & 0,0000 & \multirow{3}{*}{$<0,0001$} \\
\hline & Não & 1 & - & \\
\hline & Ignorado & 0,51 & 0,0017 & \\
\hline \multirow{3}{*}{$\begin{array}{l}\text { Envolveu-se em acidente de } \\
\text { carro depois de ter usado } \\
\text { qualquer quantidade de álcool } \\
\text { ou outra droga }\end{array}$} & $\operatorname{Sim}$ & 4,10 & 0,0000 & \multirow{3}{*}{$<0,0001$} \\
\hline & Não & 1 & - & \\
\hline & Ignorado & 0,30 & 0,0000 & \\
\hline
\end{tabular}


ANEXO 6 


\section{DETALHAMENTO DOS MODELOS MULTIVARIADOS FINAIS}

Passos para o modelo de análise multivariada das variáveis de risco associadas ao uso de droga para características pessoais dos alunos da USP (valores correspondentes ao odds ratio da categoria)

\begin{tabular}{|l|l|c|c|c|c|c|c|}
\hline \multicolumn{1}{|c|}{ variáveis } & categoria & $\mathbf{1}$ & $\mathbf{2}$ & $\mathbf{3}$ & $\mathbf{4}$ & $\mathbf{5}$ & $\mathbf{6}$ \\
\hline Pratica religião & não & 1,6 & 1,6 & 1,6 & 1,6 & 1,7 & 1,7 \\
\hline Faixa etária & $15-19$ & & 1,3 & 1,3 & 1,2 & 1,4 & 1,5 \\
& $20-24$ & & 1,7 & 1,7 & 1,6 & 1,6 & 1,7 \\
\hline Sexo & feminino & & & 1,3 & 1,3 & 1,3 & 1,4 \\
\hline Mora com & amigos/só & & & & 1,9 & 2,0 & 1,9 \\
\hline Trabalho & sim & & & & & 1,3 & 1,3 \\
\hline Principal confidente & namorado & & & & & & 1,5 \\
& irmão & & & & & & 2,1 \\
& amigos & & & & & & 2,8 \\
& terapeuta & & & & & & 3,6 \\
\hline
\end{tabular}

Passos para o modelo de análise multivariada das variáveis de risco associadas ao uso de droga para características relacionadas a atitudes, opiniões e uso pessoal dos alunos da USP (valores correspondentes ao odds ratio da categoria)

\begin{tabular}{|l|l|c|c|c|c|c|c|c|c|}
\hline \multicolumn{1}{|c|}{ variáveis } & categoria & $\mathbf{1}$ & $\mathbf{2}$ & $\mathbf{3}$ & $\mathbf{4}$ & $\mathbf{5}$ & $\mathbf{6}$ & $\mathbf{7}$ & $\mathbf{8}$ \\
\hline $\begin{array}{l}\text { Dúvidas sobre álcool e } \\
\text { drogas }\end{array}$ & $\begin{array}{l}\text { prof. } \\
\text { amigo }\end{array}$ & $\begin{array}{c}3,4 \\
2,3\end{array}$ & $\begin{array}{c}2,8 \\
2,4\end{array}$ & $\begin{array}{r}2,5 \\
2,5\end{array}$ & $\begin{array}{c}2,5 \\
2,5\end{array}$ & $\begin{array}{c}2,5 \\
2,4\end{array}$ & $\begin{array}{c}2,4 \\
1,9\end{array}$ & $\begin{array}{c}2,2 \\
1,8\end{array}$ & $\begin{array}{c}2,3 \\
1,6\end{array}$ \\
\hline Uso de álcool & $\operatorname{sim}$ & & 5,6 & 3,7 & 2,3 & 2,3 & 1,6 & 1,6 & 1,6 \\
\hline Uso de tabaco & $\operatorname{sim}$ & & & 5,5 & 4,4 & 4,4 & 3,7 & 3,6 & 3,4 \\
\hline $\begin{array}{l}\text { Experimentou droga antes } \\
\text { de entrar na universidade }\end{array}$ & $\operatorname{sim}$ & & & & $\mathbf{8 , 1}$ & $\mathbf{8 , 1}$ & 5,6 & 5,5 & 5,0 \\
\hline $\begin{array}{l}\text { Envolveu-se em acidente de } \\
\text { trânsito após uso de droga }\end{array}$ & sim & & & & & 2,8 & 3,0 & 3,2 & 2,9 \\
\hline Experimentar maconha & aprova & & & & & & 4,6 & 3,7 & 2,7 \\
\hline Experimentar inalantes & aprova & & & & & & & 2,3 & 2,1 \\
\hline Uso regular de maconha & aprova & & & & & & & & 3,2 \\
\hline
\end{tabular}


Passos para o modelo de análise multivariada das variáveis de risco associadas ao uso de droga para características familiares dos alunos da USP (valores correspondentes ao odds ratio da categoria)

\begin{tabular}{|c|c|c|c|c|c|c|c|c|c|c|}
\hline variáveis & categoria & 1 & 2 & 3 & 4 & 5 & 6 & 7 & 8 & 9 \\
\hline Escolaridade do pai & $\begin{array}{l}2^{\circ} \text { grau } \\
\text { superior }\end{array}$ & $\begin{array}{l}1,8 \\
2,7\end{array}$ & $\begin{array}{l}1,5 \\
2,0\end{array}$ & $\begin{array}{l}1,5 \\
1,8\end{array}$ & $\begin{array}{l}1,5 \\
1,8\end{array}$ & $\begin{array}{l}1,5 \\
1,8\end{array}$ & $\begin{array}{l}1,5 \\
1,8\end{array}$ & $\begin{array}{l}1,5 \\
1,8\end{array}$ & $\begin{array}{l}1,5 \\
1,8\end{array}$ & $\begin{array}{l}1,5 \\
1,7\end{array}$ \\
\hline Escolaridade da mãe & superior & & 1,7 & 1,6 & 1,6 & 1,6 & 1,6 & 1,6 & 1,6 & 1,6 \\
\hline Renda familiar & $+40 \mathrm{SM}$ & & & 1,4 & 1,4 & 1,4 & 1,4 & 1,4 & 1,4 & 1,4 \\
\hline Mãe/uso freq. álcool & $\operatorname{sim}$ & & & & 2,9 & 2,4 & 2,3 & 2,2 & 2,2 & 2,1 \\
\hline Irmão/uso freq. álcool & $\operatorname{sim}$ & & & & & 1,9 & 1,9 & 1,8 & 1,5 & 1,5 \\
\hline Pai/uso freq. droga & $\operatorname{sim}$ & & & & & & 3,7 & 2,8 & 2,6 & 2,5 \\
\hline Mãe/uso freq. droga & $\operatorname{sim}$ & & & & & & & 2,0 & 1,7 & 1,7 \\
\hline Irmão/uso freq. droga & $\operatorname{sim}$ & & & & & & & & 3,4 & 3,3 \\
\hline Pais & separados & & & & & & & & & 1,5 \\
\hline
\end{tabular}

Passos para o modelo de análise multivariada das variáveis de risco associadas ao uso de droga para características da vida social dos alunos da USP (valores correspondentes ao odds ratio da categoria)

\begin{tabular}{|l|l|c|c|c|c|c|}
\hline \multicolumn{1}{|c|}{ variáveis } & categoria & $\mathbf{1}$ & $\mathbf{2}$ & $\mathbf{3}$ & $\mathbf{4}$ & $\mathbf{5}$ \\
\hline Amigos/uso freq. drogas & $\operatorname{sim}$ & 5,1 & 5,2 & 5,1 & 5,1 & 5,1 \\
\hline Influenciável pelos amigos & $\operatorname{sim}$ & & 1,6 & 1,6 & 1,5 & 1,5 \\
\hline Horas livres/fim de semana & todo tempo & & & 2,9 & 2,8 & 2,6 \\
\hline Atividades nas hs. livres & $\begin{array}{l}\text { culturais } \\
\text { bares/festas }\end{array}$ & & & & 5,4 & 6,0 \\
10,8 & 11,1 \\
\hline $\begin{array}{l}\text { Satisfeito com o tempo que } \\
\text { pratica essas atividades }\end{array}$ & sim & & & & & 1,3 \\
\hline
\end{tabular}


Passos para o modelo de análise multivariada das variáveis de risco associadas ao uso de droga para características da vida acadêmica dos alunos da USP (valores correspondentes ao odds ratio da categoria)

\begin{tabular}{|c|c|c|c|c|c|c|}
\hline variáveis & categoria & 1 & 2 & 3 & 4 & 5 \\
\hline \multirow[t]{18}{*}{ Unidade } & $\mathrm{ECA}$ & 6,3 & 6,2 & 5,4 & 5,4 & 5,4 \\
\hline & $\mathrm{EE}$ & 2,7 & 3,2 & 2,4 & 2,8 & 2,9 \\
\hline & EEFE & 8,9 & 10,0 & 9,4 & 10,0 & 9,9 \\
\hline & $\mathrm{EP}$ & 4,0 & 3,8 & 3,2 & 3,4 & 3,3 \\
\hline & FAU & 9,2 & 8,1 & 7,5 & 8,0 & 8,1 \\
\hline & FCF & 4,1 & 4,2 & 4,3 & 4,7 & 4,9 \\
\hline & FD & 3,9 & 3,5 & 3,1 & 3,4 & 3,6 \\
\hline & $\mathrm{FE}$ & 5,1 & 5,3 & 5,2 & 5,5 & 5,3 \\
\hline & FEA & 4,0 & 4,0 & 3,7 & 3,8 & 3,8 \\
\hline & FFLCH & 4,5 & 5,0 & 5,6 & 5,7 & 5,9 \\
\hline & FM & 5,1 & 5,0 & 4,0 & 4,3 & 4,5 \\
\hline & FMVZ & 5,6 & 5,0 & 4,1 & 4,6 & 5,0 \\
\hline & FO & 5,6 & 5,8 & 4,5 & 5,0 & 5,3 \\
\hline & IAG & 6,9 & 7,8 & 6,0 & 6,1 & 6,0 \\
\hline & IB & 9,3 & 10,2 & 9,6 & 10,6 & 10,6 \\
\hline & IF & 2,9 & 3,1 & 3,1 & 2,9 & 3,0 \\
\hline & IG & 11,4 & 11,0 & 9,9 & 10,6 & 10,9 \\
\hline & IP & 8,5 & 8,6 & 8,2 & 8,9 & 9,0 \\
\hline \multirow{5}{*}{$\begin{array}{l}\text { Ocupação quando falta às } \\
\text { aulas }\end{array}$} & cinema/clube & & 3,1 & 2,8 & 2,6 & 2,6 \\
\hline & estuda em casa & & 2,0 & 2,0 & 2,0 & 2,0 \\
\hline & dorme/ocioso & & 3,8 & 3,5 & 3,3 & 3,2 \\
\hline & trabalha & & 2,5 & 2,6 & 2,4 & 2,3 \\
\hline & centro acadêmico & & 6,3 & 4,3 & 4,1 & 3,9 \\
\hline \multirow[t]{3}{*}{ Lugares freqüentados na USP } & centro acadêmico & & & 4,9 & 4,8 & 4,8 \\
\hline & centro esportivo & & & 2,5 & 2,4 & 2,4 \\
\hline & lanchonete & & & 2,1 & 2,1 & 2,1 \\
\hline $\begin{array}{l}\text { Deixa de fazer trabalhos } \\
\text { acadêmicos }\end{array}$ & $\operatorname{sim}$ & & & & 1,7 & 1,7 \\
\hline Desempenho escolar & passou c/ dep. & & & & & 1,4 \\
\hline
\end{tabular}

